Project No. 09-785

\title{
Assessment of Embrittlement of VHTR Structural Alloys in Impure Helium Environments
}

\section{Reactor Concepts RD\&D}

Dr. Wendy Crone University of Wisconsin, Madison 


\title{
Assessment of Embrittlement of VHTR Structural Alloys in Impure Helium Environments
}

\begin{abstract}
The environmental degradation of intermediate heat exchanger (IHX) materials in impure helium has been identified as an area of research with major ramifications on the design of very high temperature reactors (VHTR). It has been reported that in some helium enviroments, non ductile failure is a significant failure mode for Alloy 617 for long-term elevated-temperature service. Non ductile failure of intermediate exchangers can result in catastropic conquences; however, the knowledge of creep crack initiation and creep crack growth (CCG) in candidate alloys is very limited. Current codes and code cases for the candidate alloys do not provide specific guidelines for effects of impure helium on the high temperature behavior. The work reported here explores creep crack growth characterization of Alloy 617 and Alloy $800 \mathrm{H}$ at elevated temperatures in air and impure helium environments, providing information on the reliability of these alloys in VHTR for long-term service. Alloy 617 was found to exhibit superior tensile properties, hardness, and CCG resistance compared to Alloy $800 \mathrm{H}$. For Alloy 617 test at $700{ }^{\circ} \mathrm{C}$, a notable increase in the resistance to crack growth was measured in air compared to the helium environment; CCG results for Alloy $800 \mathrm{H}$ suggest that air and helium environments produce similar behavior. Testing of grain boundary engineered (GBE) Alloy 617 samples revealed that this technique produces superior mechanical properties in many respects; however, GBE samples exhibited inferior resistance to creep crack growth compared to the other Alloy 617 samples tested under similar conditions. Grain size is noted as a confounding factor in creep crack growth resistance.
\end{abstract}

\section{INTRODUCTION}

Helium is the coolant that has been chosen for the Next Generation Nuclear Plant (NGNP), a very high temperature helium-cooled reactor (VHTR) for generating electricity and cogenerating hydrogen using the process heat from the reactor. The helium coolant in high temperature reactors inevitably contains low levels of impurities during steady-state operation. The primary impurities are small amounts of $\mathrm{H}_{2}, \mathrm{H}_{2} \mathrm{O}, \mathrm{CH}_{4}, \mathrm{CO}, \mathrm{CO}_{2}$ and $\mathrm{N}_{2}$ from a variety of sources in the reactor circuit. These impurities are problematic because the structural alloys used in the heat exchangers can experience significant long-term corrosion by these gaseous impurities present at elevated temperatures. The maximum primary helium coolant temperature in the high temperature reactor is expected to be at $850-1000{ }^{\circ} \mathrm{C}$, although early prototype designs may use a lower maximum temperature. Currently, the primary candidates for intermediate heat exchangers are Alloy 617, Haynes 230, Alloy $800 \mathrm{H}$ and Hastelloy X. The corrosion may involve oxidation, carburization or decarburization depending on temperature, oxygen partial pressure, carbon activity, and alloy composition. These corrosion reactions can substantially affect long-term mechanical properties such as crack-growth rate and fracture toughness, creep rupture, and fatigue. Although there are some studies on the effects of impurities of helium coolant on creep rupture and fatigue strength, very little is known about the effects of impurities on the creep crack initiation and crack growth rate in candidate alloys at elevated temperatures. Stress-assisted grain boundary oxidation is one mechanism of creep crack 
growth, which may result in brittle failure of the candidate alloys during long term elevated temperature service. However, current codes for the candidate alloys do not provide specific guidelines for effects of impure helium on the high temperature mechanical behavior.

\subsection{Objectives}

This proposal aims to evaluate the role of impurities in helium coolant on the stress assisted grain boundary oxidation and creep crack growth in candidate alloys at elevated temperatures. The objectives of the project are listed as follows:

- To evaluate the stress assisted grain boundary oxidation and creep crack initiation and crack growth in the temperature range of $500-850{ }^{\circ} \mathrm{C}$ in a prototypical helium environment.

- To evaluate the effects of oxygen partial pressure in helium on the stress assisted grain boundary oxidation and creep crack growth in impure helium at $700{ }^{\circ} \mathrm{C}$, and $850{ }^{\circ} \mathrm{C}$ respectively.

- To characterize the microstructure of candidate alloys after long term exposure to an impure helium environment in order to understand the correlation between stress assisted grain boundary oxidation, creep crack growth, material composition and impurities in the helium coolant.

- To evaluate grain boundary engineering (GBE) as a method to mitigate the stress assisted grain boundary oxidation and creep crack growth of candidate alloys in impure helium.

\subsection{Tasks}

To accomplish the proposed objectives, the project consisted of three tasks as follows:

Task A: Creep crack initiation and crack growth rate measurements of candidate alloys in helium.

Task B: Evaluation of the effects of oxygen impurities in helium on the stress-assisted grain boundary oxidation and creep crack growth.

Task C: Evaluation of the effects of grain boundary engineering on the mitigation of stress-assisted grain boundary oxidation and creep crack growth.

\section{MATERIALS AND METHODS}

\subsection{Materials and Specimens}

Two candidate alloys were studied in detail: Alloy 617 and Alloy $800 \mathrm{H}$. Alloy 617 is the leading candidate alloy for intermediate heat exchangers. It has been reported that Alloy 617 can be used at temperatures as high as $982^{\circ} \mathrm{C}$. Alloy $800 \mathrm{H}$ is currently approved under ASME code for nuclear service for up to $760{ }^{\circ} \mathrm{C}$ and could be immediately used in a lower temperature reactor. 
Table 1 Chemical compositions of the tested alloys

\begin{tabular}{|l|c|c|c|c|c|c|c|c|c|c|c|c|c|c|}
\hline \multicolumn{1}{|c|}{ Element } & Ni & Cr & Fe & Co & Mo & Ti & Al & C & Si & Mn & Cu & P & B & S \\
\hline Alloy 617 & 54.1 & 22.2 & 1.6 & 11.6 & 8.6 & 0.4 & 1.1 & 0.05 & 0.1 & 0.1 & 0.04 & --- & $<0.001$ & $<0.002$ \\
\hline Alloy $800 \mathrm{H}$ & 30.65 & 19.7 & 46.24 & 0.1 & --- & 0.54 & 0.56 & 0.061 & 0.42 & 1.27 & 0.2 & 0.024 & --- & 0.001 \\
\hline
\end{tabular}

Table 1 presents the chemical compositions of the as-received alloys. All 617 and $800 \mathrm{H}$ samples used in these studies were provided by Dr. Richard Wright at Idaho National Laboratory (INL), Idaho Falls, ID, USA. The materials from INL were cut from much larger samples and were solution annealed. Before the creep crack growth testing, both Alloy 617 and Alloy $800 \mathrm{H}$ were solution treated (ST) at $1200{ }^{\circ} \mathrm{C}$ for one hour and then quenched in water, as suggested by Special Metals. Because the Alloy 617 and Alloy $800 \mathrm{H}$ materials will ultimately be used for extended periods of time and at high temperatures during heat exchanger service, the materials were further heated to $850{ }^{\circ} \mathrm{C}$ for 2000 hrs in air to age the materials. During the aging process, small coupons of the candidate alloys were removed at specific time intervals. Hardness and tensile testing of the aged coupons were performed to evaluate the mechanical properties of the alloys as a function of aging time (testing details to follow). Rolling direction was tracked throughout all stages of the sample preparation.

Compact tension (CT) specimens for the creep crack growth (CCG) experiments were fabricated from the aged alloy materials. Figure 1 presents the CT specimen geometry defined by ASTM standard E1457-07 [1]. After an investigation into the necessary stress levels needed to induce creep crack growth within the candidate alloys, along with a comprehensive evaluation of the anticipated stress levels in the load-bearing components of the CCG testing apparatus, design values of $\mathrm{W}=50 \mathrm{~mm}, \mathrm{~B}=6.25 \mathrm{~mm}$, and $\mathrm{a}=27.5 \mathrm{~mm}$ for the CT specimens were chosen. Electric discharge machining (EDM) was used to fabricate the CT specimens, with the orientation of the crack being aligned with the rolling direction of the samples. Fine-wire EDM was used to machine the final $3.75 \mathrm{~mm}$ length of the crack at a width of $\sim 100 \mu \mathrm{m}$.

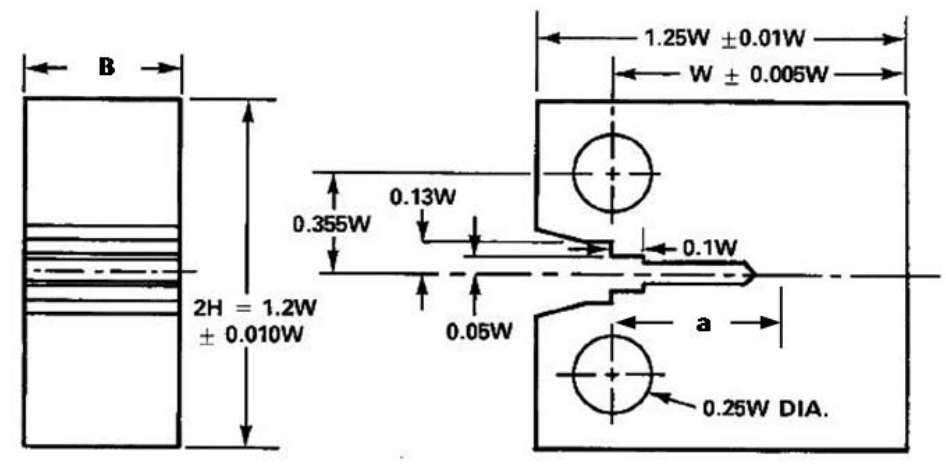

Figure 1 Geometry of compact tension (CT) specimens as defined by ASTM standard E1457-07. Values of $\mathrm{W}=50 \mathrm{~mm}, \mathrm{~B}=6.25 \mathrm{~mm}$, and $\mathrm{a}=27.5 \mathrm{~mm}$ were chosen for the studies presented herein.

Coupons of $\sim 40 \times 10 \times 5 \mathrm{~mm}^{3}$ were prepared by electrical discharge machining. Dogbone specimens for tensile testing were fabricated from the aged coupons by electrical discharge machining after heat treatment was completed. Figure 2 presents the tensile specimen geometry defined by ASTM standard E8 [2]. EDM machining was again used to fabricate the specimens. 
The specimen cross-sectional area of WxT $=3.2 \times 3.125 \mathrm{~mm}^{2}$ was chosen based on considerations of the anticipated strength of the alloys and the capacity of the load cell (more discussion to follow).

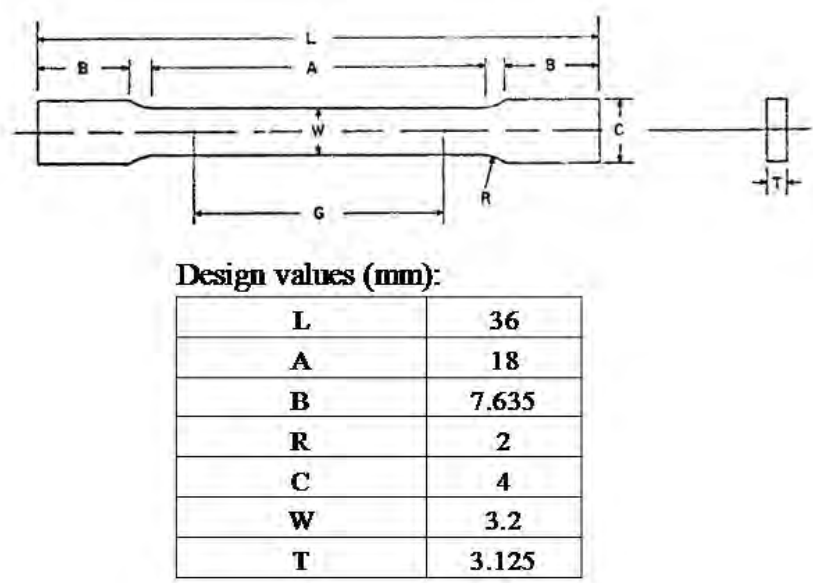

Figure 2 Geometry of tensile specimens as defined by ASTM standard E8, along with the design values

\subsection{Creep Crack Growth (CCG) Testing and Apparatus}

To carry out the objectives of this project, we developed an apparatus for conducting CCG experiments on candidate alloys at elevated temperatures and in controlled environments, including impure helium. Design of the CCG testing apparatus was performed considering the requirements established in ASTM standard E 1457-07 for performing CCG measurements on metals and alloys. The apparatus was designed for testing three CT specimens in series within an environmental chamber and under dead-weight loading (Figure 3), and the direct current potential drop (DCPD) technique was employed to monitor crack growth continuously during testing. The capability of testing three specimens simultaneously is important for efficiently evaluating variability of CCG behavior under identical conditions. The composition of the impure helium used for these CCG studies is presented in Table 2.

\begin{tabular}{|l|c|}
\hline Gas & Composition (ppm) \\
\hline Carbon monoxide & 12 \\
\hline Carbon Dioxide & 1.5 \\
\hline Oxygen & 0.5 \\
\hline Nitrogen & 0.5 \\
\hline Argon & 0.5 \\
\hline Water vapor & 0.2 \\
\hline
\end{tabular}

Table 2 Composition of impure helium used for these studies.
As described in a published conference proceeding [3], a carbon steel frame, standing approximately six feet tall, constitutes the overall structure of the CCG testing apparatus. A retort tube, fabricated with Inconel 600 alloy, was designed to withstand elevated temperatures and to be isolated environmentally from the ambient conditions. Access ports at the top and bottom of the retort tube were positioned to allow the tension rods (Figure 3b), fabricated with Inconel 617 alloy, to deliver a constant load to the specimens throughout the testing duration. Inconel 625 was machined to make the clevises 
that connect the tension rods to the CT specimens, with Inconel 625 pins linking the specimens to the clevises.

A 2:1 ratio pivot arm positioned above the chamber (Figure 3a), which connects to the load rod on one side and a weight stack on the other, provides a means for both applying a vertical load to the specimens as the load assembly translates vertically and reducing the overall mass required (a 2:1 reduction) to load the specimens. A hydraulic arm supports the pivot arm when CCG testing is not in progress, and a catch plate (not shown in Figure 3) positioned below the weight stack provides a soft base for absorbing the impact of the weight stack should a CT specimen fail rapidly.

A bellows flange (Figure 3b), which provides a seal with inches of allowable travel to accommodate vertical translation of the tension rods (e.g., due to thermal expansion and specimen cracking), was positioned at the top of the tube. As explained in the ASTM standard, real-time monitoring of crack growth within each CT specimen is performed using the direct current potential drop technique; therefore access ports for electrical wires for DCPD monitoring were included at the top of the tube (not shown). Additionally, accesses ports for a thermocouple and gas inlet/outlet lines were included (also not shown). A three-zone, $1200{ }^{\circ} \mathrm{C}$ maximum temperature split-tube furnace (Thermcraft Inc., Winston-Salem, NC) surrounds the majority of the environmental chamber, providing uniform temperature control. Insulator supports, fabricated with Inconel 600, are attached to the tension rods to provide thermal barriers above and below the CT specimens.

Figure 4 presents a schematic of the overall CCG testing system (the test frame of Figure 3 is not included). Three tanks were connected to the CCG chamber to allow for long ( $>1$ month) testing times with uninterrupted gas flow. A backflow prevention system, consisting of a back pressure regulator and sealed reservoirs, was put in place to prevent any unwanted gases from entering the chamber through the outflow lines. Valves for gas vials were inserted into the flow lines both before and after the chamber to allow gas samples to be extracted for analysis before and during testing. A valving system (not shown explicitly) was installed to control the direction of gas flow through the chamber (e.g., top-to-bottom or bottom-to-top flow). A power supply provided a constant current to the CT specimens, and a voltmeter was used to measure the potential drops on each of the three specimens. Microsoft Excel and LabVIEW software programs were used to record the voltage and quality-assurance data, respectively, continuously during testing.

An image of three CT specimens mounted before testing is presented in Figure 5. The image was taken before the electrical wiring was welded to the specimens. Braided ceramic sleeving for electrically isolating the specimens from the clevises can be seen. In the orientation shown, the precracks in the CT specimens are facing down. 
a)

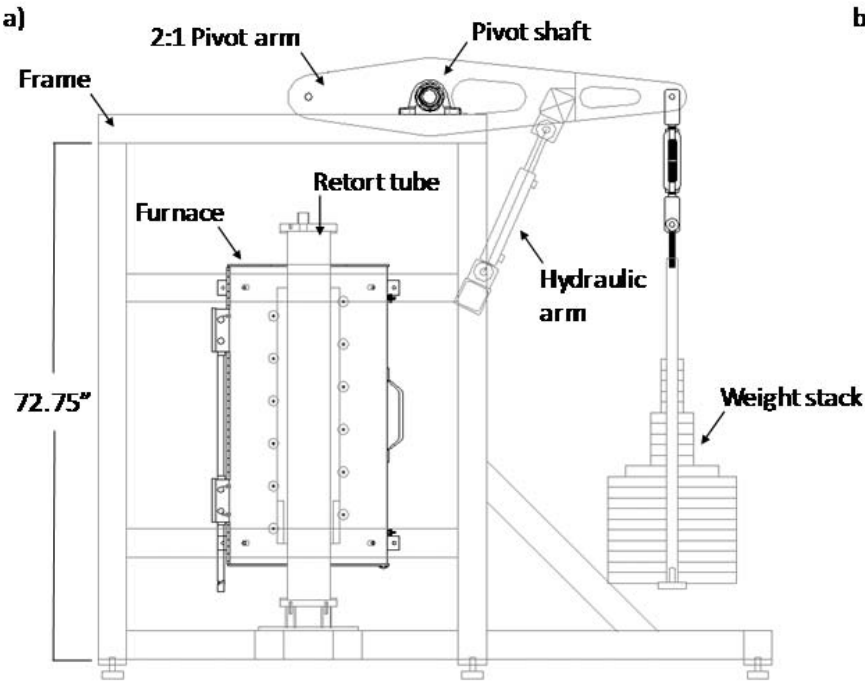

b)

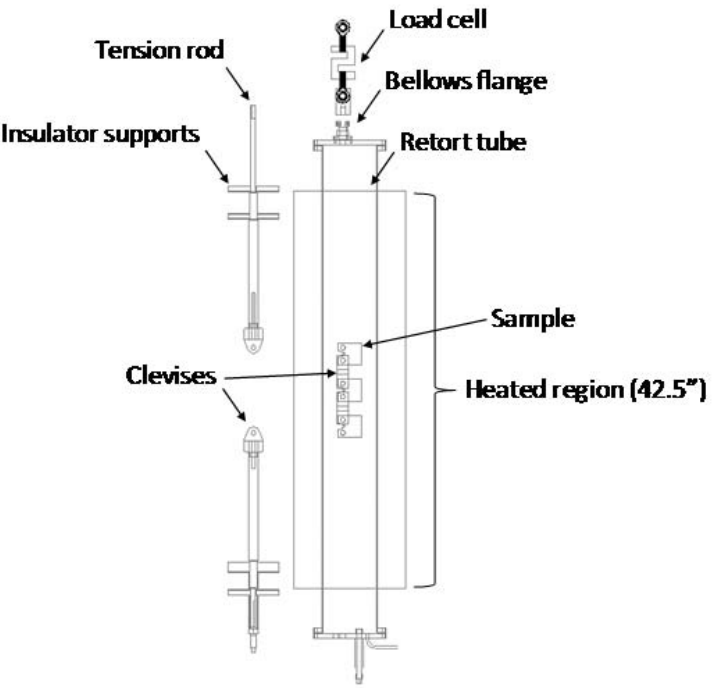

Figure 3 (a) Schematic of the creep crack growth apparatus. (b) Schematic of the retort tube, highlighting the placement of the three compact tension specimens within the tube. The tension rods (shown outside the retort tube) are connected via the clevises and pins (not shown) to the samples (shown inside the retort tube) during testing.

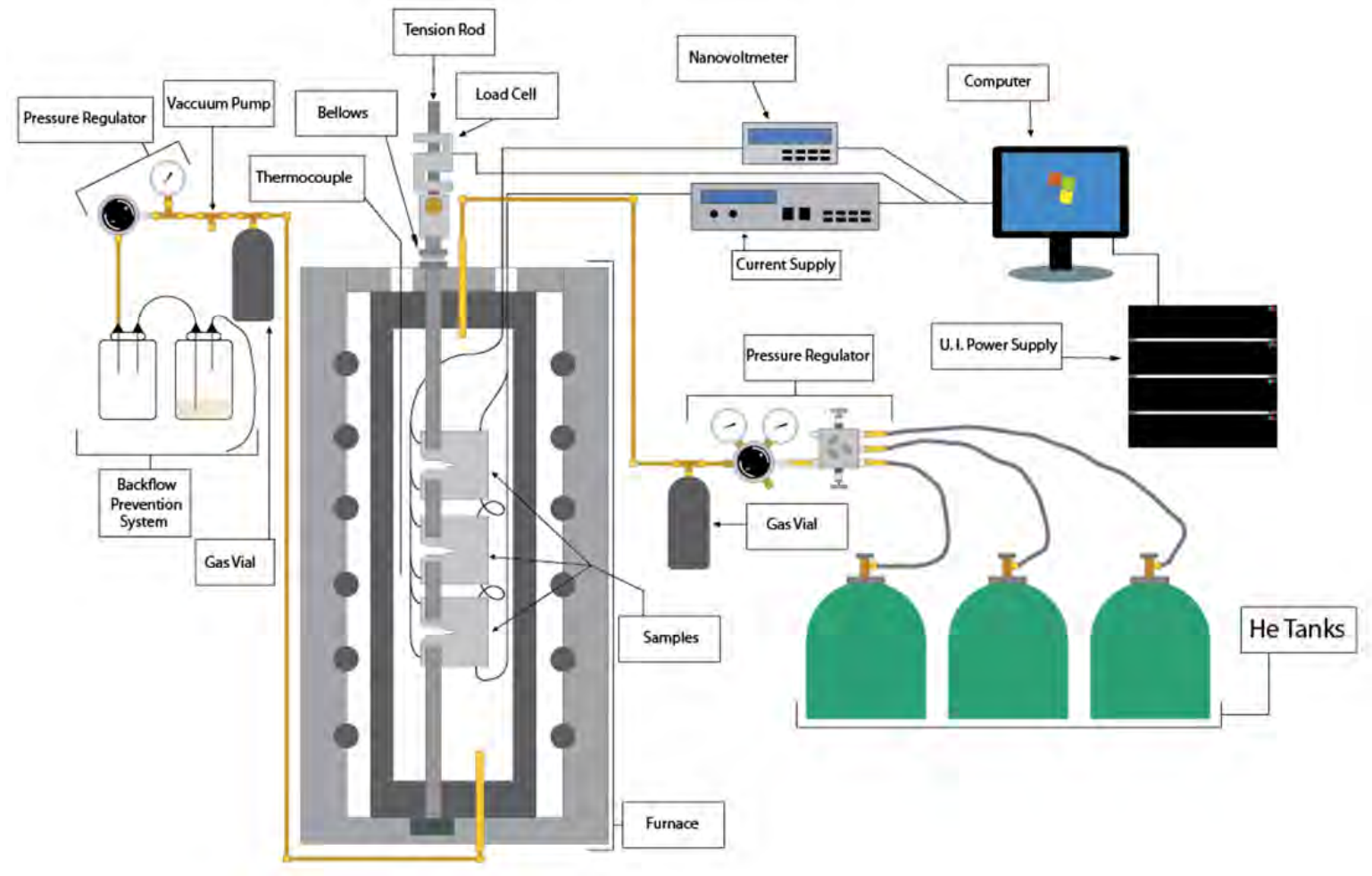

Figure 4 Idealized schematic depicting the key components of the creep crack growth (CCG) testing system. 


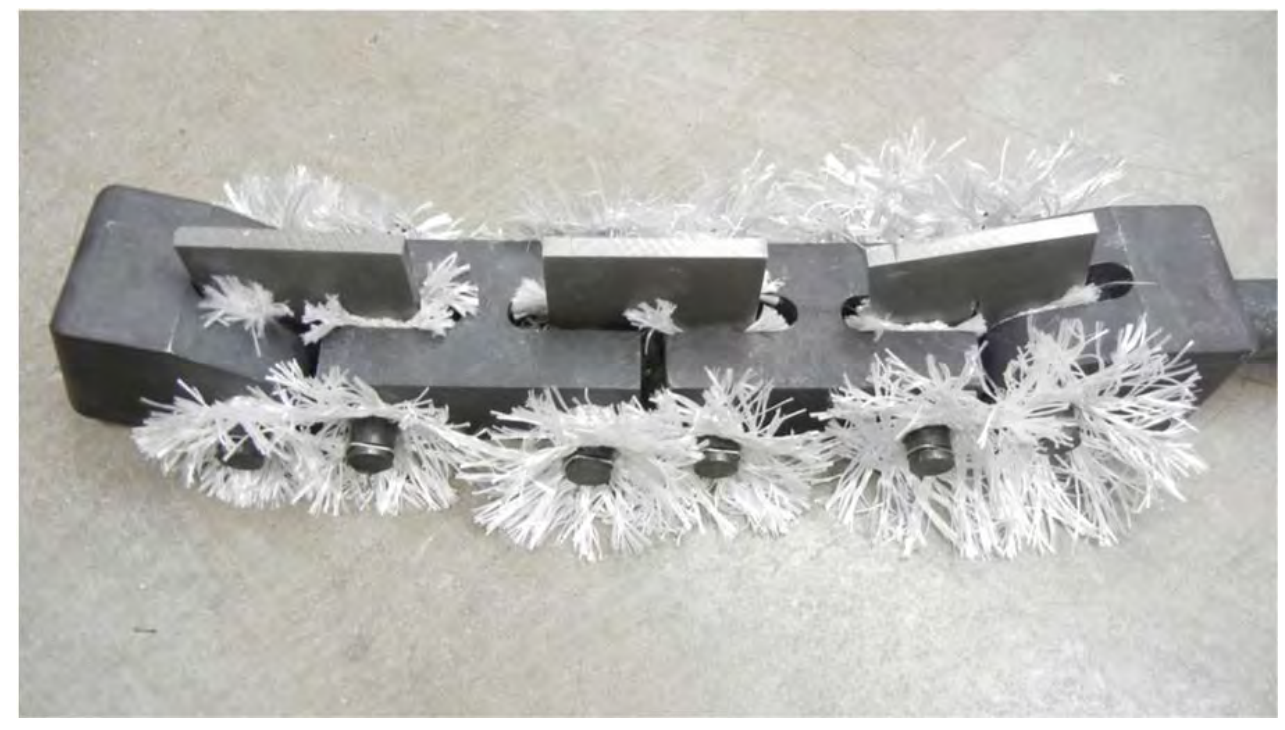

Figure 5 Image of three CT specimens mounted in the clevises prior to CCG testing (electrical wiring not shown). The braided ceramic sleeving that surrounds the pins and electrically isolates the samples from the clevises.

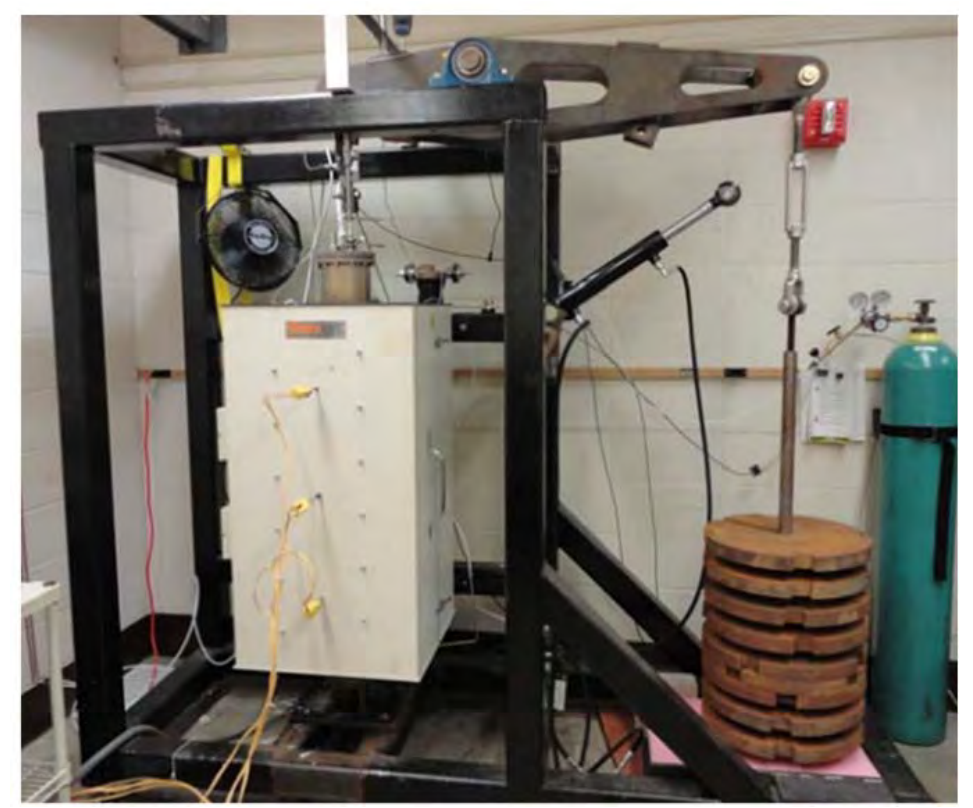

Figure 6 Image of the creep crack growth testing apparatus, shown loaded with 9 steel plates (100 lbs per plate).

Figure 6 shows an image of the CCG apparatus during operation - steel plates are suspended below the pivot arm, the catch plate below the weights is in place, and the hydraulic arm is disengaged. A fan used for cooling the top of the retort tube can be seen above the chamber. 


\subsubsection{Environmental control}

In order to maintain a constant, contamination-free environment within the chamber during CCG testing, a flushing and baking protocol was developed and implemented. Prior to CCG testing in helium, a roughing pump was used to bring the chamber down to a pressure of several millitor for 15-20 min, and then ultra high purity argon was flowed through the chamber from the bottom to the top for 15-20 min. This cycle of pumping followed by argon flushing was repeated twice. Subsequently, the chamber was bought up to 1 psig in argon, and the temperature of the chamber was brought up to $300{ }^{\circ} \mathrm{C}$. The chamber was allowed to bake in argon for $\sim 24$ hours at $300{ }^{\circ} \mathrm{C}$, with the gas constantly flowing through the chamber at a rate of $\sim 55 \mathrm{ccm}$. After the 24-hour bake, helium was flowed into the chamber with a top-to-bottom flow direction. When the pressure became stabilize at $1 \mathrm{psig}$, the temperature of the chamber was brought up to the testing temperature (either $700{ }^{\circ} \mathrm{C}$ or $850{ }^{\circ} \mathrm{C}$ ). The gauge pressure in the chamber was then maintained at 1 psi for the duration of the CCG testing. To verify the effectiveness of the flushing/baking procedure, gas samples were extracted from the flow lines before and after they entered the chamber, and mass spectra of the gas samples were acquired (Thermostar, Pfeiffer).
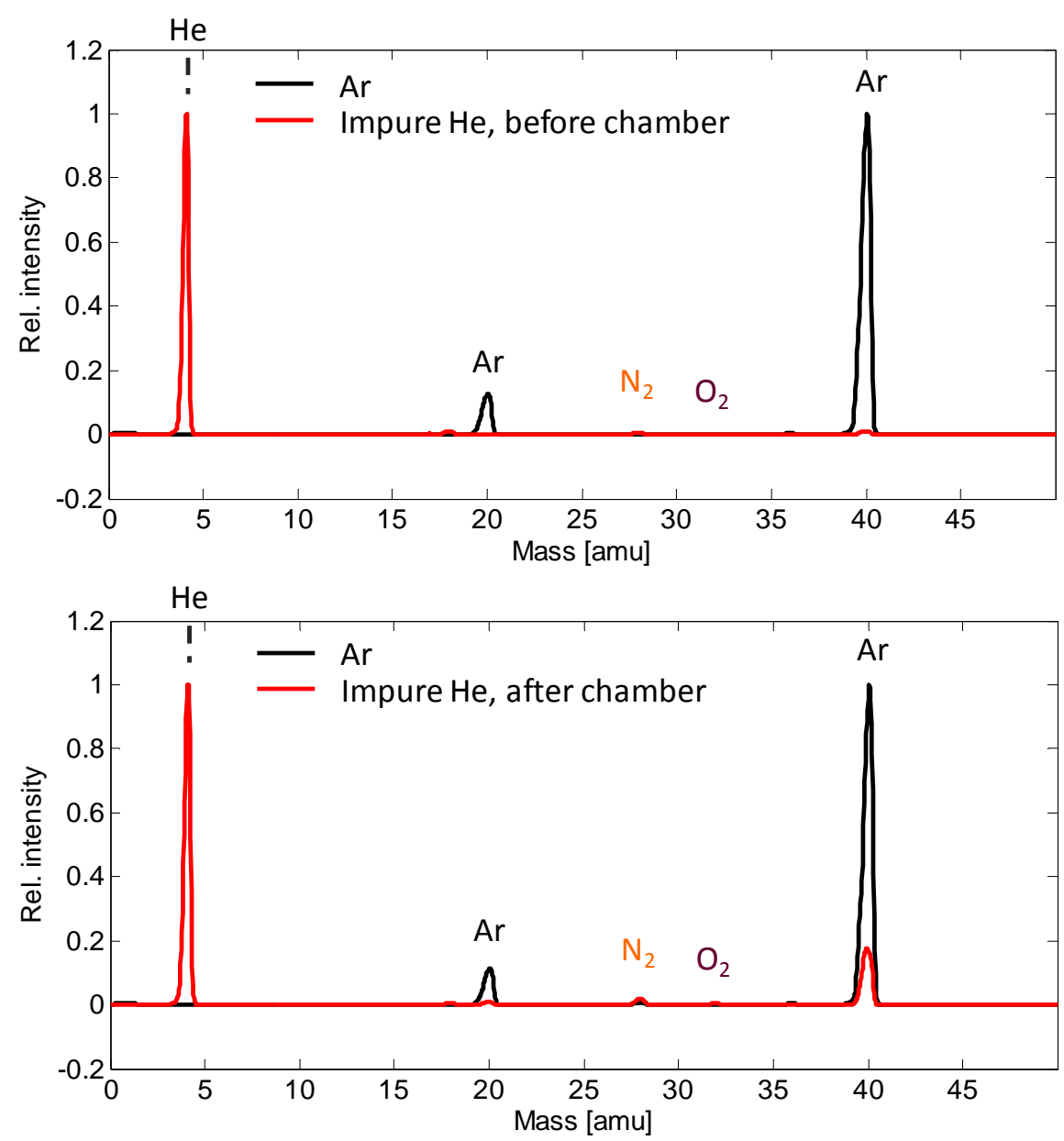

Figure 7 Mass spectra of impure He gas extracted from the flow lines before (top) and after (bottom) entering the CCG chamber. Argon spectra are present as a reference. Argon peaks in the He spectra are due to argon in the lines of the mass spectrometer. 
Figure 7 presents mass spectra taken from the flow lines before and after they entered the chamber after the chamber had been heated to $300^{\circ} \mathrm{C}$ for $\sim 20 \mathrm{hrs}$. Argon spectra are present in the background for a reference. Argon peaks present in the He spectra are due to the argon that was used to flush the lines in the mass spectrometer prior to introducing the gas samples to the system. As the spectra of Figure 7 show, the amount of impurities (e.g., $\mathrm{N}_{2}$ and $\mathrm{O}_{2}$ ) present in both data are comparable, with only a slightly higher presence of contamination in the gas extract from the line leaving the chamber. Spectra taken from the lines periodically during several 1month tests (data not shown) demonstrate that the level of contamination does not change appreciable throughout the testing duration; therefore, it was concluded that the flushing/baking procedure, along with the quality of the sealing of the CCG system, was acceptable for keeping contamination to a minimum.

\subsubsection{Crack growth and stress intensity factor quantification}

The direct current potential drop (DCPD) technique was used to nondestructively monitor changes in electrical conductivity through the CCG specimens due to cracking. Protocols established in ASTM standard E 1457-07 were implemented to convert the DCPD voltage signals into crack-length measurements and to calculate the stress intensity factors, $\mathrm{K}_{\mathrm{I}}$, for each sample over the course of testing. The following equation was used to calculate the crack length from the DCPD voltage signal:

$$
a / W=\frac{2}{\pi} \cos ^{-1}\left[\frac{\cosh ^{\pi Y_{0}} / 2 W}{\cosh \left[\frac{V}{V_{0}} \cosh ^{-1}\left\{\frac{\cosh ^{\pi Y_{0}} / 2 W}{\cosh ^{\pi a_{0}} / 2 W}\right\}\right]}\right]
$$

where $\mathrm{a}_{0}$ is the initial crack size, $\mathrm{V}_{0}$ is the baseline voltage signal measured before crack propagation begins, $\mathrm{Y}_{0}$ is half the distance between the output voltage leads, and $\mathrm{V}$ is the voltage signal.

Initial validation of the DCPD technique involved using EDM machining to cut precracks of various lengths into stainless steel samples and then using Equation (1) to predict the length of the precrack. Initial results indicated good agreement (e.g., errors on the order of 5\%) between the predicted and the known values. During CCG testing, Equation (1) was applied to the DCPD data in real time to approximate the crack length continuously. After each CCG test was completed, measurement of the final crack length was performed using SEM imaging, and the crack-length data were corrected to reflect the true crack length as a function of time. Once the voltage signals were converted into accurate crack measurements, determination of the crack growth rate, da/dt, was done using custom Matlab scripts by smoothing the DCPD data and then calculating the slope of the crack length versus time data using the point-to-point technique. Figure 8 presents two example cases that demonstrate the conversion of DCPD voltage signals into crack-length measurements. 

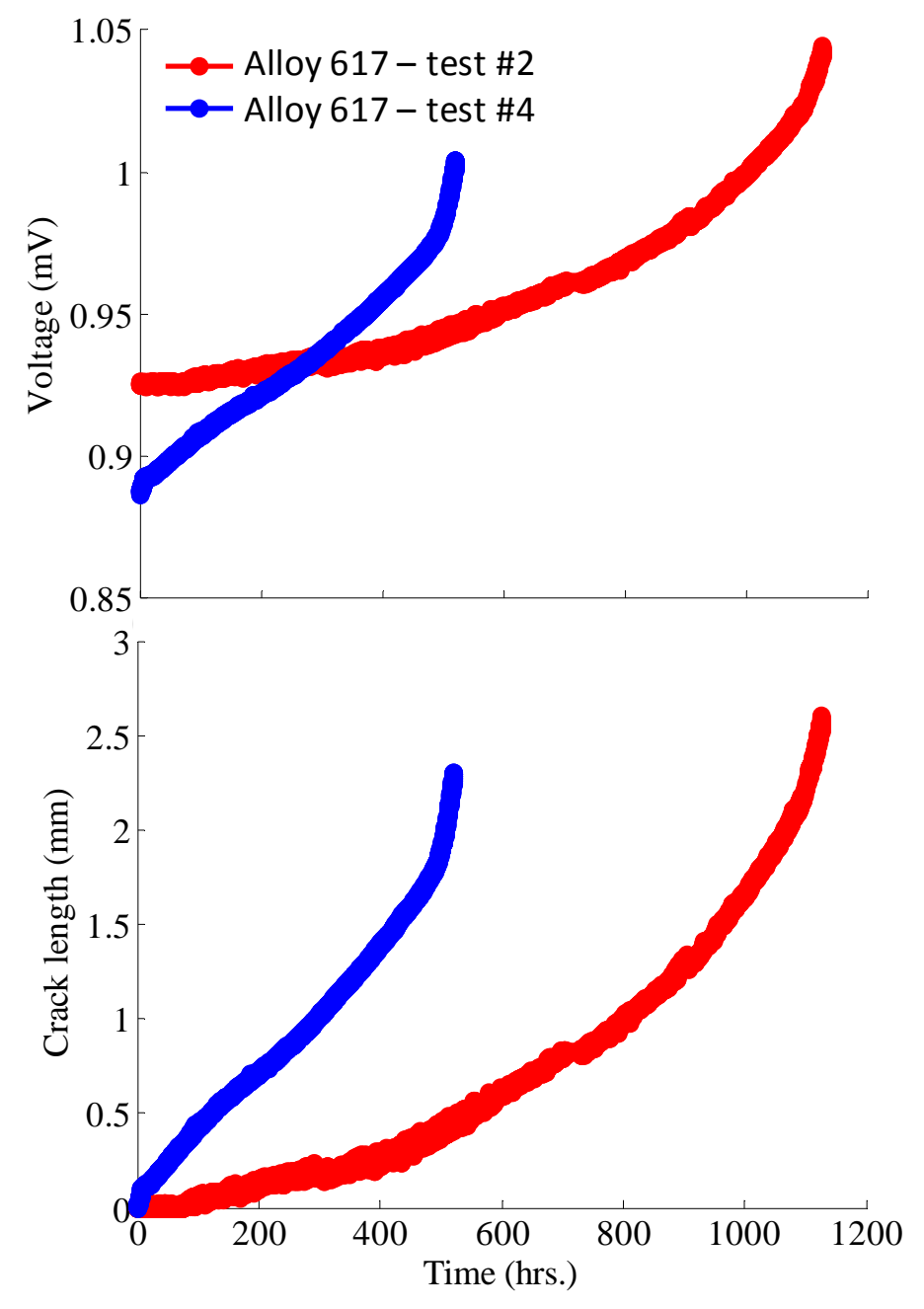

Figure 8 DCPD data (top) and calibrated crack length-data (bottom) to demonstrate the conversion of voltage signlas to crack lengths during CCG testing.

To predict the stress state near the tip of the crack in the CT specimen as a function of the applied load and the specimen geometry, the linear elastic stress intensity factor, $K_{I}$, was determined as:

$$
K_{I}=Y\left(\frac{a}{W}\right) \sigma \sqrt{a},
$$

where, a is length of the initial crack, $\mathrm{W}$ defines the overall geometry of the specimen, $\sigma$ is the applied nominal stress, and $\mathrm{Y}(\mathrm{a} / \mathrm{W})$, a function of geometry , is provided explicitly in ASTM standard E 1457-07. Custom Matlab scripts were used to perform the calculations of stress intensity factors from the converted DCPD data. 


\subsection{Tensile Testing}

The dogbone specimens were subjected to uniaxial tension using a screw-driven Instron materials testing machine to measure their tensile properties. A digital image correlation (DIC) technique was employed to measure the strain within the specimens. Each specimen was painted with a speckle pattern (Ultra-flat black spray pain, Rust-Oleum) prior to testing, and optical images of the specimens were taken during testing. A custom Matlab script was used to analyze the optical images and extract the strain values by tracking the displacements of local regions of the speckle pattern. Results for ultimate tensile strength (UTS) and yield stress ( $\sigma_{\mathrm{Y}}$ ) were extracted from the stress-strain curves generated by combing the load results from the Instron machine with the strain results from the DIC technique. Because the DIC technique utilized a local view of the sample surface, it was not able to capture the global strain within the samples. The \% elongation at failure was determined by aligning the broken fragments of the tensile specimens and measuring the final gauge length. The tensile properties of two stocks of the Alloy 617 samples were measured in order to investigate the reproducibility of the aging technique employed to age the samples. Alloy $800 \mathrm{H}$ dogbone samples were machined both parallel and perpendicular to the rolling direction in order to investigate possible anisotropy in the mechanical behavior of those samples.

\subsection{Hardness Testing}

Hardness samples were created from the coupons by polishing the surface to a mirror finish using 120, 240, 400, 600, 800, 1200, and 2000 grit sand papers (Allied HighTech) followed by a final polishing with a high-concentration diamond suspension (Allied HighTech). Vickers Microhardness Testing was performed using a Wilson Microhardness Testing Machine to measure the hardness of the candidate alloys as a function of aging time. A load of $0.5 \mathrm{kgf}$ was used to create the indents, with a 10 second dwell time, using a Vickers diamond indenter. Measurements of the areas of the indents were made manually, and the Vickers hardness, Hv, was calculated automatically by the Wilson machine. 20 indentations were made per sample, and the results from the 20 measurements were averaged to obtain the hardness value.

\subsection{Microstructure Analysis}

Grain boundary engineering (GBE) and microstructure characterization of GBE samples were performed by Integran Technologies. The GBE optimization was performed on as-received (i.e., not solution treated and not aged) Alloy 617 samples. The following quote describing the GBE process was taken from a report from Integran - "The GBE processing involved repetitive deformation-annealing cycles, and it primarily relied on the formation of annealing twins during the early stage of recrystallization to facilitate the formation of other low $\Sigma$ special grain boundaries. In an effort to maximize the fraction of special grain boundary (Fsp) content in Alloy 617, a series of thermo-mechanical processing steps were conducted in accordance with the general multi-step processing principles outlined in Integran's US Patents 5,702,543 and $6,129,795$. Pre-strain was applied to the samples by cold rolling at room temperature. The total amount of pre-strain applied was less than 30\%. The heat treatments were carried out in an air furnace. Since the processing temperatures were relatively high $\left(1000^{\circ} \mathrm{C}-1100^{\circ} \mathrm{C}\right)$, the heat treatment times were kept short ( $<10$ minutes at temperature) to achieve full recrystallization but 
without causing excessive grain growth. All the heat treatments were conducted in air, followed by air cooling.”

For structural characterization of GBE samples, each sample surface was mechanically polished to a $1 \mu \mathrm{m}$ finish and subsequently electropolished in a solution of $10 \%$ perchloric acid in methanol at $-40^{\circ} \mathrm{C}$ using an applied voltage of $40 \mathrm{~V}$ for 10 seconds. This rendered the surfaces suitable for electron backscattered diffraction pattern analysis (EBSP). Orientation Imaging Microscopy (OIM) was performed to automatically index the EBSP patterns and provide a complete description of the crystallographic orientations in the samples before and after each optimization trial. The crystallographic

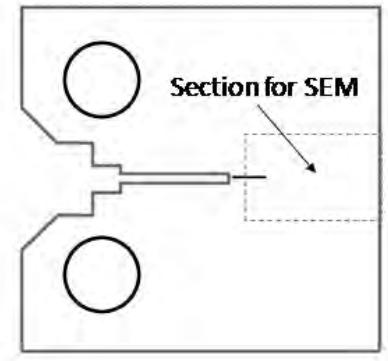

Figure 9 Image of a CT specimen highlighting the region removed for SEM inspection. orientations determined at each step (from the electron backscattered diffraction patterns) were calibrated to be accurate within $\pm 0.5^{\circ}$. All crystallographic misorientations were determined from changes in the electron diffraction pattern as the incident electron beam traverses the grain boundaries. All grain boundaries were classified in accordance with the Coincidence Site Lattice (CSL) model using Brandon’s criterion for allowed angular deviation.

After completion of each CCG test, the three CT specimens were removed from the apparatus, and coupons from each specimen were removed via EDM for subsequent SEM inspection of the cracks. Figure 9 shows the region of the CT specimen that was removed. After removal, the coupons were sliced in half (specifically, EDM cuts were made through the coupons in the direction of the crack at a depth of B/2) to reveal the interior of the samples. Each slice was then ground using 240, 600, 800, and 1200 grit sand papers followed by a final polishing using 0.05 mm silica colloid. The polished samples were then ultrasonically cleaned in acetone for 3 to 5 minutes.

The polished samples created from CT specimens subjected to CCG were examined under SEM to evaluate the crack length and crack morphology. Electron backscatter diffraction (EBSD) was used to examine the crystallographic orientations of the samples and reveal the misorientation of grains and the strain near the cracks. Because the sizes of the grains is relatively large, low magnification (50x to $100 \mathrm{x}$ ) was required to reveal multiple grains, and the sample were tilted at $70^{\circ}$ degree during EBSD.

\section{RESULTS AND DISCUSSION}

\subsection{Results and Discussion of Mechanical Properties of Candidate Alloys}

The tensile properties and hardness of Alloy 617 and Alloy $800 \mathrm{H}$ samples aged at $850{ }^{\circ} \mathrm{C}$ were measured as a function of aging time to assess how their mechanical properties evolve during the aging process. As mentioned above in Section 2.3, two tensile tests were performed for each specimen. In the following bar-chart plots of tensile properties, the height of the bar represents 
the average of the two measurements, and the upper and lower lines of the error bars reflect the higher and lower measurements, respectively. In the hardness plots, the error bars reflect the standard deviation of the measured values, with 20 measurements done for each condition. Figure 10, Figure 11, and Figure 12 present the ultimate tensile strength (UTS), yield stress $\left(\sigma_{\mathrm{Y}}\right)$, and \% elongation at failure for the Alloy 617 samples as a function of aging time. Figure 13 presents the hardness results for the Alloy 617 samples. Results for both stocks (stock \#1 and stock \#2) are displayed to demonstrate the reproducibility of the aging treatments. Results from the as-received (As Is) and solution-treated (Sol Tre) samples are displayed on the left sides of the plots, and the results for the grain boundary engineered (GBE) samples are included on the right sides of the plots.

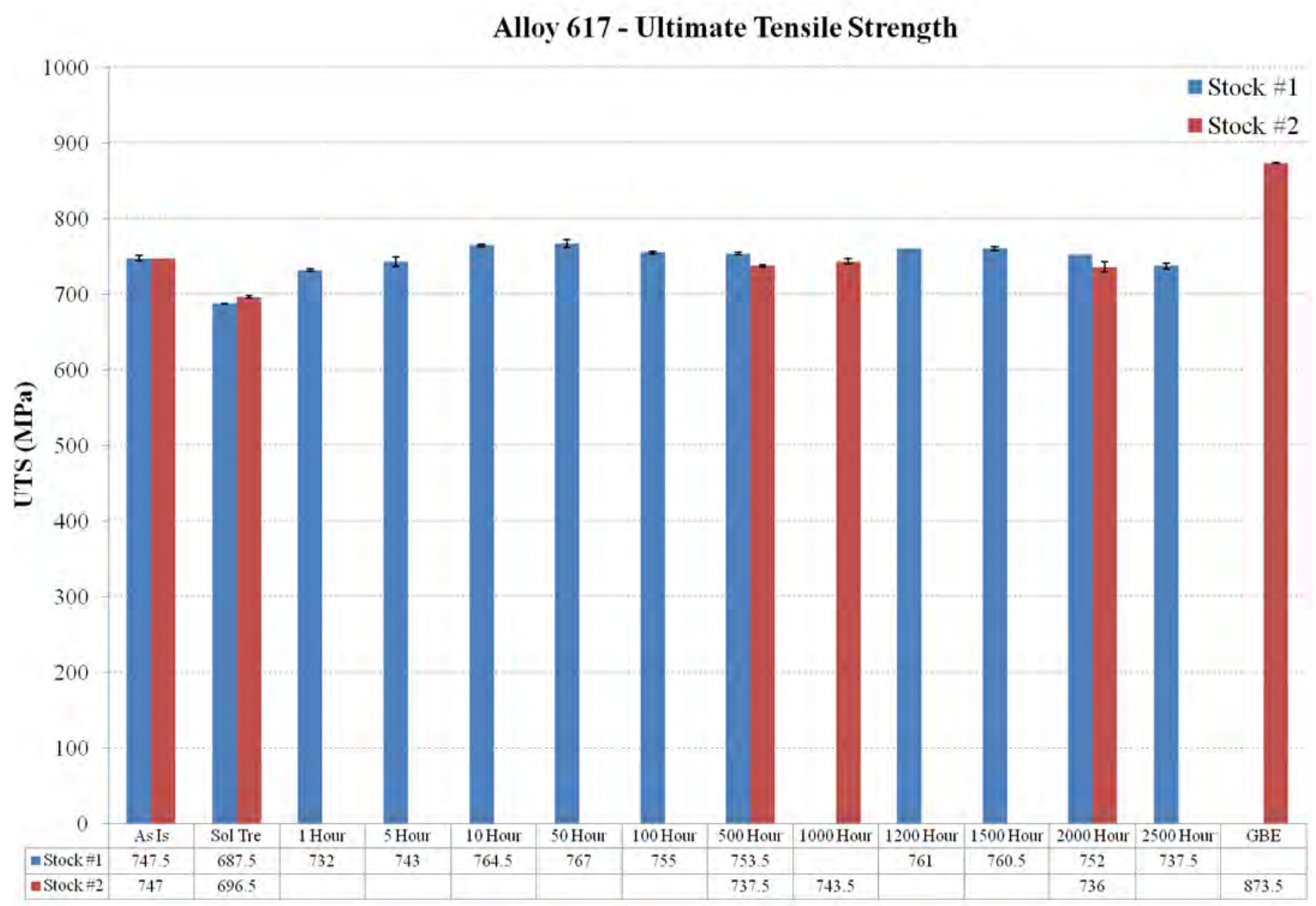

Figure 10 Ultimate tensile strength results for Alloy 617 samples as a function of aging time. Results for the GBE samples are plotted on the right side of the graph. 


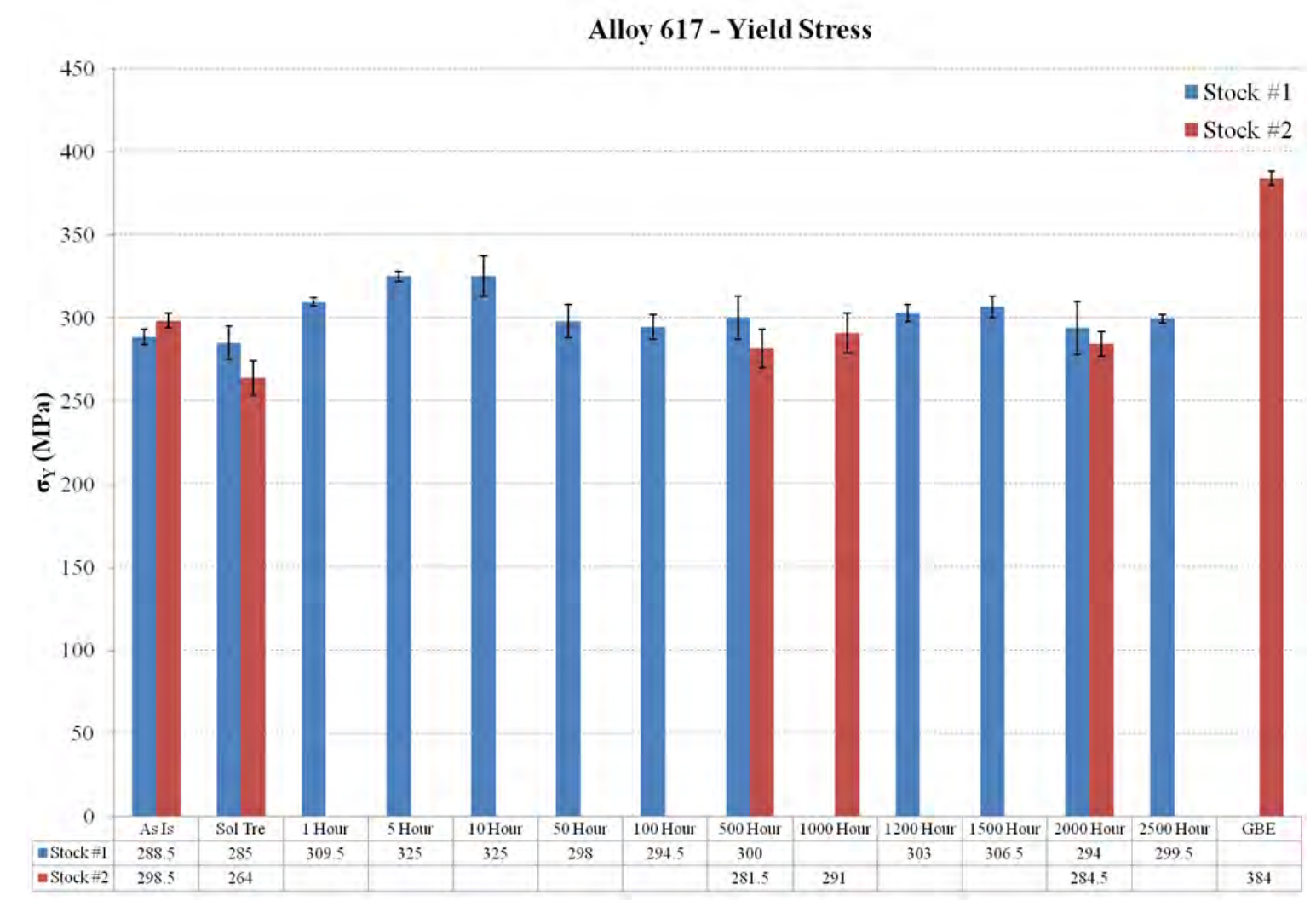

Figure 11 Yield stress results for Alloy 617 samples as a function of aging time. Results for the GBE samples are plotted on the right side of the graph. 


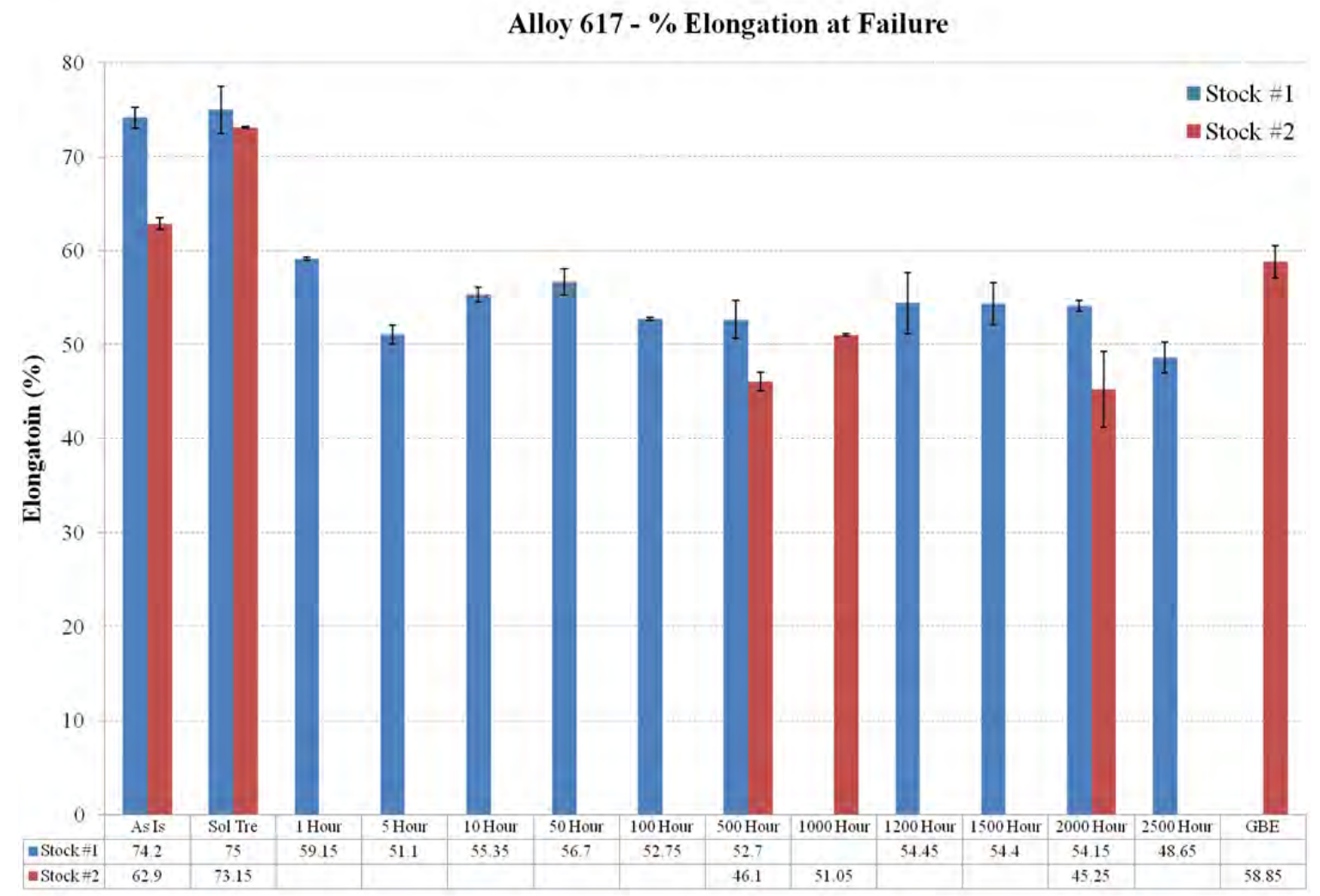

Figure 12 Results for \% elongation at failure for Alloy 617 samples as a function of aging time. Results for the GBE samples are plotted on the right side of the graph. 


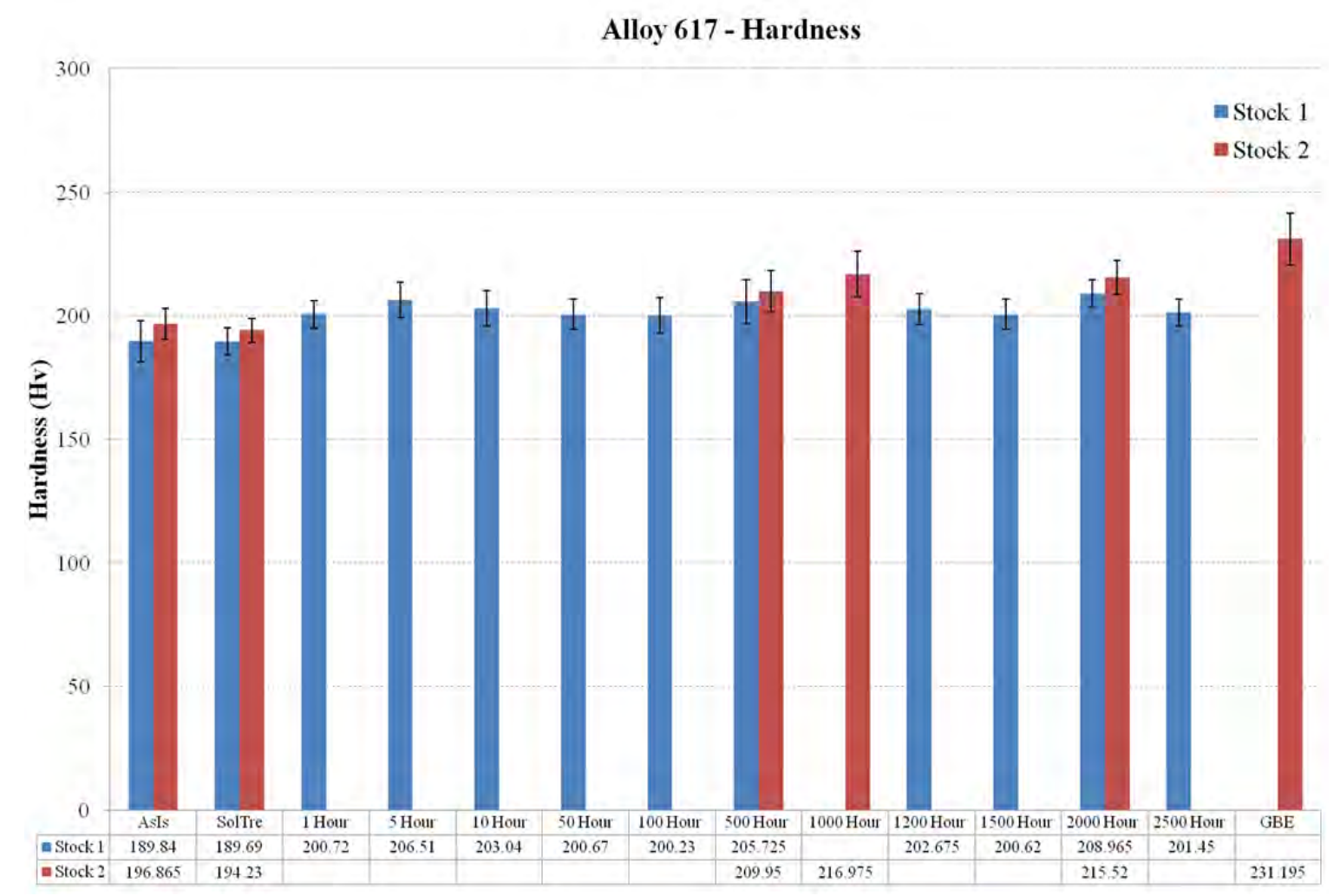

Figure 13 Results for hardness of Alloy 617 samples as a function of aging time. Results for the GBE samples are plotted on the right side of the graph.

The tensile properties and hardness of the stock \#1 and stock \#2 samples are consistent for the vast majority of the measurements, with the error bars overlapping in most cases. The exception to this is the \% elongation results, although the differences in the results for stock \#1 and stock \#2 are not extraordinary.

Good correlation is observed between the trends of the UTS and $\sigma_{\mathrm{Y}}$ plots, with the variations in $\sigma_{\mathrm{Y}}$ being more apparent as a function of aging time. The \% elongation results from 1 hour of aging and beyond follow a similar trend (the results for \% elongation from the as-received and solution-treated samples are higher than the rest and thus do not follow the pattern). No obvious trend exists for hardness as a function of aging, with the majority of the measured values falling within the error bars of the others. The GBE samples exhibit superior properties (UTS, $\sigma_{\mathrm{Y}}$, and $\mathrm{Hv}$ ), with its value for \% elongation at failure only being smaller than those of the as-received and solution-treated samples.

Figure 14, Figure 15, and Figure 16 present the ultimate tensile strength (UTS), yield stress $\left(\sigma_{\mathrm{Y}}\right)$, and $\%$ elongation at failure for the Alloy $800 \mathrm{H}$ samples as a function of aging time. Figure 17 presents the hardness results for the Alloy $800 \mathrm{H}$ samples. Tensile property results for samples aligned both parallel and perpendicular to the rolling direction were measured to investigate possible anisotropy in mechanical properties due to the rolling process. 


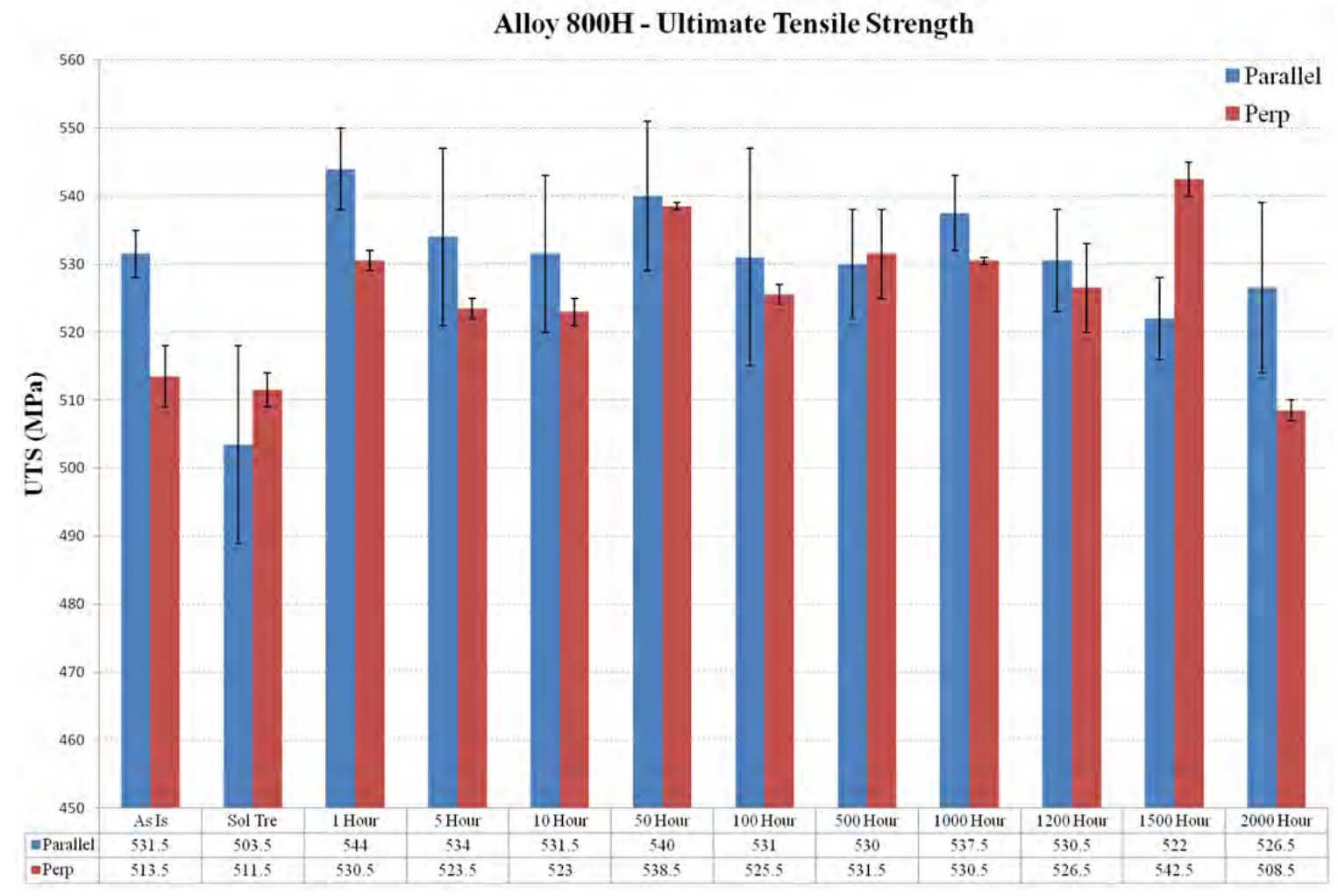

Figure 14 Ultimate tensile strength results for Alloy $800 \mathrm{H}$ samples as a function of aging time. 


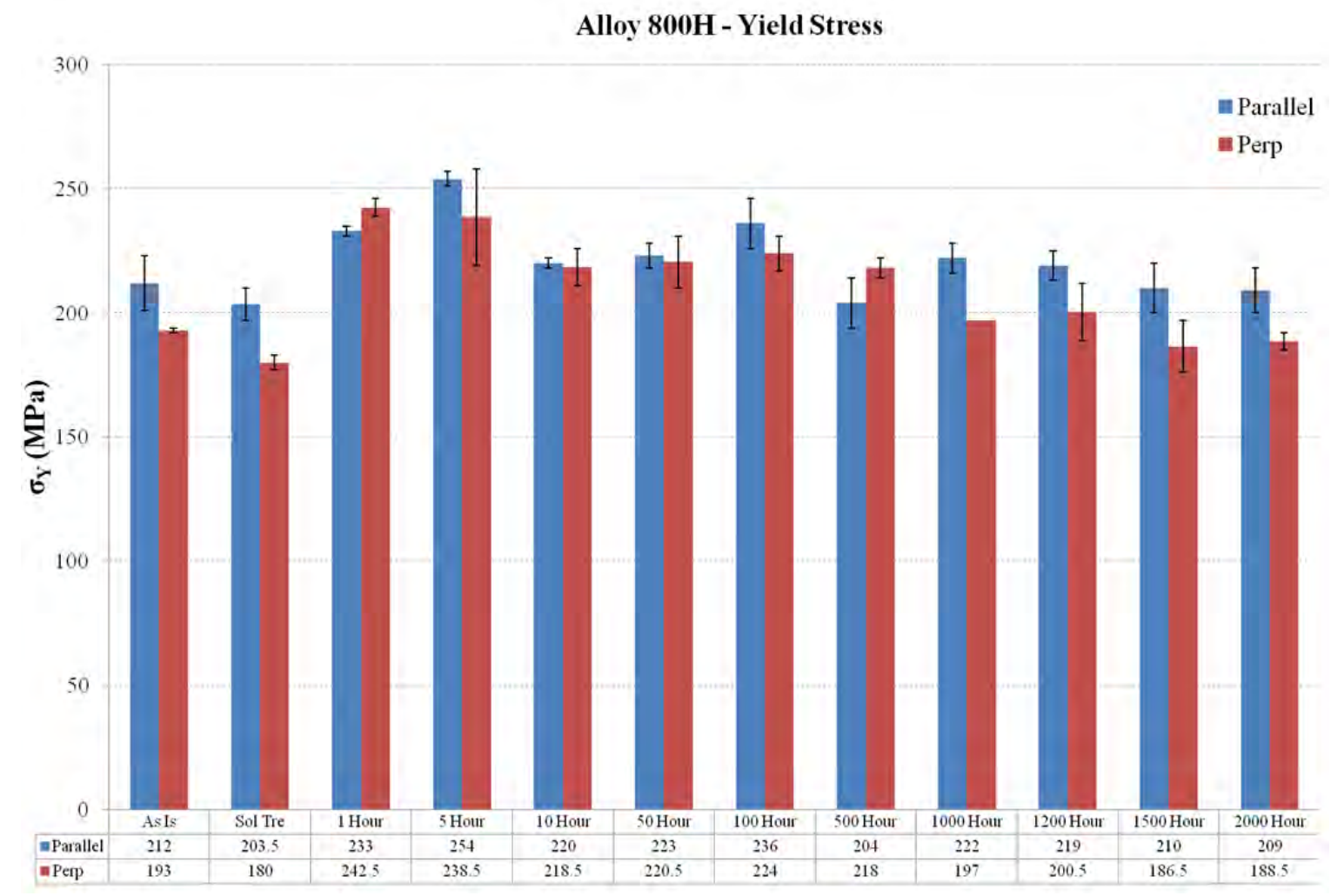

Figure 15 Yield stress results for Alloy $800 \mathrm{H}$ samples as a function of aging time. 


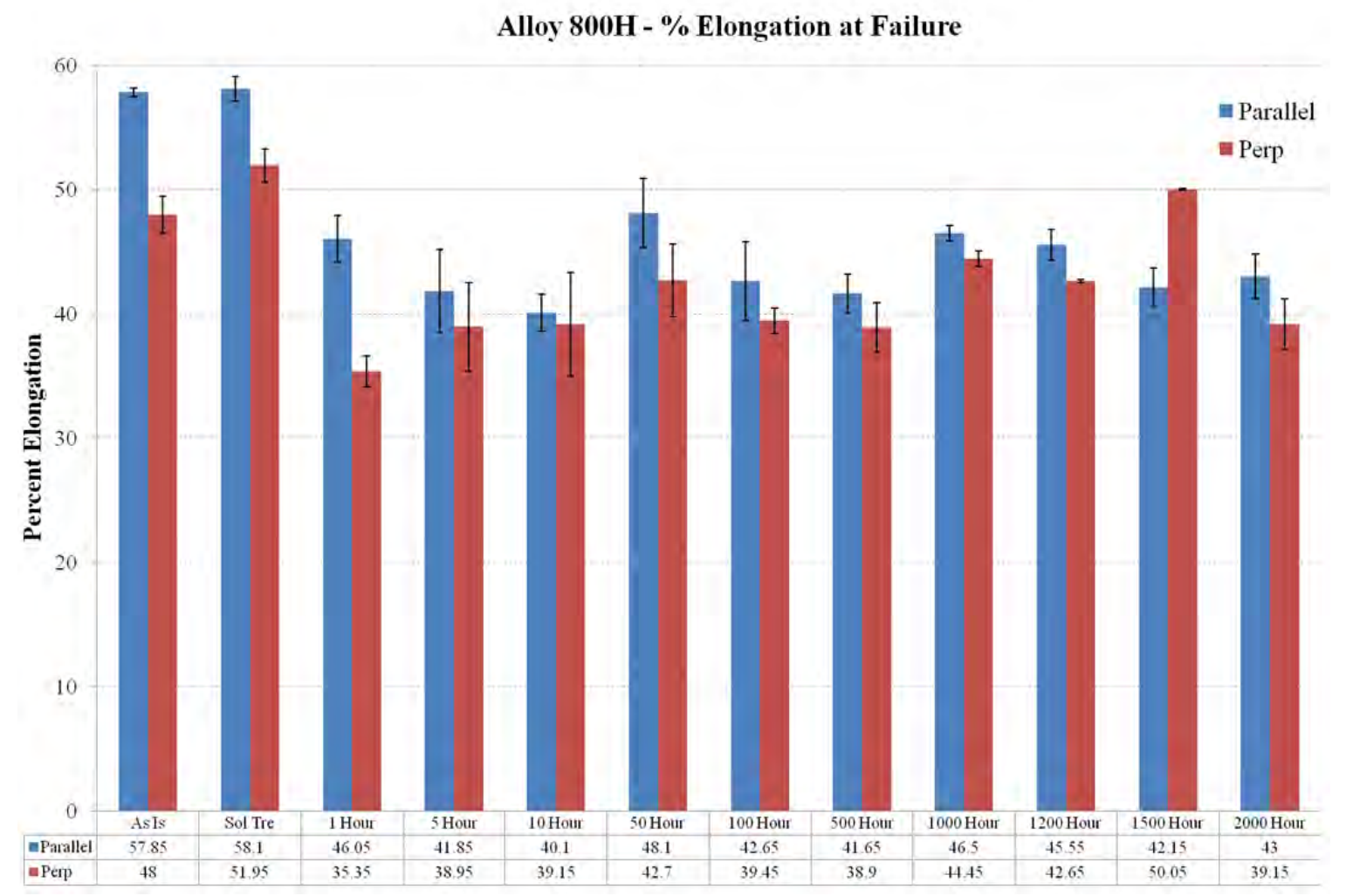

Figure 16 Results for \% elongation at failure for Alloy $800 \mathrm{H}$ samples as a function of aging time. 


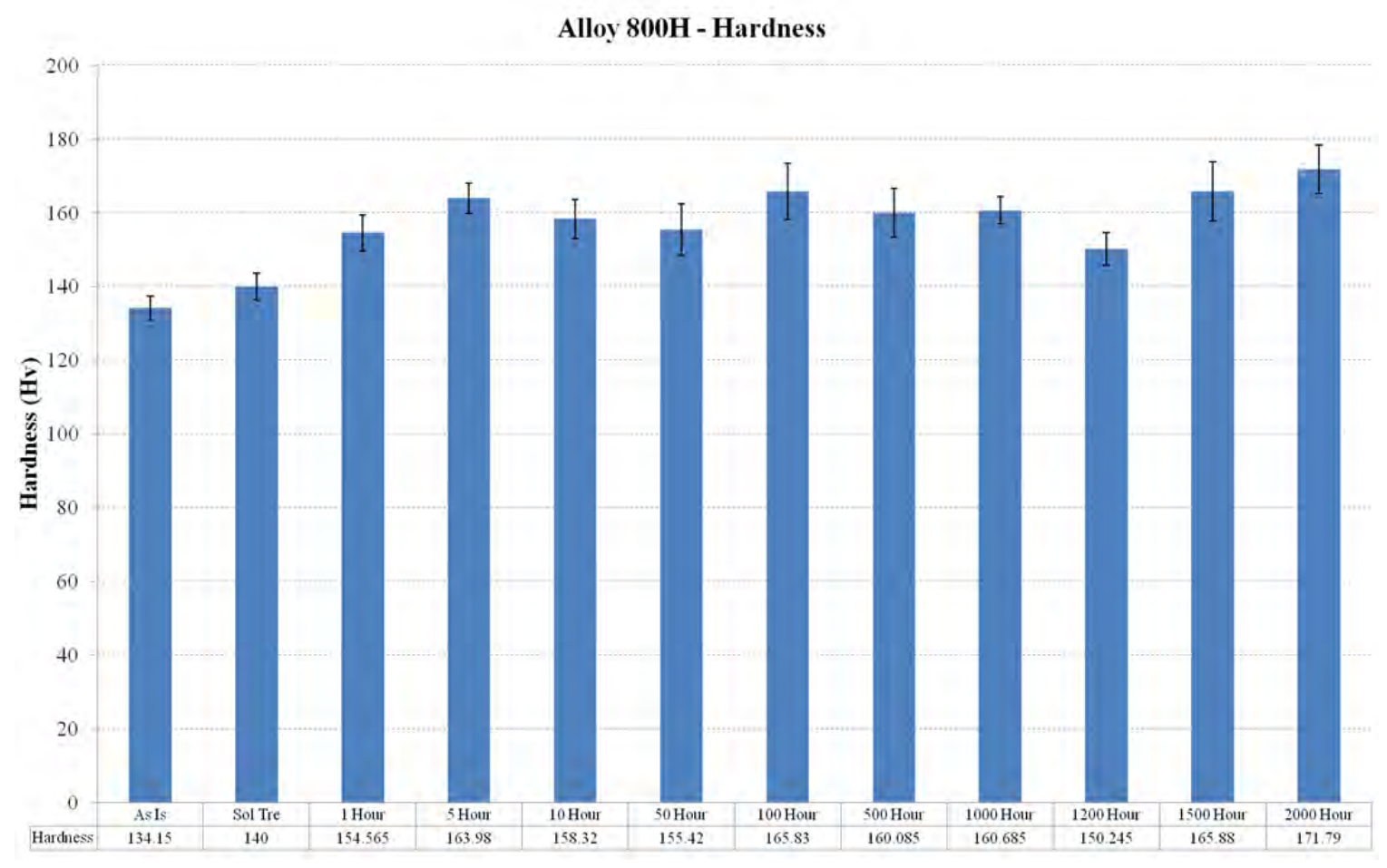

Figure 17 Results for hardness of Alloy $800 \mathrm{H}$ samples as a function of aging time.

For the majority of the aging times, the tensile properties of the $800 \mathrm{H}$ samples aligned parallel to the rolling direction are superior to those of the samples aligned perpendicular to the rolling direction. Unlike the results from the Alloy 617 samples, it is difficult to find correlations between the trends of the various properties. For the samples aligned parallel to the rolling direction, the \% elongation results from 1 hour of aging and beyond follow a similar trend to that of the UTS results; however, significant variability in those UTS measurement prevents a confirmation of that correlation. One similarity between the results from the Alloy 617 samples and the Alloy $800 \mathrm{H}$ samples is the higher values for \% elongation at failure for the as-received and solution-treated samples compared to the others. Overall, in comparing the mechanical properties of the two candidate alloys, Alloy 617 exhibits superior mechanical properties.

\subsection{Results and Discussions of Task A}

The test sequence of the successful CCG tests completed is presented in Table 3. 
Table 3 Matrix of completed CCG tests

\begin{tabular}{|c|c|c|c|c|c|}
\hline Test \# & Alloy & Stock \# & Pretreatment & Temperature $\left({ }^{\circ} \mathbf{C}\right)$ & Environment \\
\hline 2 & 617 & 1 & ST + Aged & 700 & Air \\
\hline 4 & 617 & 1 & ST + Aged & 850 & Air \\
\hline 6 & 617 & 2 & GBE & 700 & He \\
\hline 7 & $800 \mathrm{H}$ & 1 & ST + Aged & 700 & Air \\
\hline 8 & 617 & 3 & None (As-received) & 700 & He \\
\hline 9 & $800 \mathrm{H}$ & 1 & ST + Aged & 700 & He \\
\hline 10 & 617 & 2 & ST + Aged & 700 & He \\
\hline 11 & 617 & 2 & ST + Aged & 850 & He \\
\hline
\end{tabular}

$\mathrm{ST}=$ solution treated, $\mathrm{GBE}=$ grain boundary engineered

The test numbers not shown in Table 3 (i.e., 1, 3, and 5) correspond to tests that failed. Tests 1 and 3 failed due to improper loading levels, and test 5 failed due to improper control of the environmental conditions within the chamber. For all CCG tests, the direction of crack propagation was parallel to the rolling direction, and the cracks were prevented from propagating through the samples entirely in order to quantify the final crack length for the calibration of the DCPD measurements. All final crack lengths were measured via SEM by cutting each CT specimen in half and measuring the length of the longest crack within the interior of the specimen. The forthcoming CCG curves for tests 2, 4, 6, 7, 8, and 9 are comprised of the data points from all three tests. Due to minimal amount of crack growth within one sample from test 10 and one sample from test 11, those curves are comprised of data points from the two remaining specimens in the test set. 


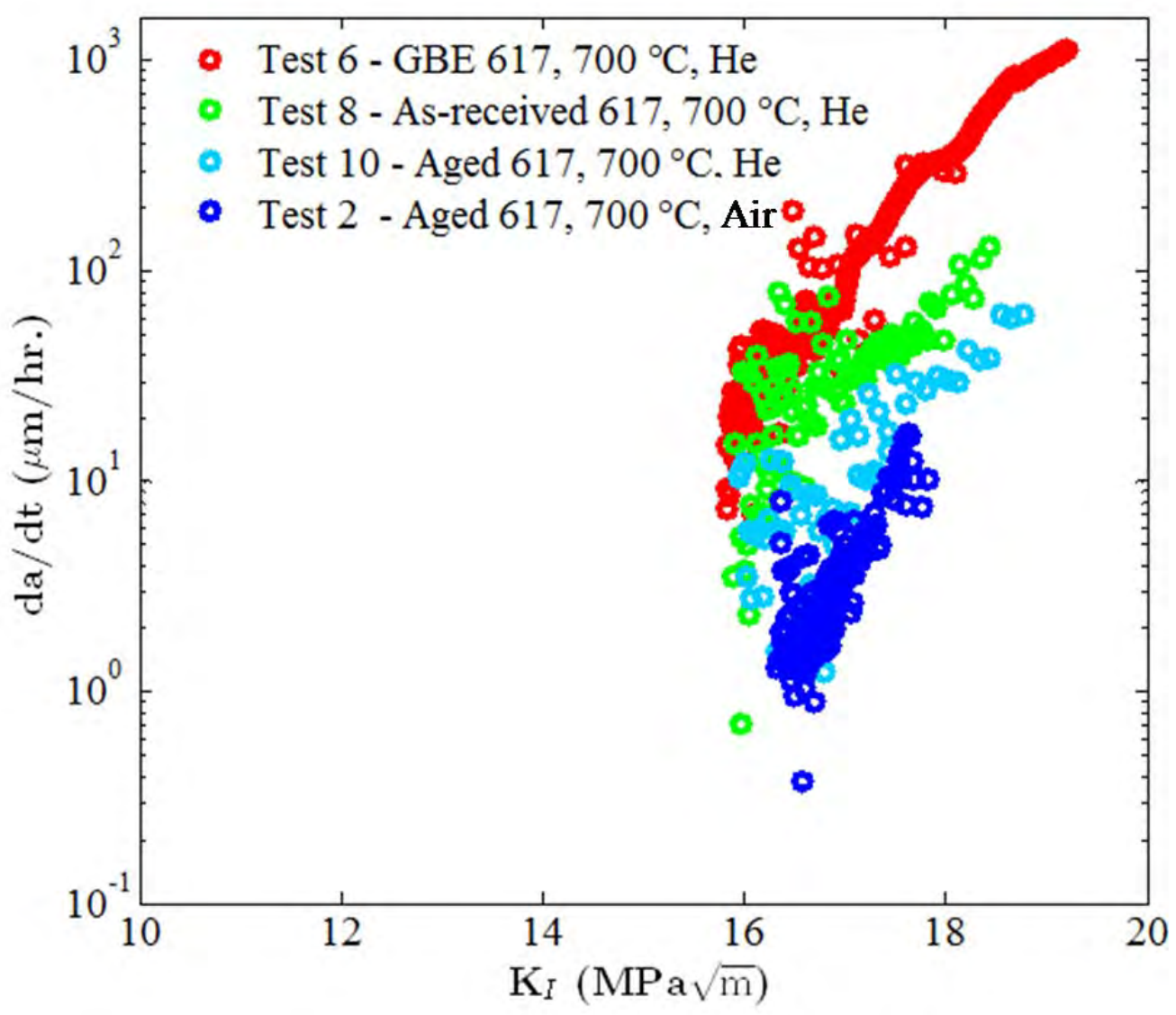

Figure 18 CCG results for Alloy 617 tested at $700{ }^{\circ} \mathrm{C}$.

The CCG results from the Alloy 617 samples tested at $700{ }^{\circ} \mathrm{C}$ are presented in Figure 18 . Results for da/dt versus $\mathrm{K}_{\mathrm{I}}$ for the 617 samples tested at $700{ }^{\circ} \mathrm{C}$ reveal that aged Alloy 617 samples tested in air at exhibit the highest resistance to crack growth, followed the aged 617 samples tested in He, followed by the as-received 617 samples tested in helium, followed by GBE samples tested in helium. 


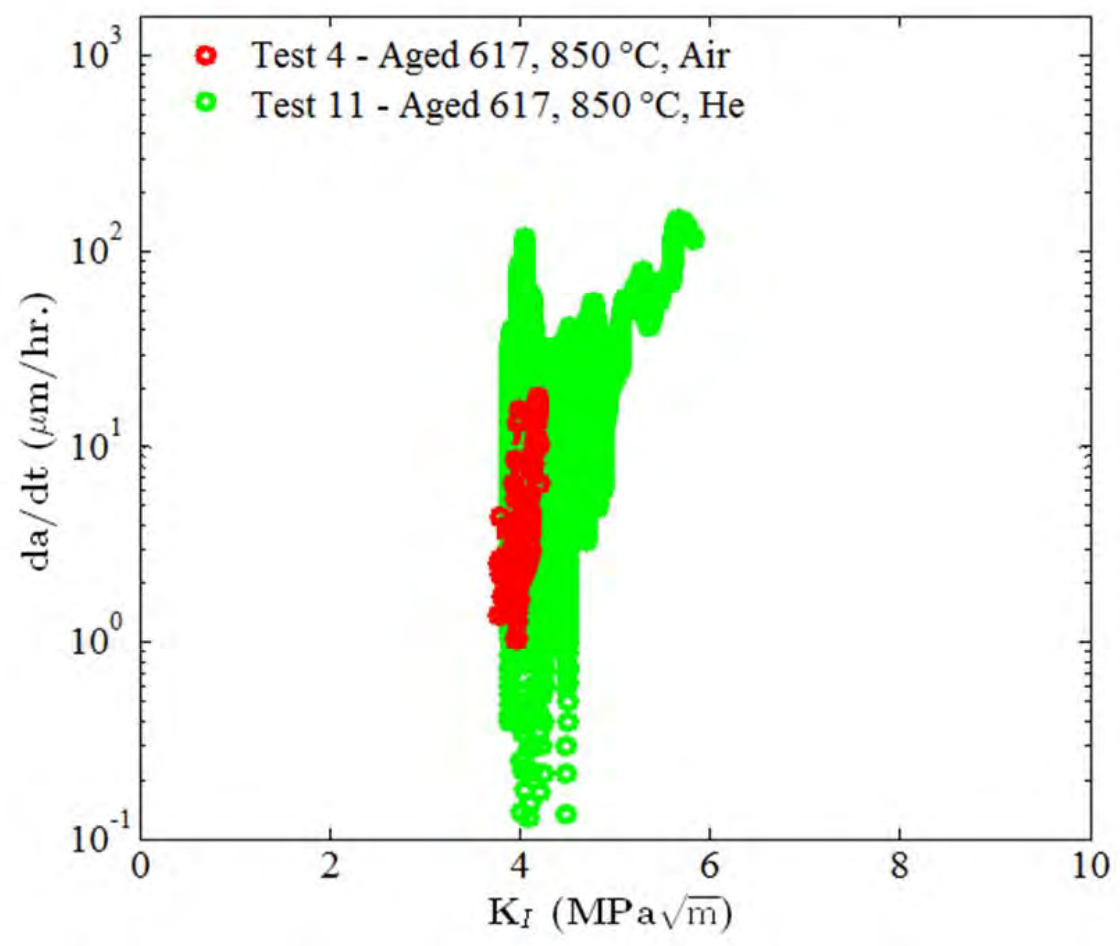

Figure 19 CCG results for Alloy 617 tested at $850{ }^{\circ} \mathrm{C}$.

The CCG results from the Alloy 617 samples tested at $850^{\circ} \mathrm{C}$ are presented in Figure 19 . The aged 617 samples tested $850{ }^{\circ} \mathrm{C}$ show a dramatic reduction in resistance to crack growth compared to the samples tested at $700{ }^{\circ} \mathrm{C}$ (e.g., $\mathrm{K}_{\mathrm{I}} \approx 4 \mathrm{MPa} \sqrt{m}$ gives rise to crack growth at 850 ${ }^{\circ} \mathrm{C}$, whereas $\mathrm{K}_{\mathrm{I}}>15 \mathrm{MPa} \sqrt{\mathrm{m}}$ is required to induce cracking at $700{ }^{\circ} \mathrm{C}$ ). At $850{ }^{\circ} \mathrm{C}$, the crackgrowth resistance appears to be slightly better in the He environment, although the early spike in $\mathrm{da} / \mathrm{dt}$ around $\mathrm{K}_{\mathrm{I}} \approx 4 \mathrm{MPa} \sqrt{m}$ (only measured in one of the samples tested in He) indicates that the crack growth rate accelerated initially but then slowed as that test progressed. Comparing the results from $700{ }^{\circ} \mathrm{C}$ and $850{ }^{\circ} \mathrm{C}$, the significant reduction in the crack growth resistance of the 617 samples tested at the higher temperature is correlated with the known dramatic reductions in creep resistance and strength, both of which likely lead to the pronounced reduction in crack growth resistance. 


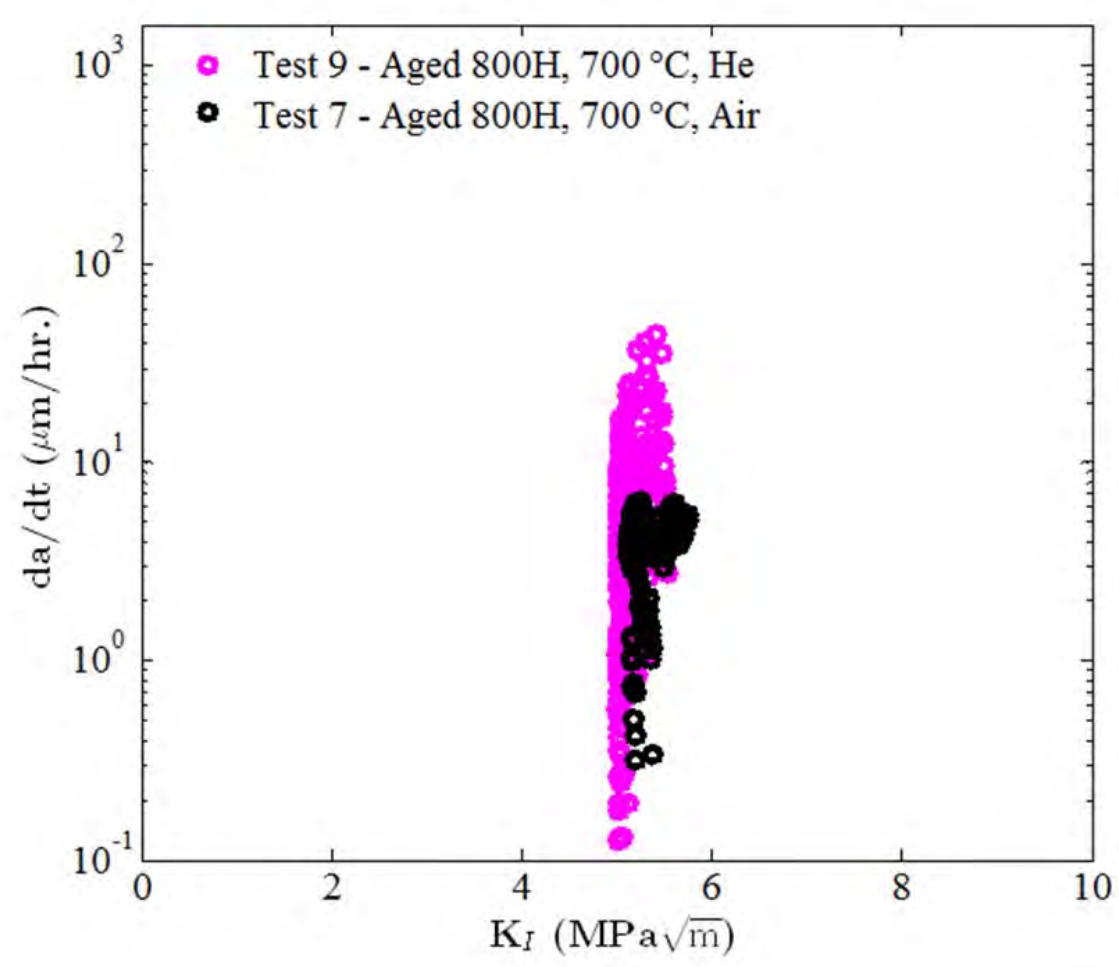

Figure 20 CCG results for Alloy $800 \mathrm{H}$ tested at $700{ }^{\circ} \mathrm{C}$.

The CCG results from the Alloy $800 \mathrm{H}$ samples tested at $700{ }^{\circ} \mathrm{C}$ are presented in Figure 20 . The $800 \mathrm{H}$ samples tested in air at $700{ }^{\circ} \mathrm{C}$ exhibit a resistance to crack growth that is substantially worse than all results obtained from the 617 samples tested at $700^{\circ} \mathrm{C}$, with performance that is only marginally better than that of the 617 samples tested at $850^{\circ} \mathrm{C}$ (e.g., $\mathrm{K}_{\mathrm{I}} \approx 5 \mathrm{MPa} \sqrt{m}$ produces crack growth in Alloy $800 \mathrm{H}$ tested at $700{ }^{\circ} \mathrm{C}$, whereas $\mathrm{K}_{\mathrm{I}} \approx 4 \mathrm{MPa} \sqrt{m}$ produces cracking in Alloy 617 at $850{ }^{\circ} \mathrm{C}$ ). The crack-growth resistance for $800 \mathrm{H}$ appears to be slightly better in the air environment as compared to He. The inferior CCG performance of Alloy $800 \mathrm{H}$ is correlated with the inferior mechanical properties measured and discussed above in Section 3.1.

\subsection{Results and Discussions of Task B}

Figure 21 shows example SEM images of the cracks formed on the outer surface and central plane of a CT specimens after creep crack growth testing. Many crack branches are readily observed. After cutting the CT specimens in half, it was found in all cases that cracks within the interior of the specimens were longer than those found on the surface. Observations of fracture surfaces of the samples (presented below) also confirmed this. As was mentioned in Section 3.2 above, the length of the longest crack within the interior of each specimen was used to quantify crack growth during CCG testing. 

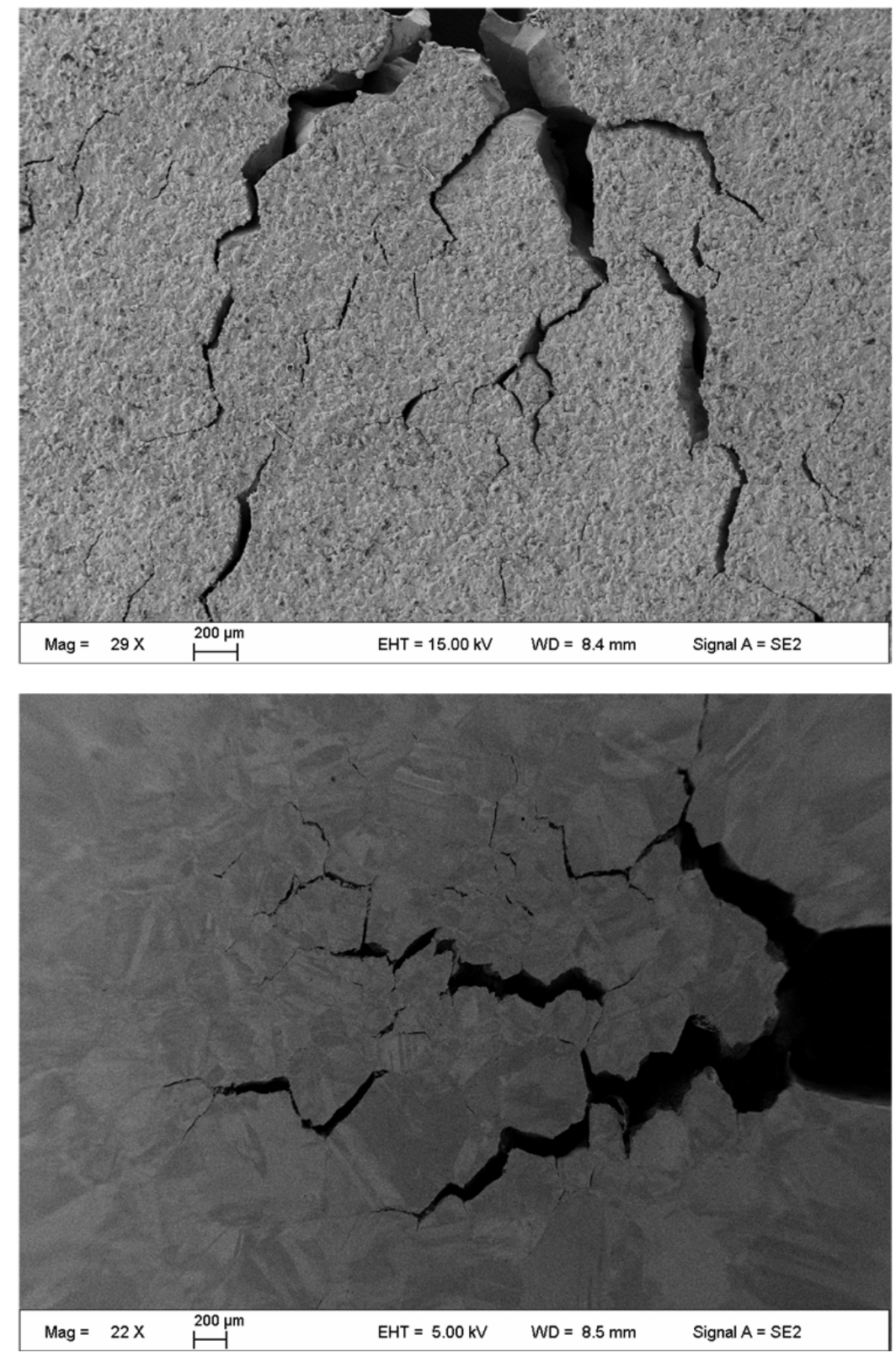

Figure 21 Example SEM images of a sample's outer surface (top) and central plane (below) after creep crack growth testing.

Figure 22 and Figure 23 present SEM images of the crack morphologies of Alloy 617 tested at $700{ }^{\circ} \mathrm{C}$ in air and in helium, respectively. One major crack is observed in samples tested in air. There are many small crack branches in samples tested in helium. In both cases, some small crack initiations and/or cavitations are observed in front of the crack tip. In Figure 22, crack propagation along the grain boundaries can be seen. It appears that the cracks initiated primarily from the triple point grain boundary junctions and the carbide regions. 

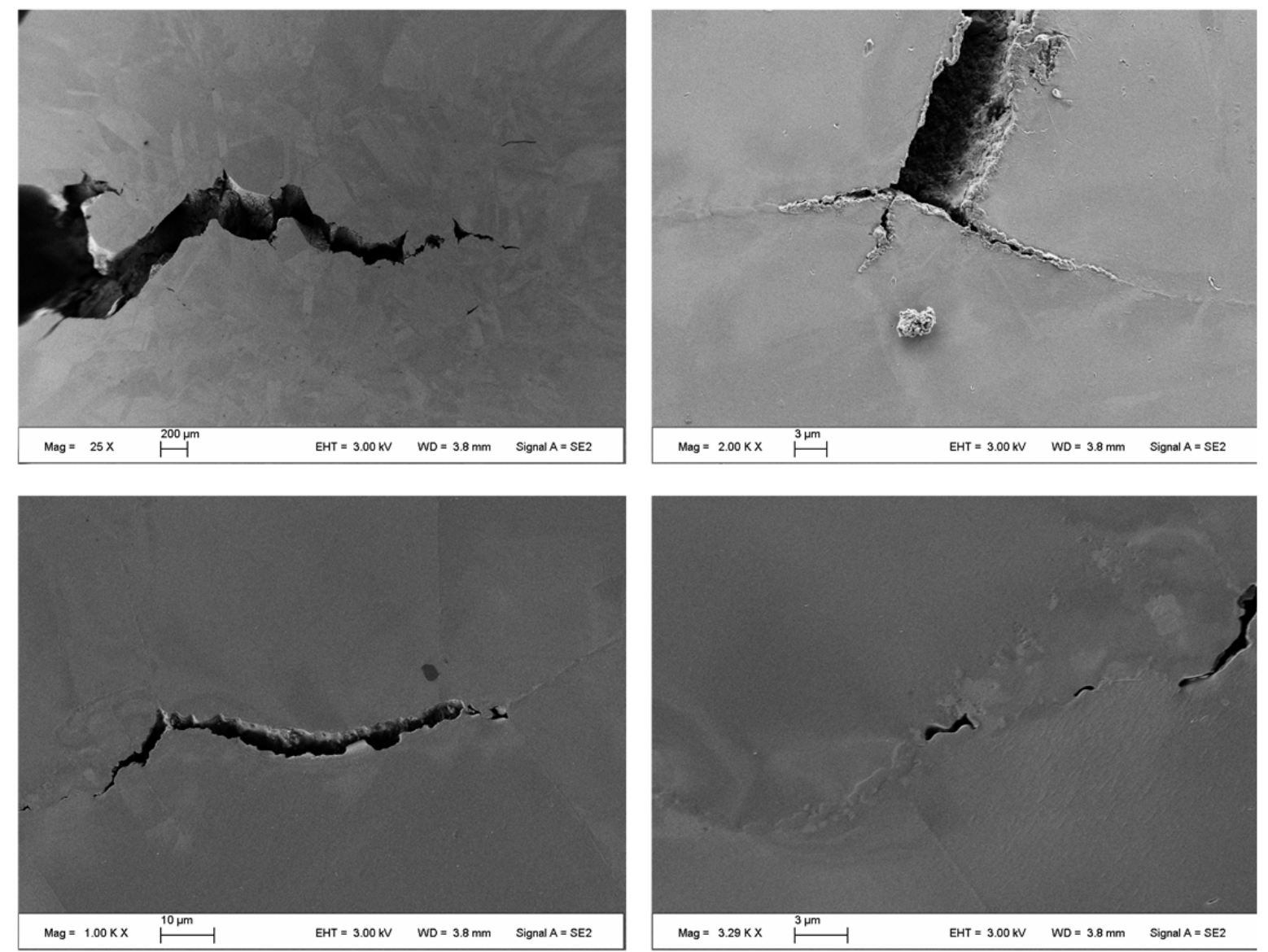

Figure 22 Crack, crack tip, crack cavitation, and crack initiations in Alloy 617 tested in air at $700{ }^{\circ} \mathrm{C}$ (Test 2). The cracks initiated and propagated along grain boundaries. The cracks appeared to have initiated at the grain triple points and at the carbide areas. 

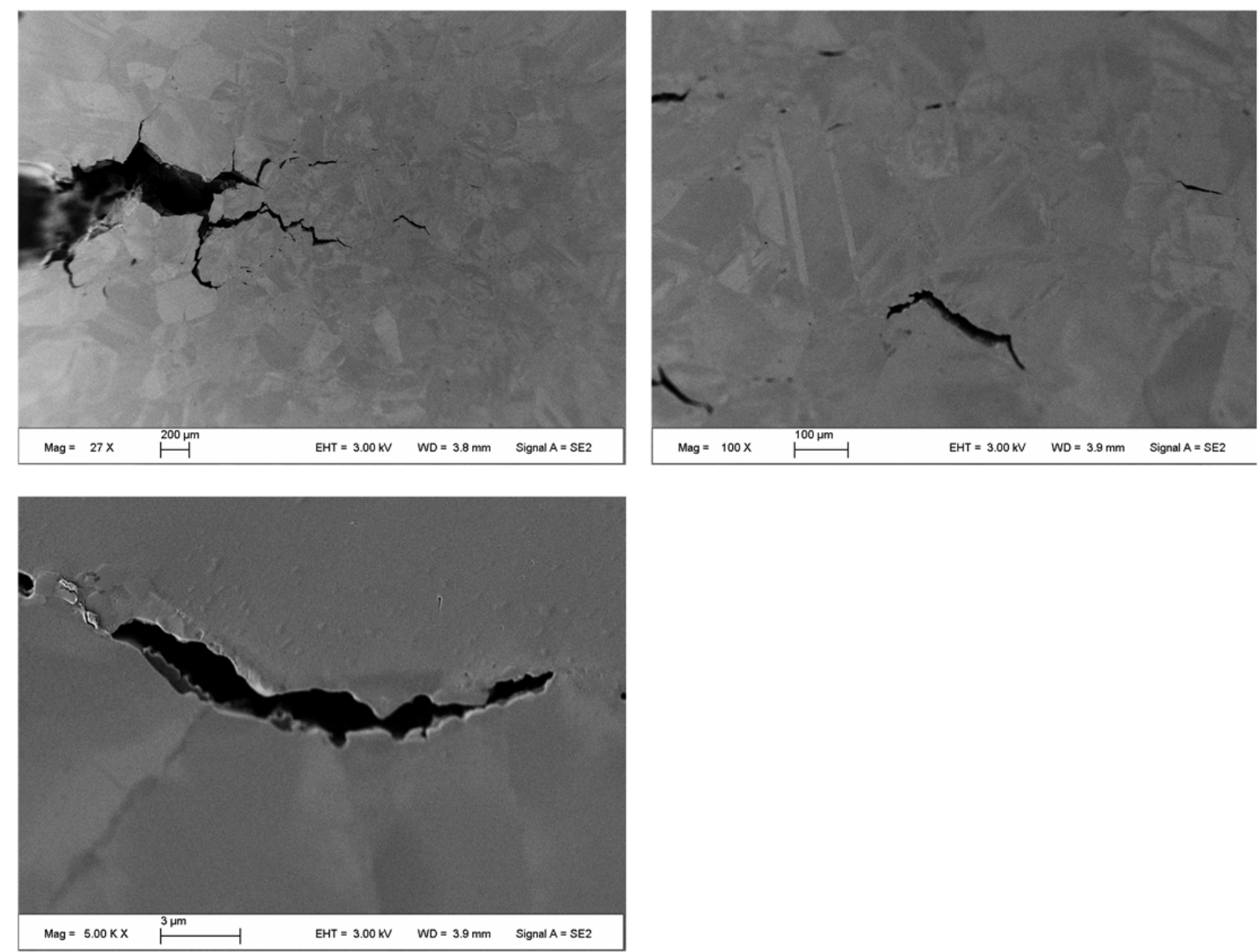

Figure 23 Cracks in Alloy 617 tested at $700{ }^{\circ} \mathrm{C}$ in helium (Test 10). Cracks are intergrannular and appear to have initiated at triple points.

Figure 24 and Figure 25 present SEM images of the cracks from Alloy 617 tested at $850{ }^{\circ} \mathrm{C}$ in air and helium, respectively. The crack morphologies appear to be similar to one another; namely, there is one major crack and many small cracks. It can be seen from the saw-shaped cracks in Figure 24 that there is significant strain in Alloy 617 tested in air. In both cases, the cracks are intergrannular, and cracks appear to have initiated from the triple point grain boundary junctions and carbide regions. 

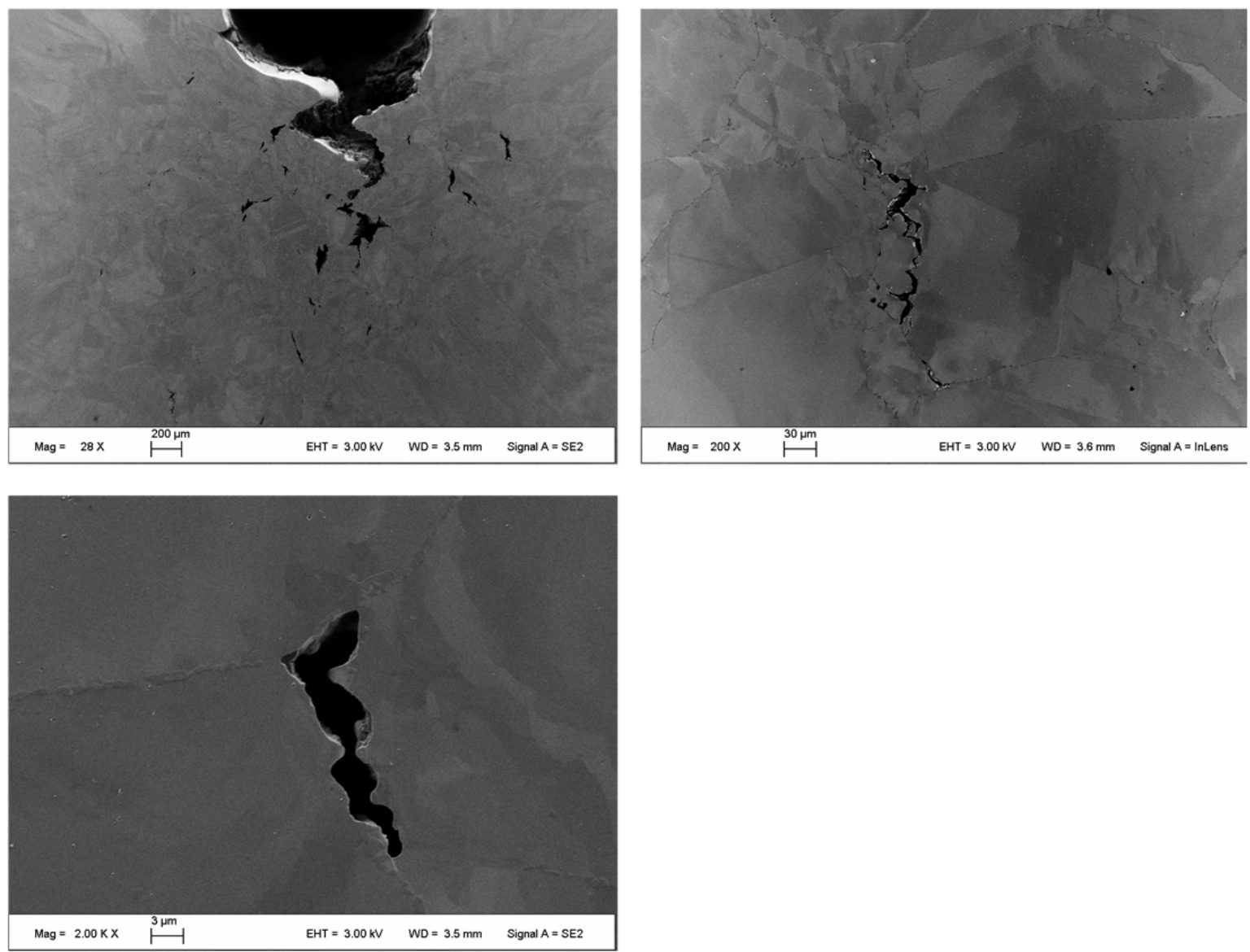

Figure 24 Cracks in Alloy 617 tested at $850{ }^{\circ} \mathrm{C}$ in air (Test 4). Many small cracks are observed. Cracks are intergrannular, and cracks appear to have initiated from the triple points and carbide regions.
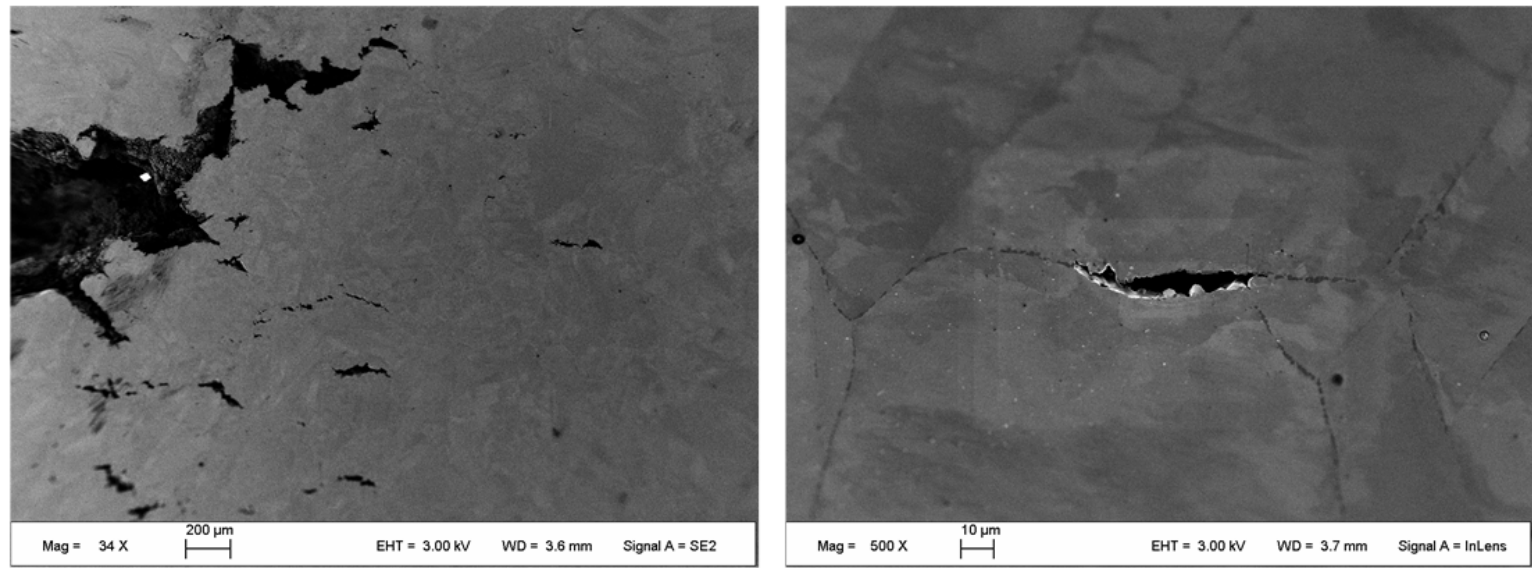

Figure 25 Cracks in Alloy 617 tested at $850{ }^{\circ} \mathrm{C}$ in helium (Test 11).

Figure 26 and Figure 27 presents SEM images of the cracks in the Alloy $800 \mathrm{H}$ sample tested at $700{ }^{\circ} \mathrm{C}$ in air and in helium, respectively. One major crack is observed in each sample, and the 
crack tips are oxidized. The cracks appear to have propagated along the grain boundaries and around the carbide phases.
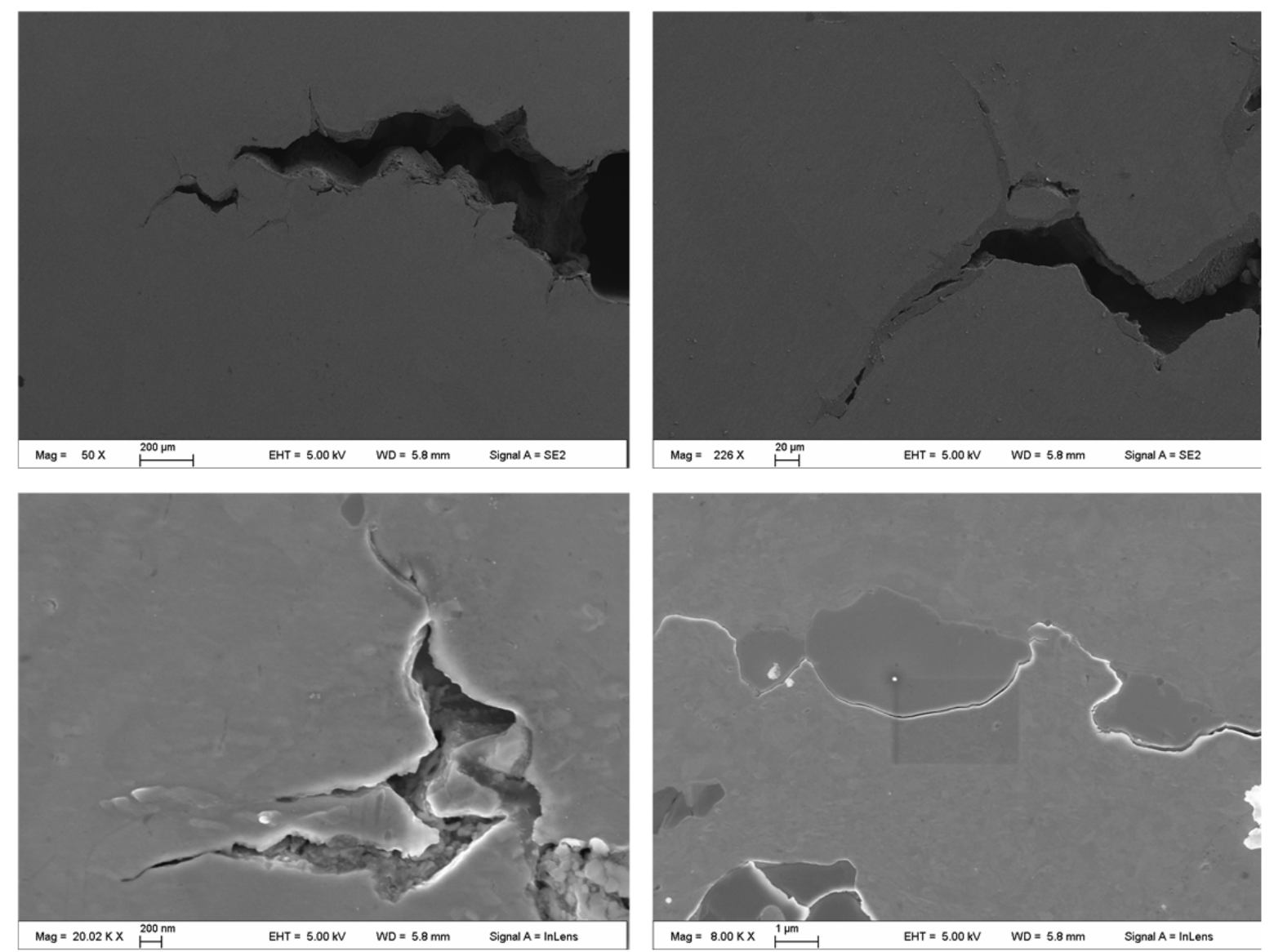

Figure 26 SEM images of cracks in Alloy $800 \mathrm{H}$ tested at $700{ }^{\circ} \mathrm{C}$ in air (Test 7). One major crack is seen, and significant oxidation in the crack tip region is observed. 

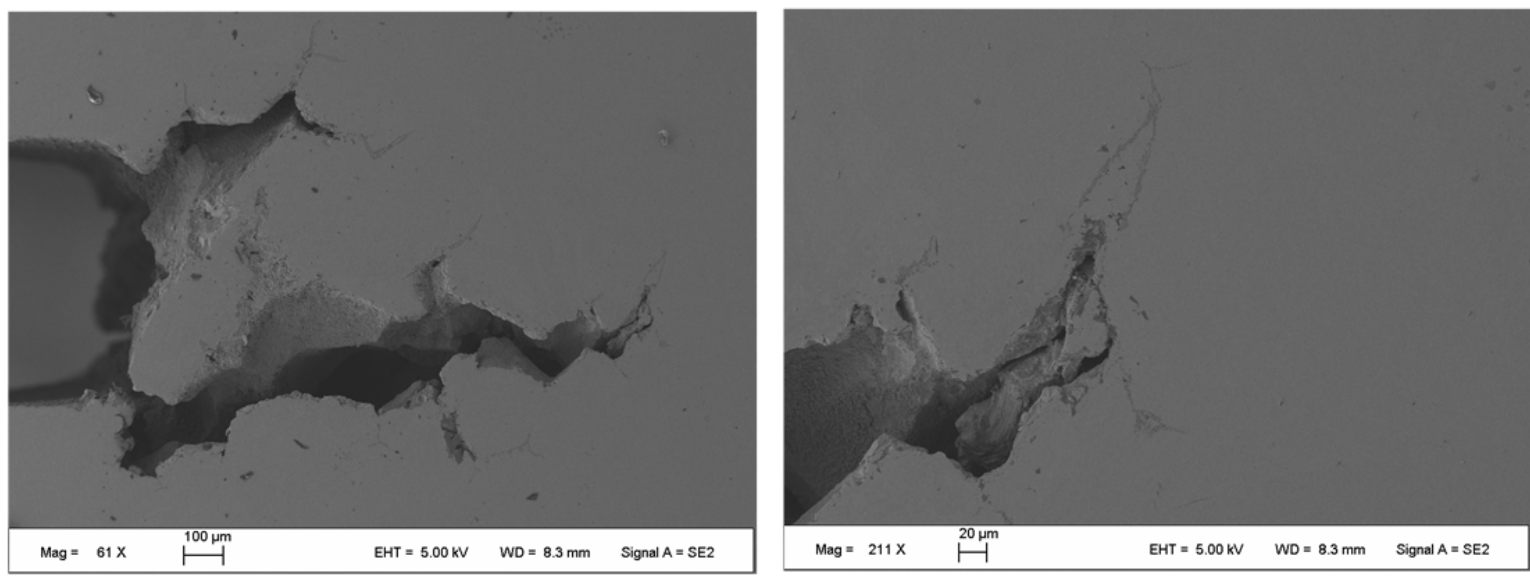

Figure 27 SEM images of cracks in Alloy $800 \mathrm{H}$ tested at $700{ }^{\circ} \mathrm{C}$ in helium (Test 9), One major crack is seen, and signs of oxidation in the crack tip and along grain boundary immediately in front of the crack tip are apparent.

Figure 28 presents an optical image of all the fracture surfaces. The black areas are regions through which the crack propagated, and the bright areas are a result of pulling the samples apart at room temperature after the CCG testing. The right side of each fracture surface is the region that was machined via EDM prior to CCG testing. It can be readily seen that the crack is longest in the center of the sample in all cases.

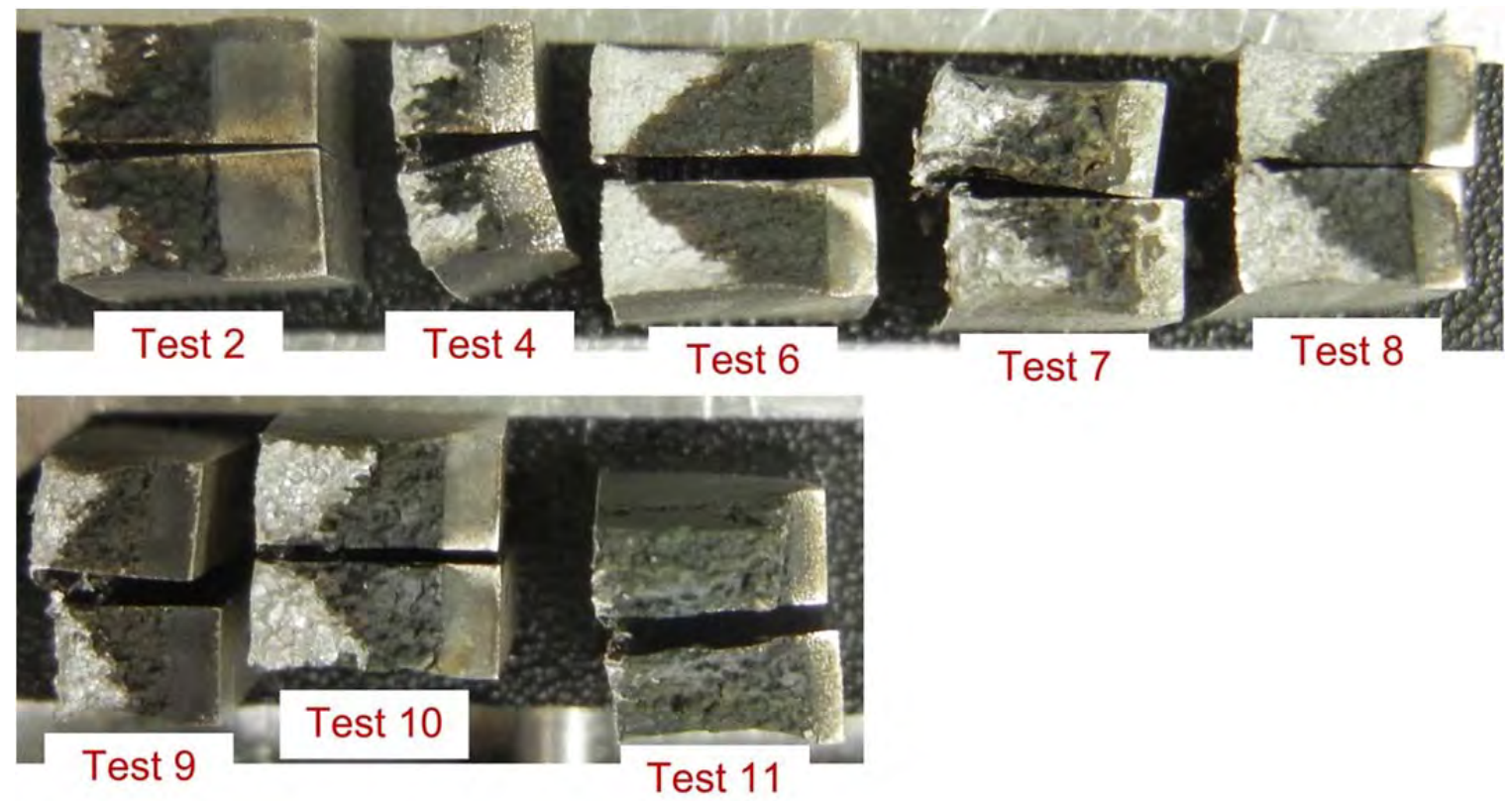

Figure 28 Optical image all fracture surfaces of a representative CCG sample from each test. The black areas of the fracture surfaces are the regions through which the crack propagated.

Figure 29 and Figure 30 present the fracture surfaces of Alloy 617 tested at $700{ }^{\circ} \mathrm{C}$ in air and helium, respectively. All cracks are intergrannular. The sample tested in air shows more severe cracking compared to the sample tested in He. 


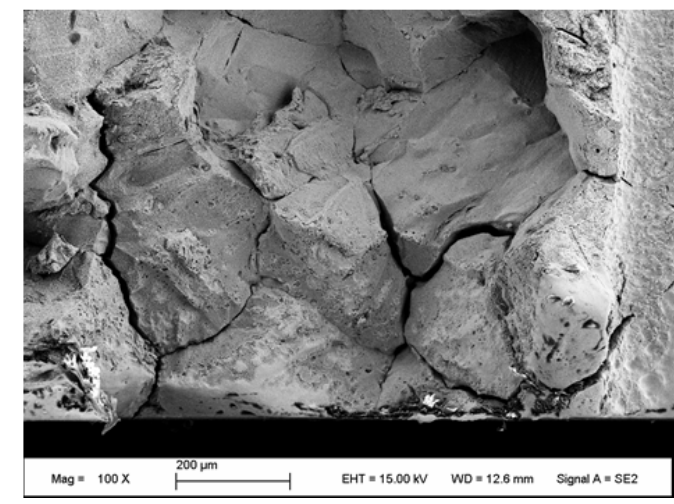

Figure 29 SEM image of the fracture surface of Alloy 617 tested at $700{ }^{\circ} \mathrm{C}$ in air (Test 2). Large grain size, and intergrannular cracking is observed.

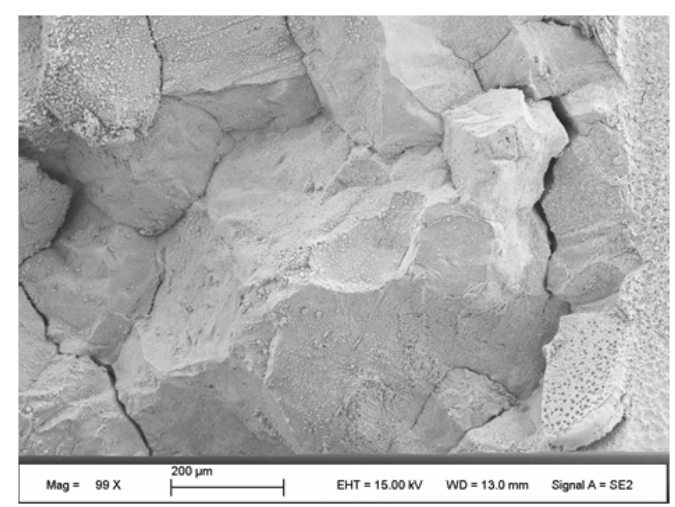

Figure 30 SEM image of the fracture surface of Alloy 617 tested at $700{ }^{\circ} \mathrm{C}$ in helium (Test 10).

Figure 31 and Figure 32 present the fracture surfaces of Alloy 617 tested at $850{ }^{\circ} \mathrm{C}$ in air and helium, respectively. Severe oxidation is seen on the fracture surfaces; therefore, the cracking mode (intergrannular or transgrannular) is difficult to determine. 


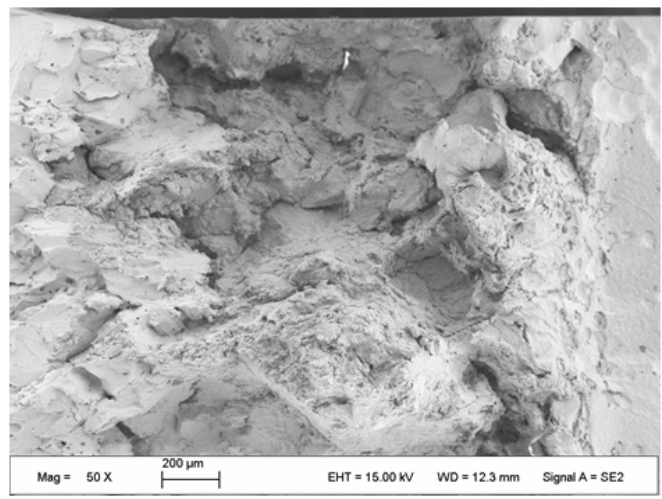

Figure 31 SEM image of the fracture surface of Alloy 617 tested at $850{ }^{\circ} \mathrm{C}$ in air (Test 4). Severe oxidation is apparent.

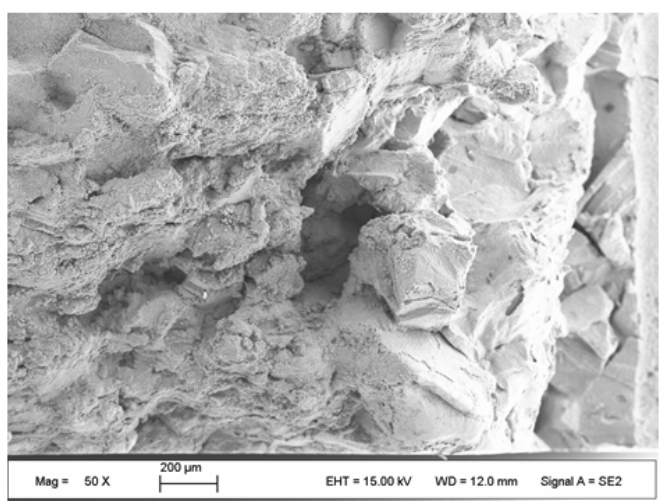

Figure 32 SEM image of the fracture surface of Alloy 617 tested at $850{ }^{\circ} \mathrm{C}$ in helium (Test 11). Large grains and severe oxidation are observed.

Figure 33 and Figure 34 show the fracture surfaces of Alloy $800 \mathrm{H}$ tested at $700{ }^{\circ} \mathrm{C}$ in air and in helium, respectively. Severe oxidation occurred in both testing conditions. 


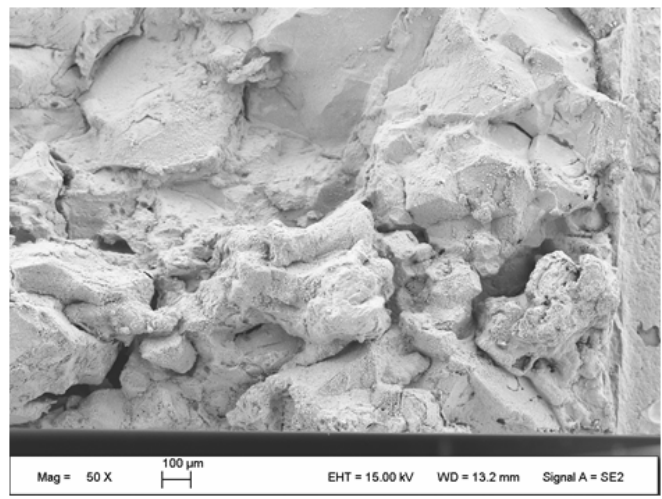

Figure 33 SEM image of the fracture surface of Alloy $800 \mathrm{H}$ tested at $700{ }^{\circ} \mathrm{C}$ in air (Test 7). Large grain size, and intergrannular cracking is observed.

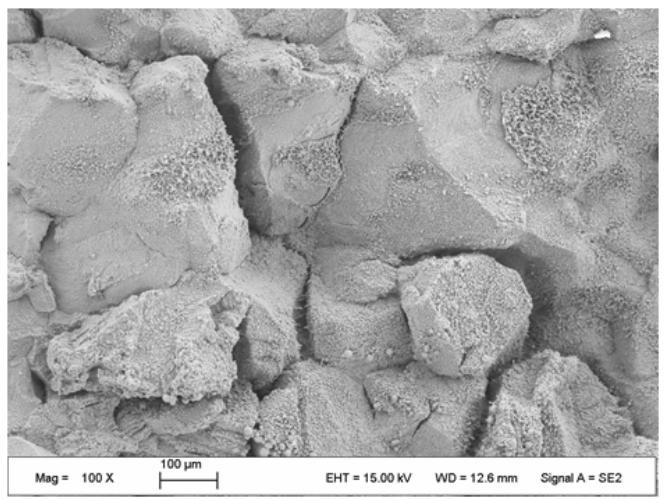

Figure 34 SEM image of the fracture surface of Alloy $800 \mathrm{H}$ tested at $700{ }^{\circ} \mathrm{C}$ in helium (Test 9).

SEM imaging of the cracks formed in both materials (Alloy 617 and Alloy $800 \mathrm{H}$ ) tested at 700 ${ }^{\circ} \mathrm{C}$ and $850{ }^{\circ} \mathrm{C}$ in air and in helium reveals that all creep cracks are intergrannular. The fracture surfaces of the materials tested at $700{ }^{\circ} \mathrm{C}$ confirm the intergrannular nature of the cracking. Severe oxidation of the Alloy 617 samples tested at $850{ }^{\circ} \mathrm{C}$ prevents a definitive confirmation of the crack mode in those samples; however, the images suggest that intergrannular cracking is the mode of crack growth in those samples as well.

Figure 35 presents the crack tip oxidation in Alloy 617 tested at $700{ }^{\circ} \mathrm{C}$ in air. Figure 36 presents the EDS mapping of a crack tip in Alloy 617 tested at $850^{\circ} \mathrm{C}$ in air. Oxidation in the crack tip and also along the grain boundaries near the crack tip is observed. The oxygen signal is weak, therefore observing oxidation near the boundaries is difficult in general. 


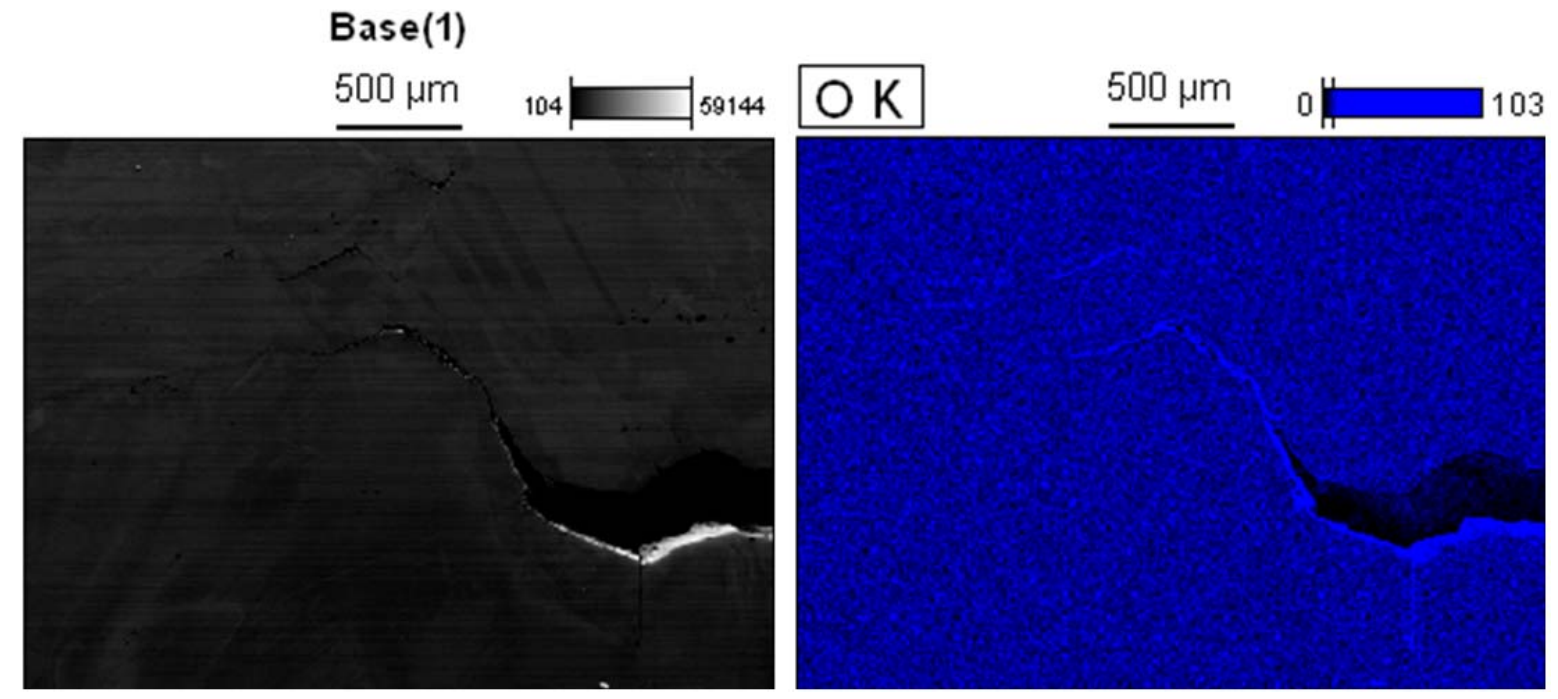

Figure 35 Crack tip oxidation in Alloy 617 tested at $700^{\circ} \mathrm{C}$ in air (Test 2).

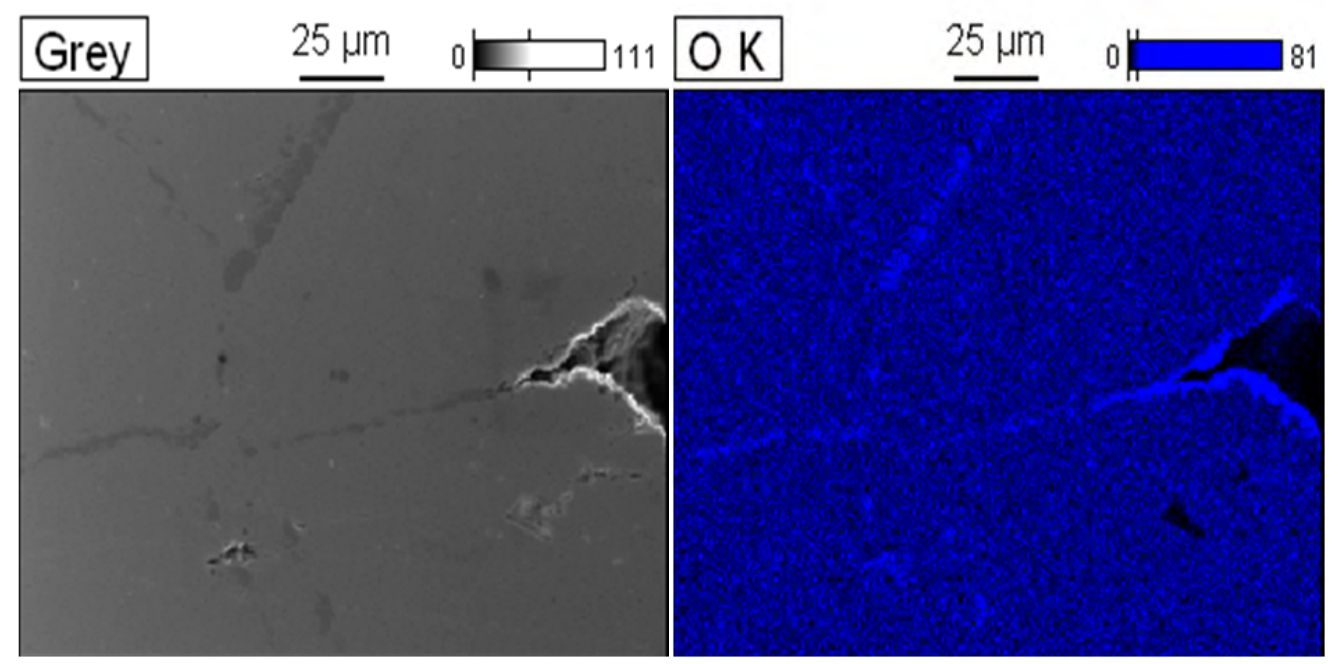

Figure 36 Crack tip oxidation and grain boundary oxidation in Alloy 617 test at $850{ }^{\circ} \mathrm{C}$ in air (Test 4).

Figure 37 presents the oxidation of Alloy 617 tested at $700{ }^{\circ} \mathrm{C}$ in air and in helium . In each image, the sample on the top is the one tested in air, and the sample on the bottom is the one tested in He. The oxidation of Alloy 617 tested in both conditions is similar, with the oxide consisting mainly of chromium oxide, although there is the presence of an aluminum-rich phase in Alloy 617 tested in He. 

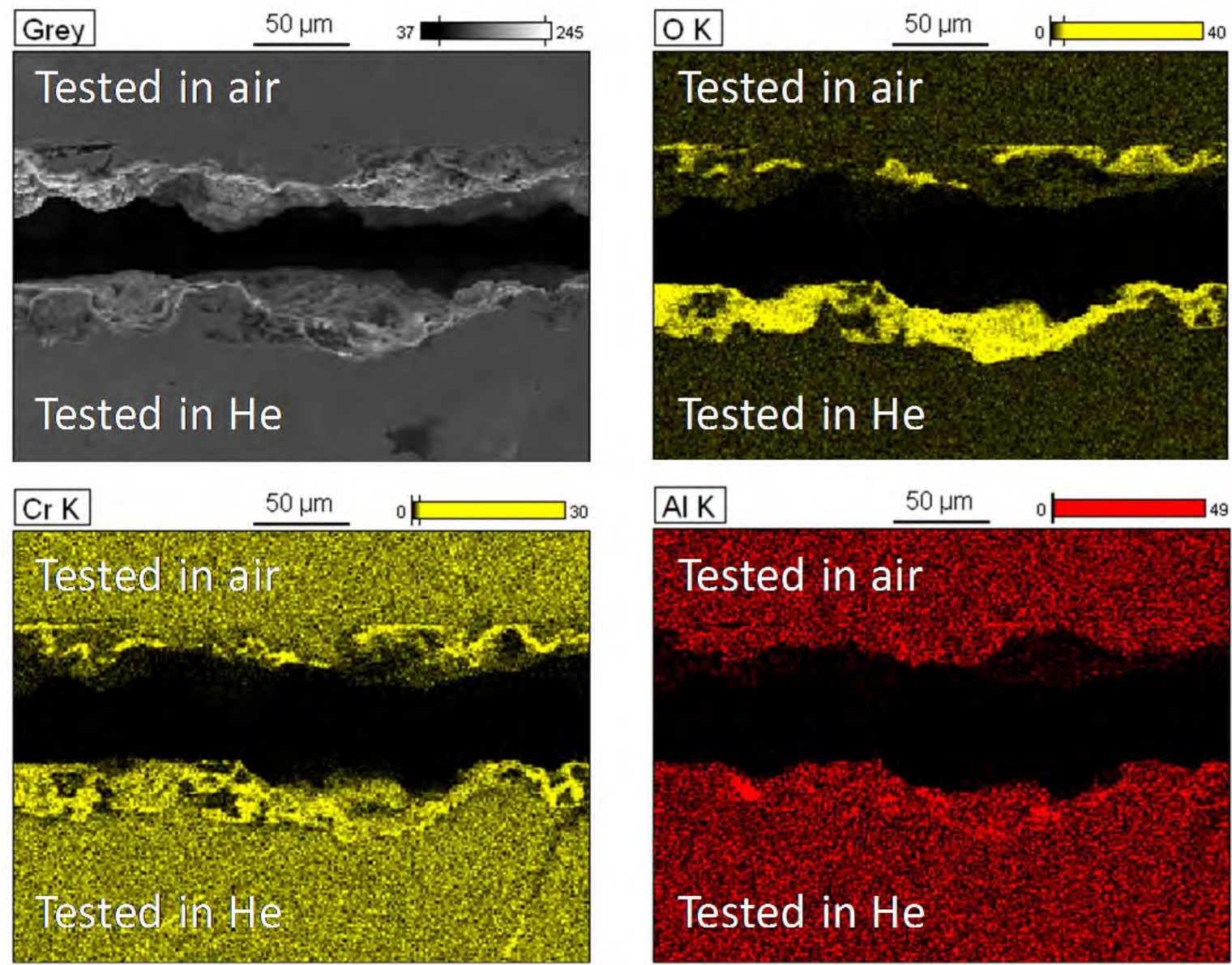

Figure 37 EDS mapping of Alloy 617 tested at $700{ }^{\circ} \mathrm{C}$ in air (top half of image) and helium (bottom half of image). An aluminum-rich phase is present in Alloy 617 tested in helium.

Figure 38 and Figure 39 show the oxidation of Alloy 617 tested at $850{ }^{\circ} \mathrm{C}$ in air and helium, respectively. As compared to Alloy 617 tested at $700^{\circ} \mathrm{C}$, a larger amount of oxidation can be seen. In addition, aluminum oxide phases are formed in the inner oxidation layer and along some of the grain boundaries at $850^{\circ} \mathrm{C}$. 

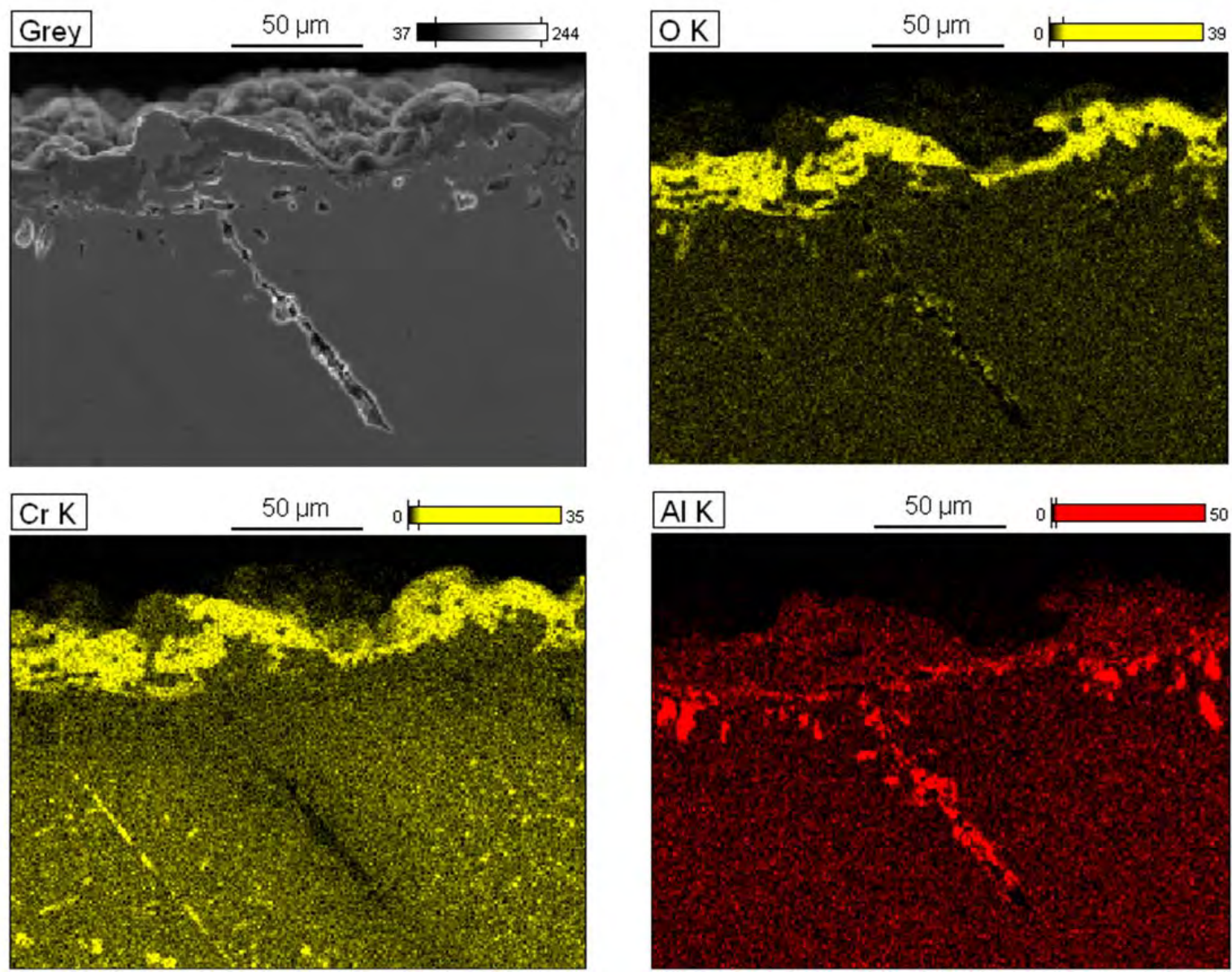

Figure 38 EDS mapping of Alloy 617 tested at $850{ }^{\circ} \mathrm{C}$ in air. A significant amount of aluminum-rich phases are observed on the surface and along some of the grain boundaries. 

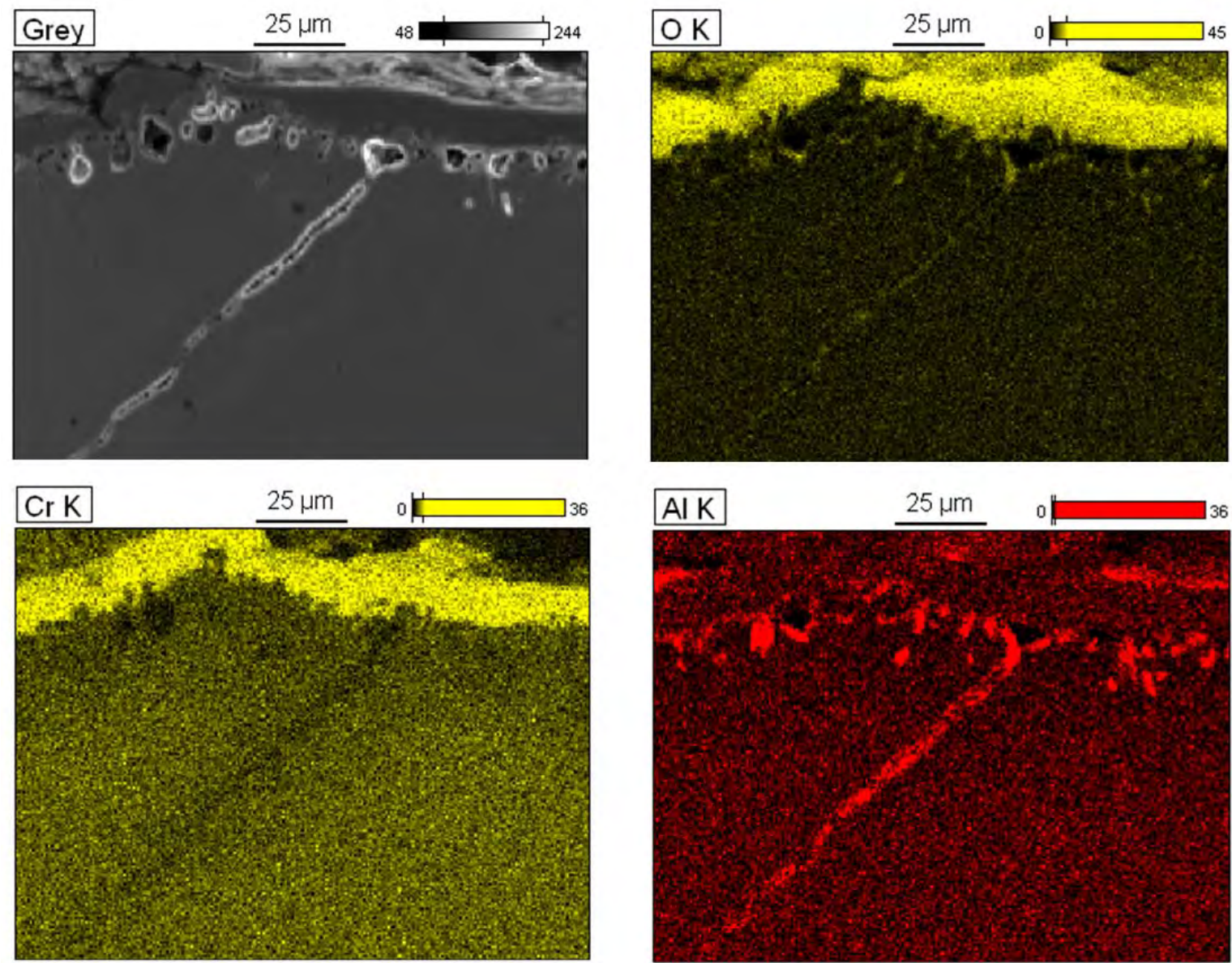

Figure 39 EDS mapping of Alloy 617 tested at $850{ }^{\circ} \mathrm{C}$ in helium. A significant amount of aluminumrich phases are observed on surface and along some of the grain boundaries.

Figure 40 and Figure 41 show the EDS mapping of the cross sections of the oxidation layers of Alloy $800 \mathrm{H}$ tested at $700 \mathrm{C}$ in air and in helium, respectively. The amount of oxidation is significantly higher in Alloy $800 \mathrm{H}$ tested in air. The outer layer is an iron oxide, and the inner layer is a chromium oxide. In Alloy $800 \mathrm{H}$ tested in helium, however, the oxidation layer is mainly chromium oxide. 

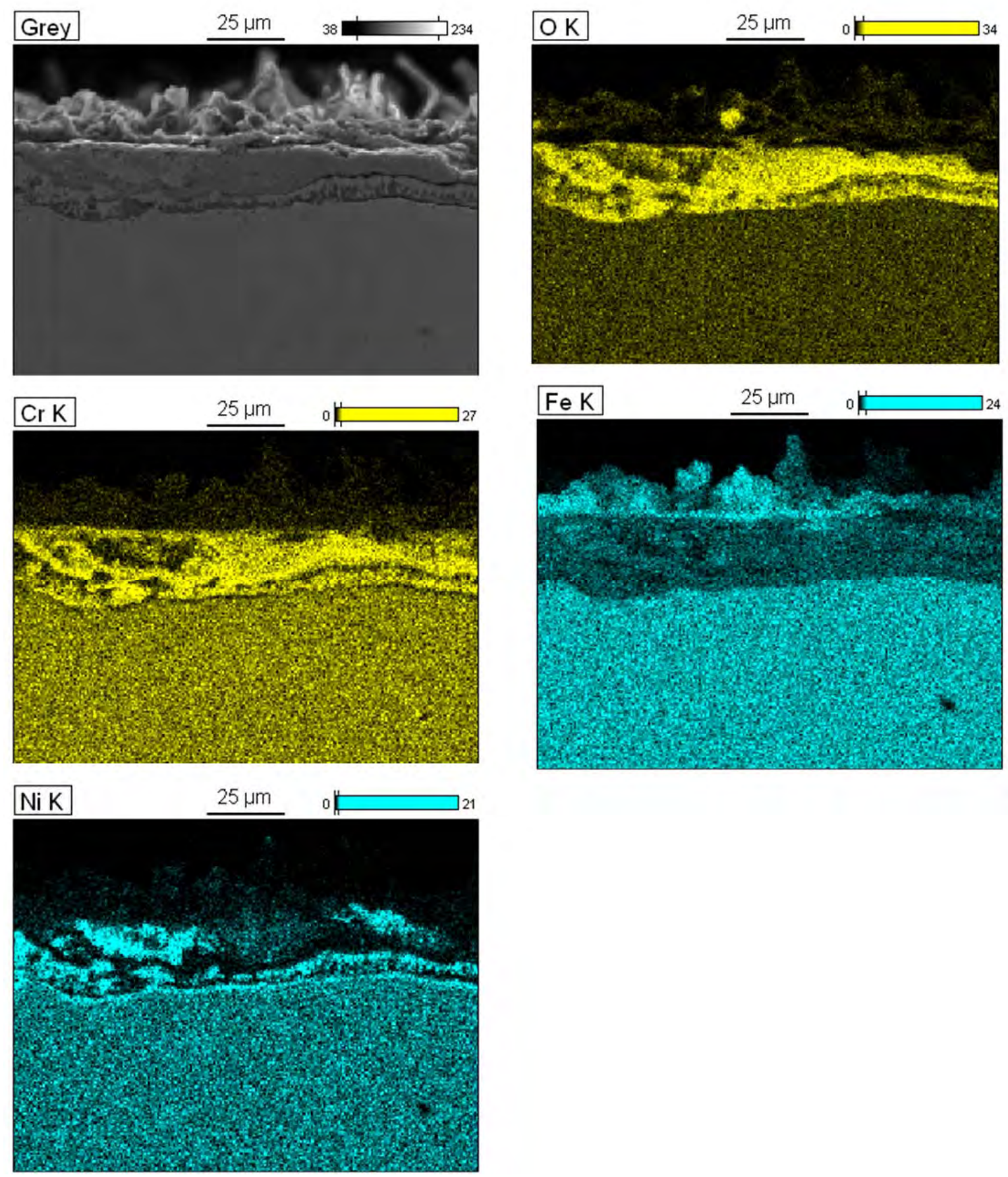

Figure 40 EDS mapping of Alloy 800 tested at $700{ }^{\circ} \mathrm{C}$ in air (Test 7). The outer layer is an iron oxide, and the inner layer is a chromium oxide. 

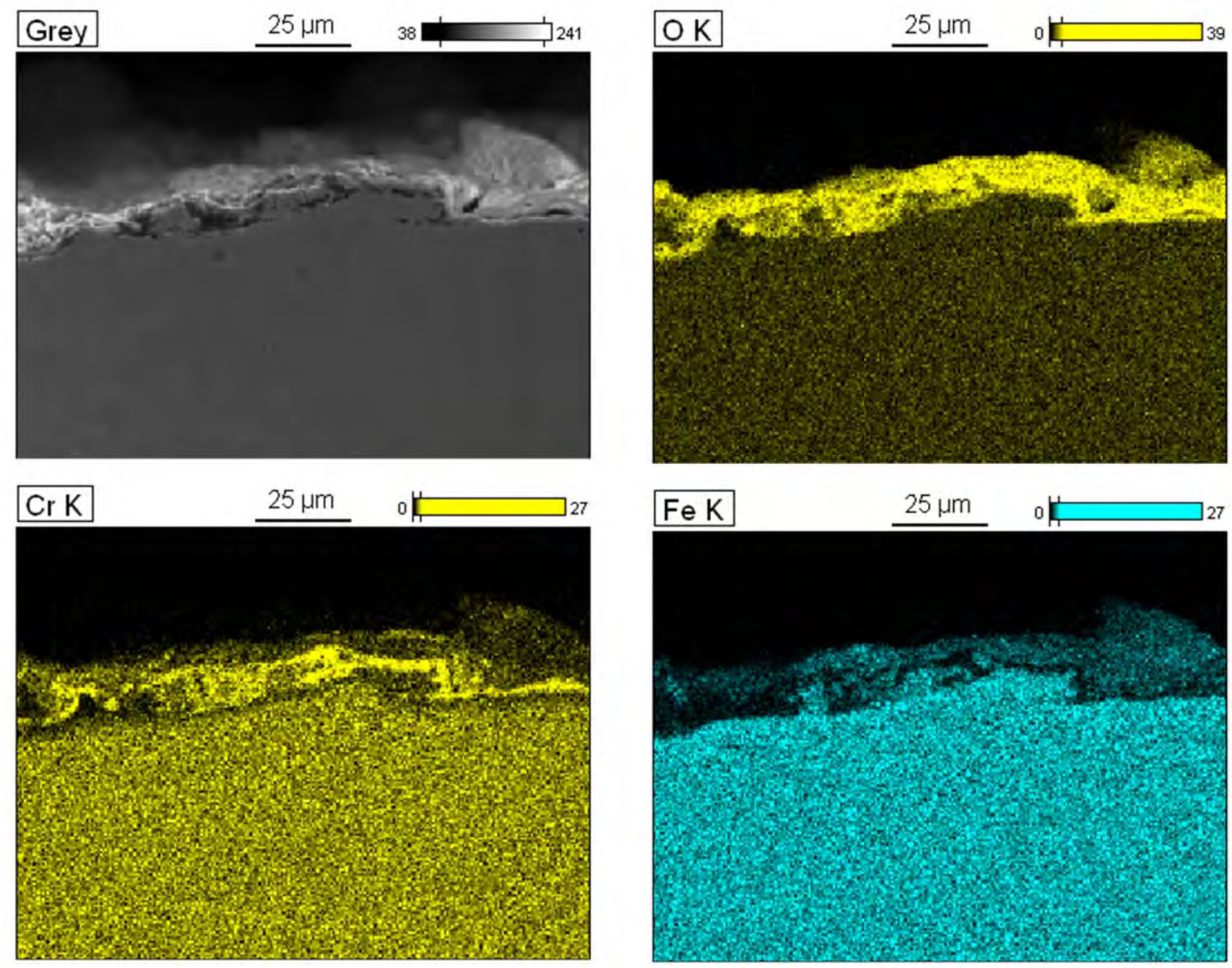

Figure 41 EDS mapping of Alloy $800 \mathrm{H}$ tested at $700{ }^{\circ} \mathrm{C}$ in helium (Test 9). The oxide is mainly a chromium oxide.

From the SEM images and EDS analyses of the oxidation of the materials tested at $700{ }^{\circ} \mathrm{C}$ in air and helium, Alloy 617 appears to have similar oxidation behavior in both environments, with a very thin oxidation layer forming on the surfaces of the alloy. This may explain the similarity in the creep crack growth rates of Alloy 617 tested in air and in impure helium. When Alloy 617 is tested at $850{ }^{\circ} \mathrm{C}$, the degree of oxidation on the surface is more severe, and again the oxidation in the air and helium environments is similar. In both environments, there is significant formation of aluminum oxide phases along the inner oxidation layer and along a number of grain boundaries. Alloy $800 \mathrm{H}$ shows some slight differences in oxidation in air compared with helium. When Alloy $800 \mathrm{H}$ was tested in air, the outer layer is iron oxide and the inner layer is chromium oxide. But when tested in helium, the oxidation layer is mainly composed of chromium oxide.

Because low magnification was required for EBSD analysis, only the center parts of the EBSD maps are focused well enough for reliable analysis of grain misorientation and strain. Therefore, the tips of the cracks and the crack-initiation regions were aligned in the center of the imaging region. 
Figure 42 and Figure 43 present reference EBSD maps of Alloy 617 and Alloy $800 \mathrm{H}$ samples, respectively, after being solution treated and aged for 2,000 hrs., but prior to CCG testing.
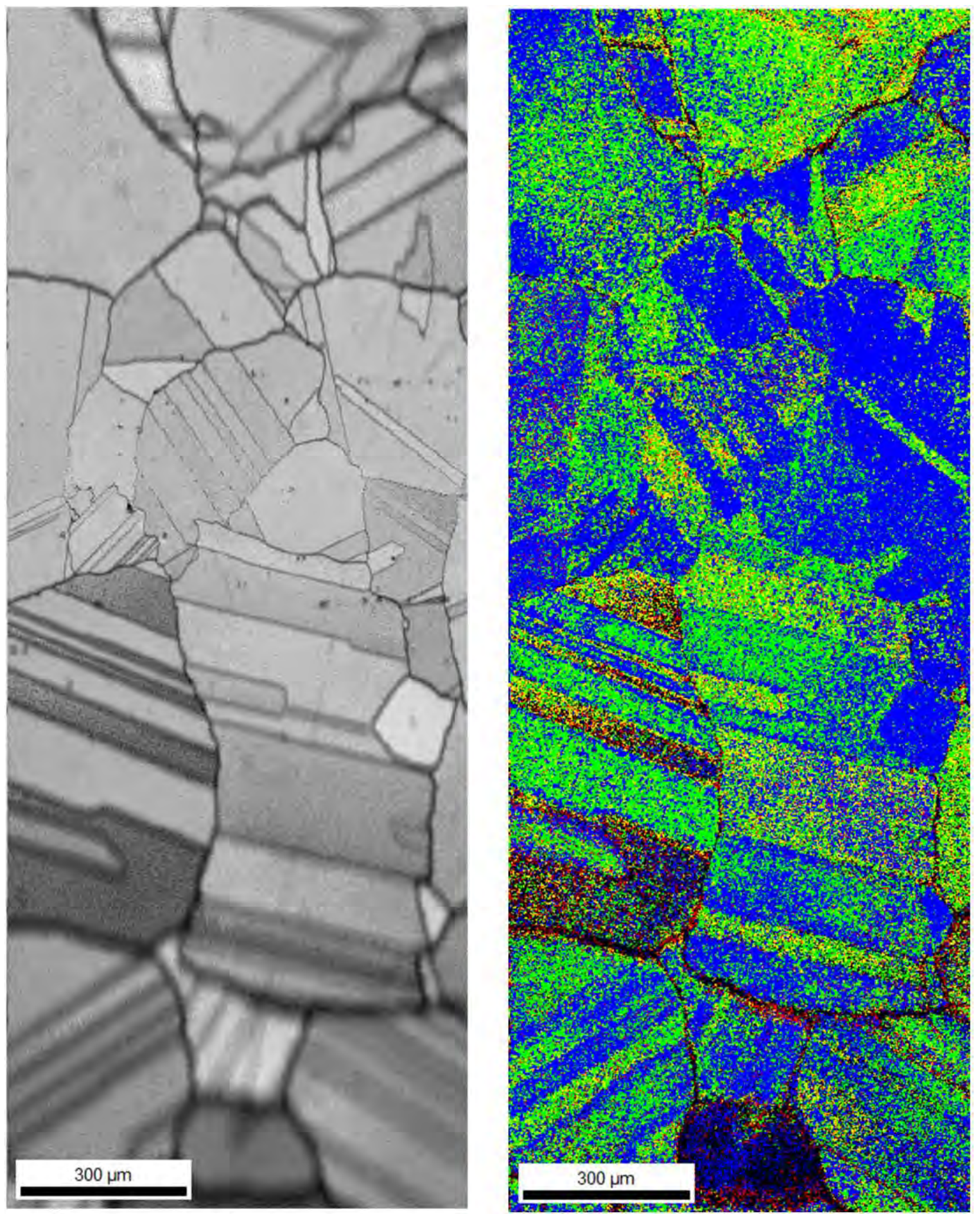

Figure 42 EBSD mapping of an Alloy 617 sample after solution treatment and aging, but prior to CCG testing. 

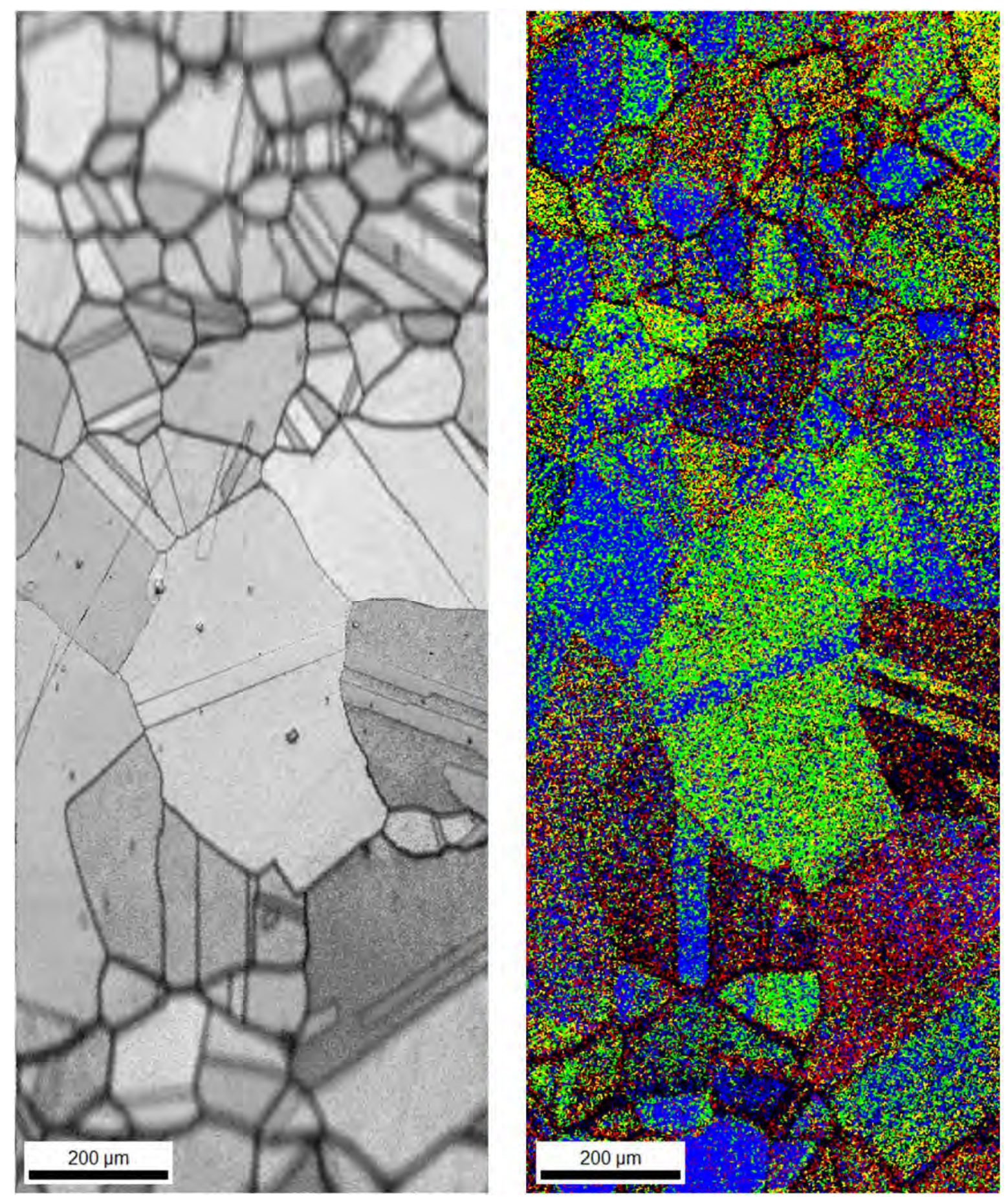

Figure 43 EBSD mapping of an Alloy $800 \mathrm{H}$ sample after solution treatment and aging, but prior to CCG testing.

Figure 44, Figure 45, Figure 46, Figure 47, Figure 48, and Figure 49 present EBSD maps of all the samples that were aged and CCG tested for both 617 and $800 \mathrm{H}$. 

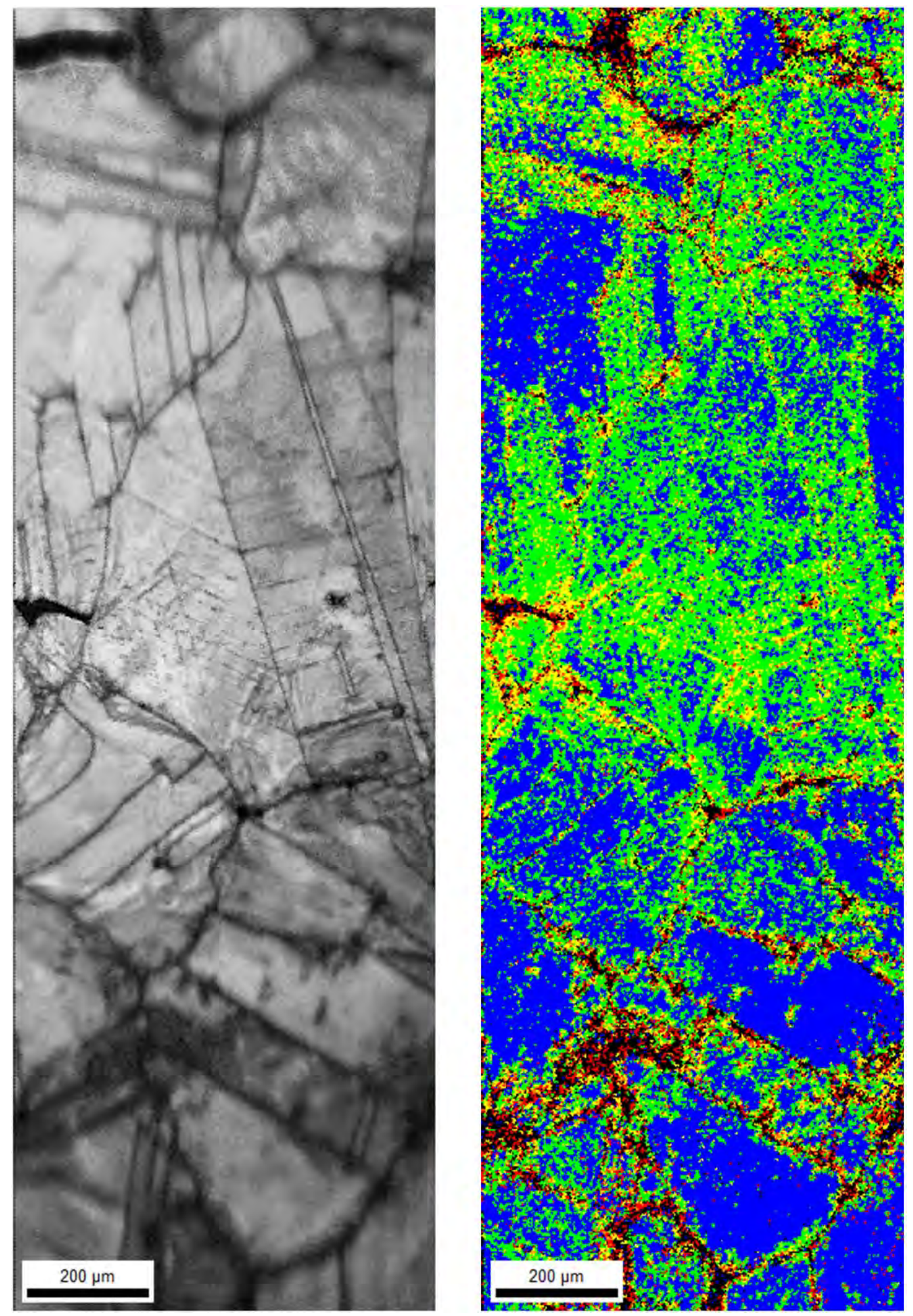

Figure 44 EBSD mapping of the crack tip and crack cavitations in Alloy 617 tested at $700{ }^{\circ} \mathrm{C}$ in air (Test 2). 

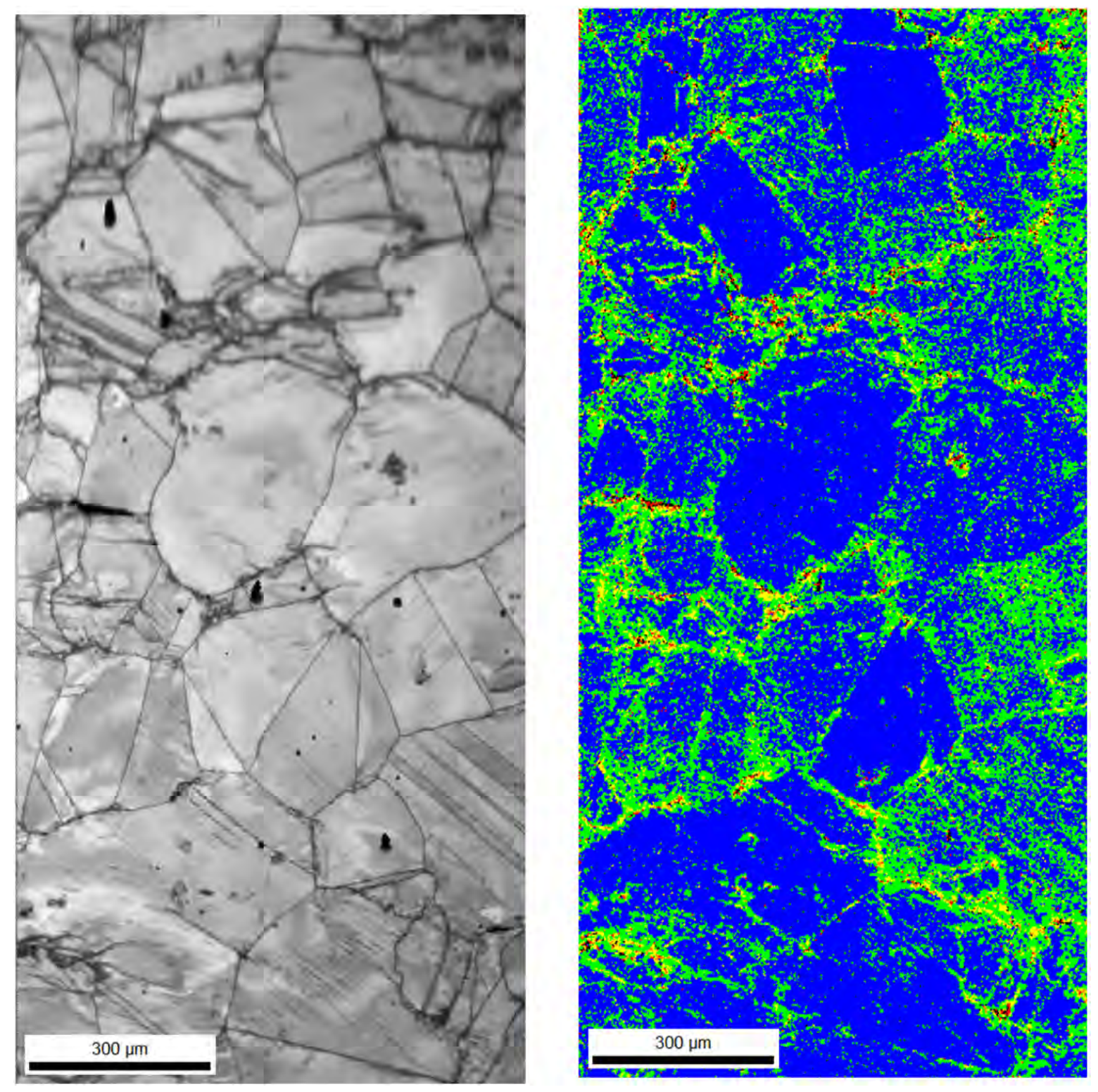

Figure 45 EBSD mapping of a crack cavitation in Alloy 617 tested at $700{ }^{\circ} \mathrm{C}$ in helium (Test 10). 

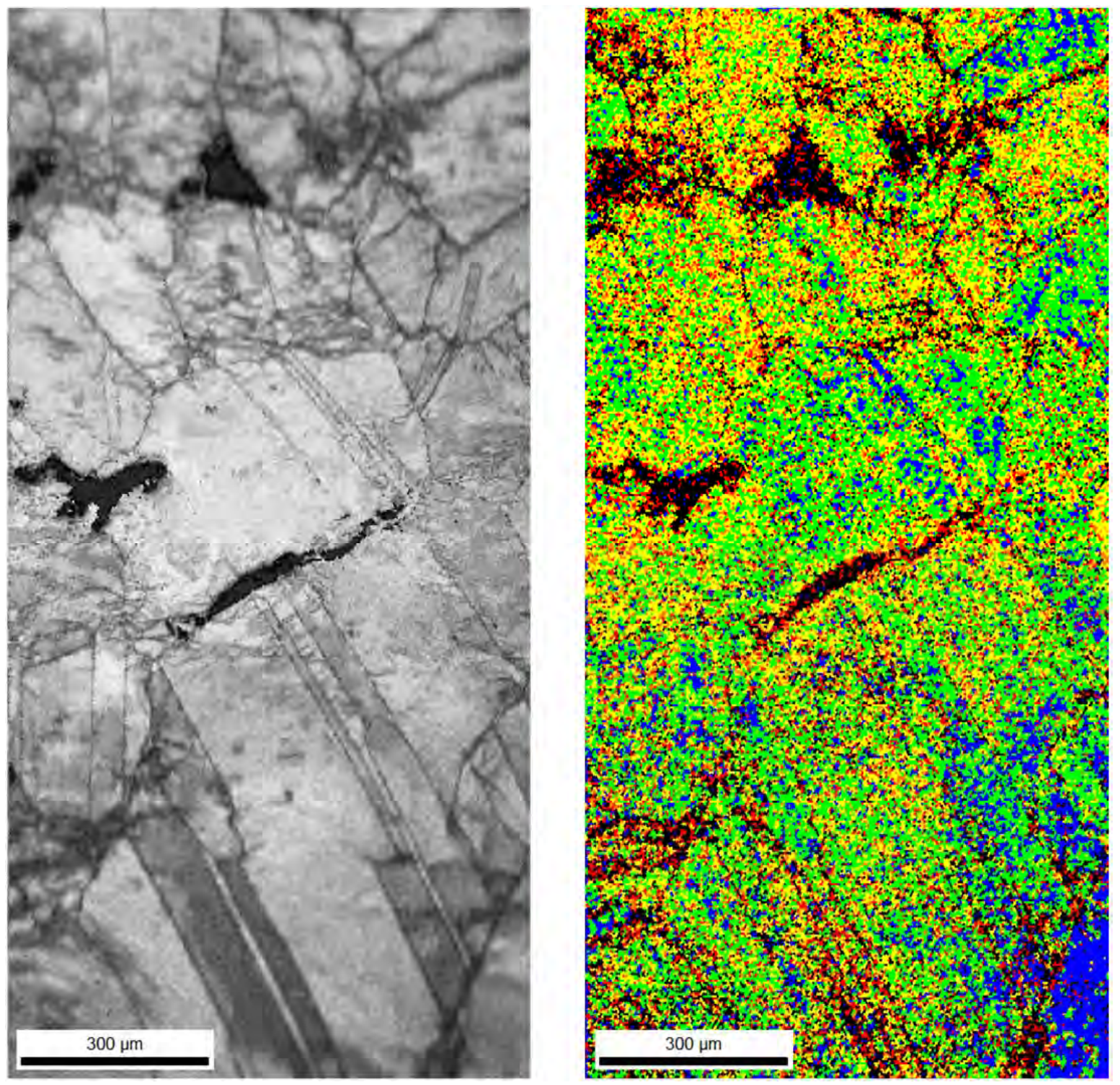

Figure 46 EBSD mapping of crack cavitations in Alloy 617 tested at $850{ }^{\circ} \mathrm{C}$ in air (Test 4). 

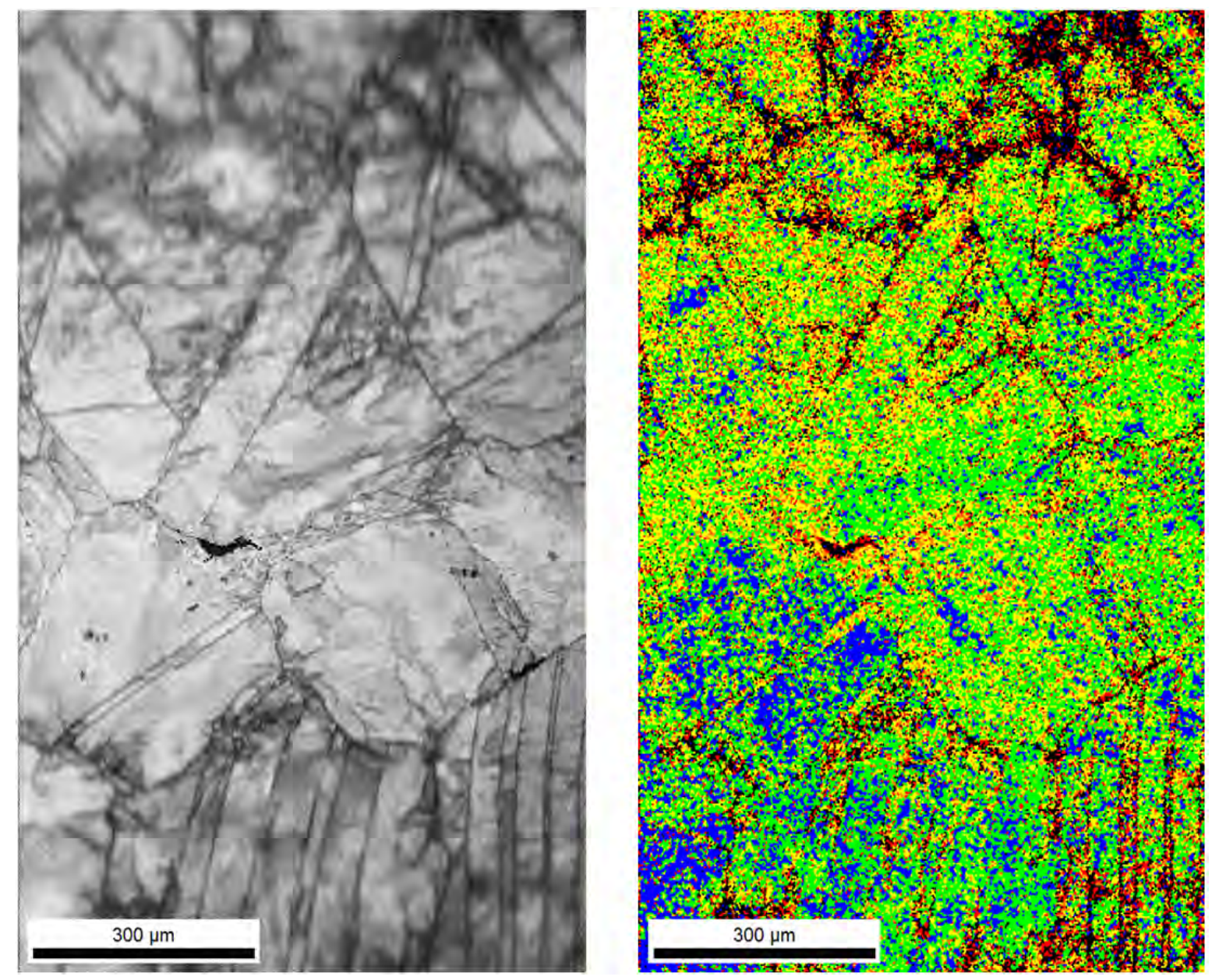

Figure 47 EBSD mapping of crack cavitations in Alloy 617 tested at $850{ }^{\circ} \mathrm{C}$ in air (Test 4). 

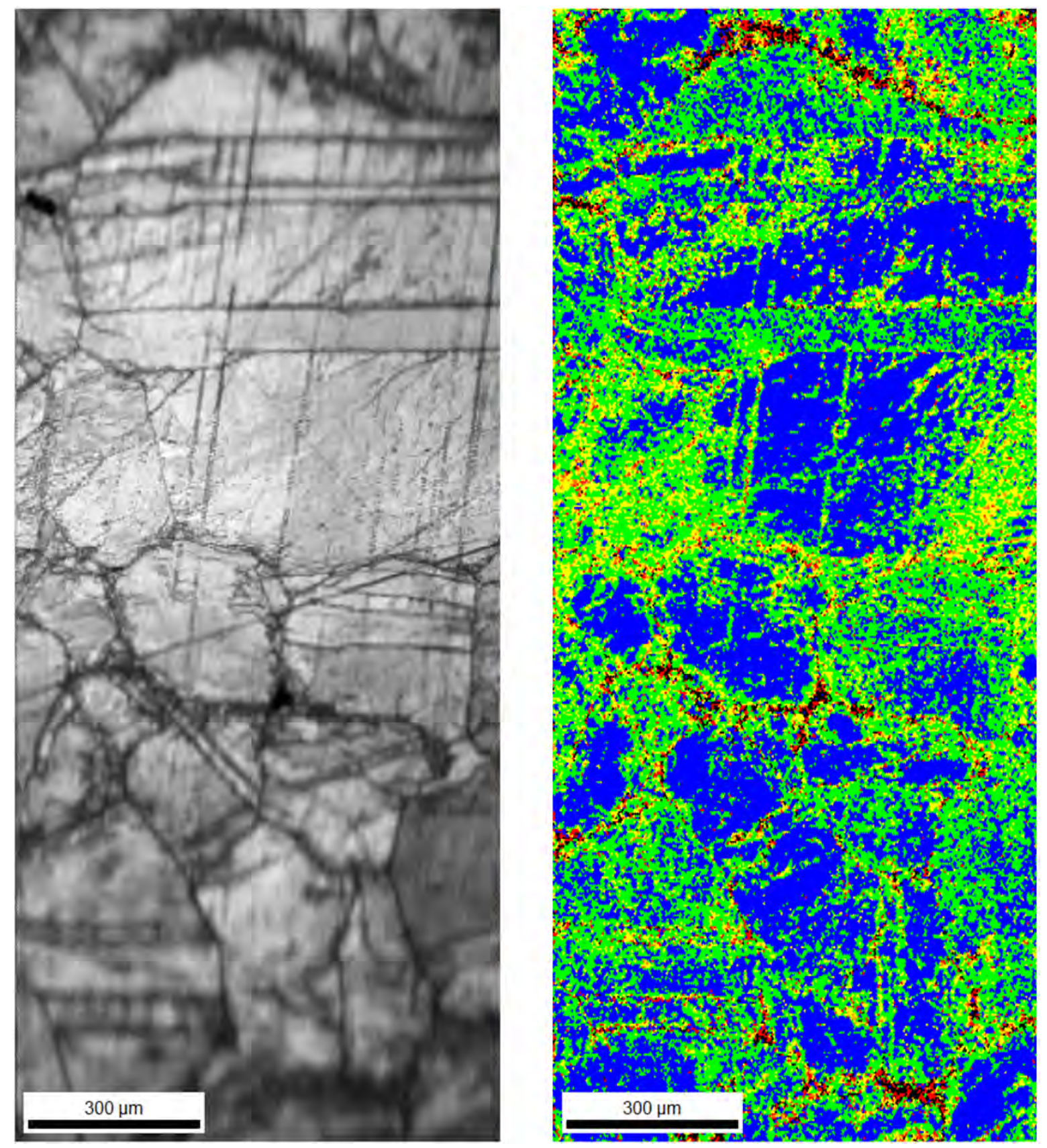

Figure 48 EBSD mapping of a crack cavitation in Alloy 617 tested at $850^{\circ} \mathrm{C}$ in helium. 

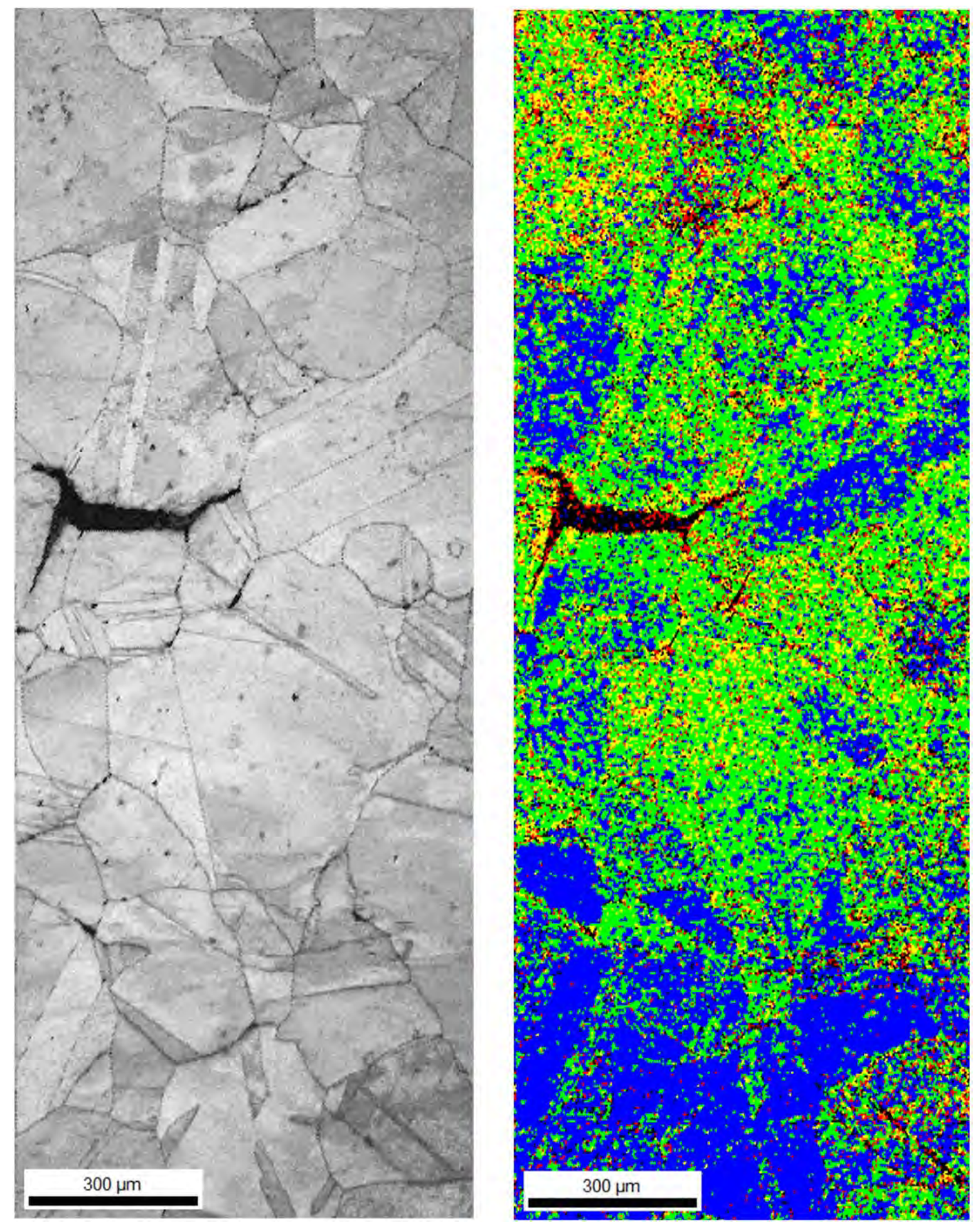

Figure 49 EBSD mapping of a crack tip in Alloy $800 \mathrm{H}$ tested at $700{ }^{\circ} \mathrm{C}$ in air (Test 7). 
Significant strain is observed in the regions near the crack tips (Figure 44 and Figure 46). In general, the cracks appear to have initiated in the grain boundaries with a higher degree of misorientation and strain (Figure 47 and Figure 59).

\subsection{Results and Discussions of Task C}

\subsubsection{Microstructure of GBE samples}

The GBE processing protocols developed Integran Technologies were successful in improving the microstructural characteristics of Alloy 617. The following description of the GBE results are paraphrased from a report provided by Integran. The improvement of the microstructural characteristics was achieved through modification of processing parameters to facilitate multiple twinning leading to an elevated frequency of special grain boundary content and enhanced special grain boundary connectivity at local triple junctions. Figure 50 presents the essential results for the as-received and GBE-optimized Alloy 617 samples. Compared to the material in the as-received condition, the microstructural characteristics of the GBE-optimized samples can be summarized as follows: (1) a grain size of $\sim 30 \mu \mathrm{m},(2)$ an enhanced 'special' (i.e., $\Sigma \leq 29$ ) grain boundary frequency in the range of $\sim 70 \%$ with a significant increase in the presence of twin variant interfaces (i.e., $\Sigma 9$ and $\Sigma 27$ ), and (3) an improved grain boundary network connectivity which is evidenced by the increase in the frequency of triple junctions with three special grain boundaries. If the assumption that the special grain boundaries are more resistant to crack initiation and propagation is correct, the enhanced connectivity of the special grain boundaries in the GBE-optimized material, as manifested in the triple junction make-up, should yield a more tortuous intercrystalline network for intergranular penetration for corrosion and cracking.
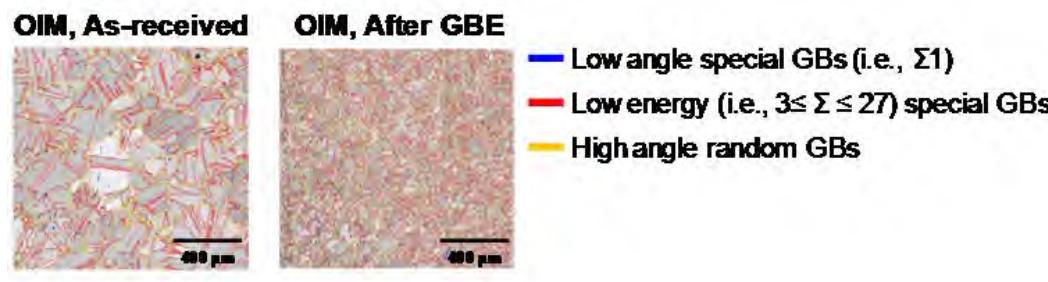

\begin{tabular}{|c|c|c|}
\hline Category & As-received & After GBE \\
\hline$\Sigma 1(\%)$ & 3.9 & 29 \\
\hline$\Sigma 3(\%)$ & 65.4 & 55.8 \\
\hline$\Sigma 98 \Sigma 27(\%)$ & 2.7 & 11.2 \\
\hline Other CSL (\%) & 4.5 & 22 \\
\hline Total Fsp (\%) & 76.5 & 72 \\
\hline Grain Size ( $1 \% \mathrm{~m})$ & 80 & 30 \\
\hline
\end{tabular}

Figure 50 GBE results from Alloy 617 samples. (Left) Orientation Imaging Microscopy (OIM) images from the 617 alloy before and after GBE. (Right) Microstructural characteristics for the as-received and the GBEoptimized. samples.

\subsubsection{Characterization of GBE Alloy 617 samples}

Figure 51 and Figure 52 present the crack morphologies of the GBE and as-received Alloy 617 samples, respectively, tested at $700{ }^{\circ} \mathrm{C}$ in helium. Cracks much more severe than those of the aged samples appeared in both samples. 

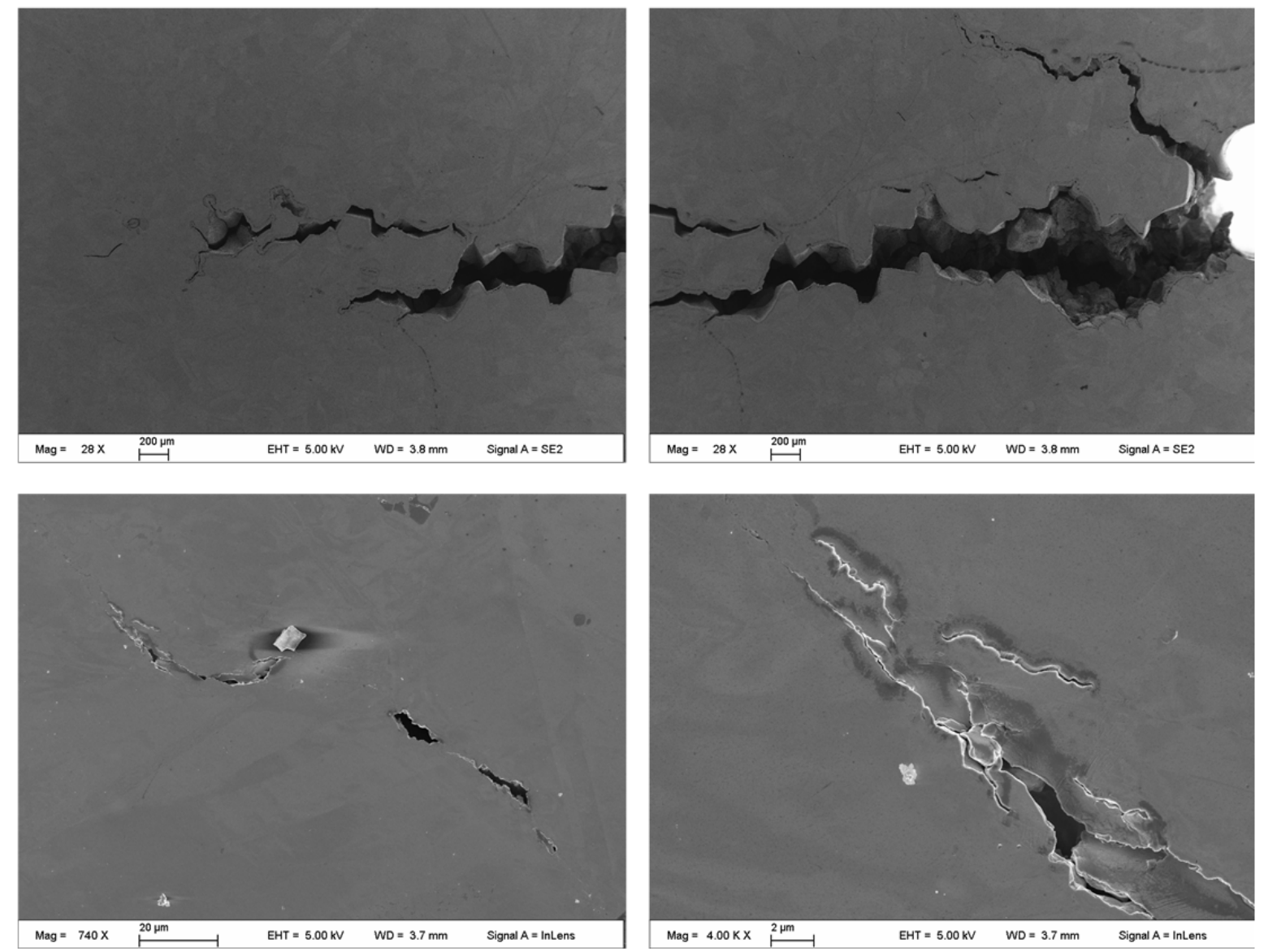

Figure 51 Cracks and crack cavitations in the as-received Alloy 617 sample tested $700{ }^{\circ} \mathrm{C}$ in helium (Test 8). Severe cracking is observed, with many tiny cracks seen in front of the major crack tip. Oxidation of the crack cavitations can be also be seen. 

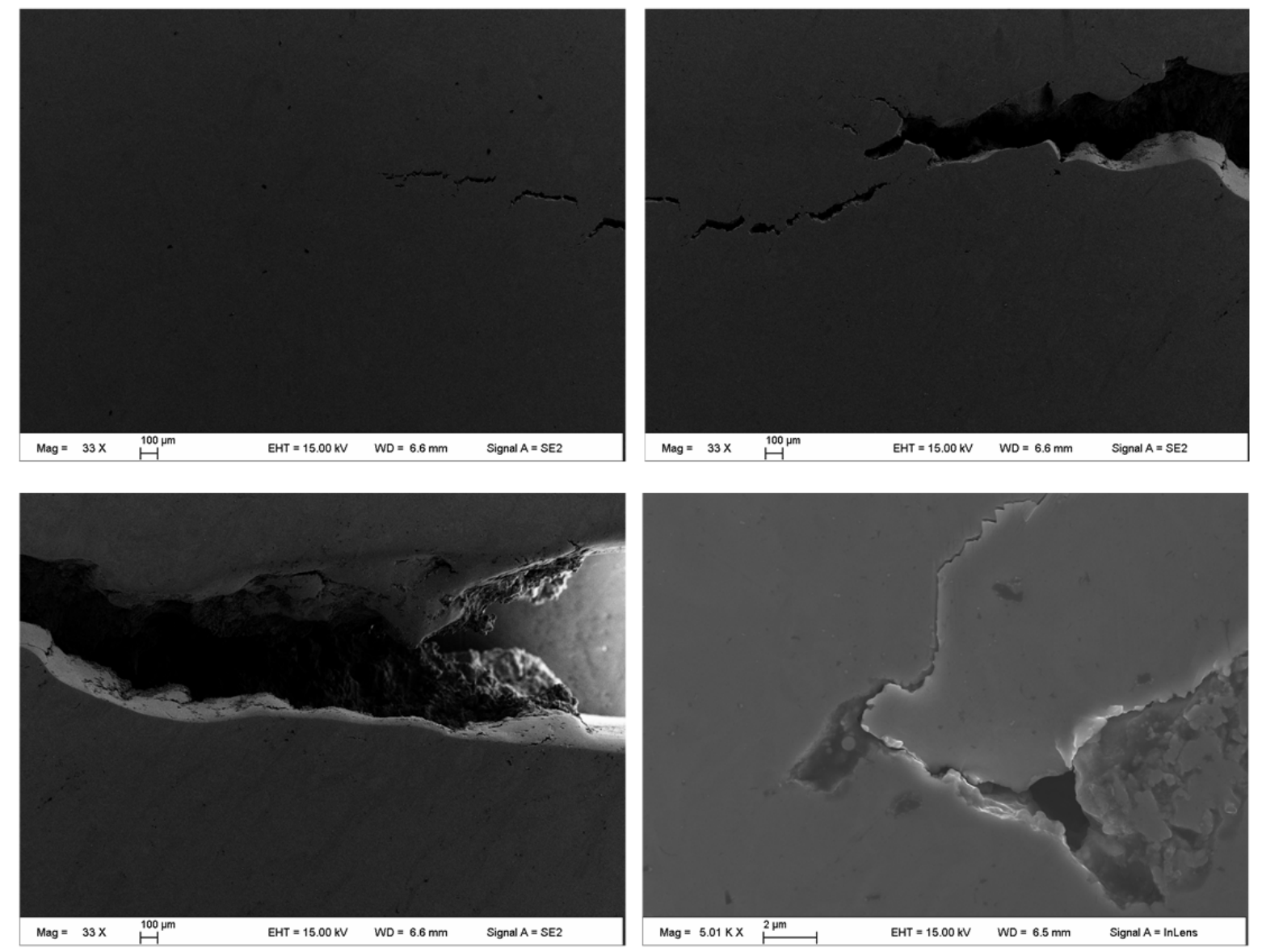

Figure 52 Crack in the GBE Alloy 617 sample tested at $700{ }^{\circ} \mathrm{C}$ in helium (Test 6).

Figure 53 and Figure 54 show the fracture surfaces of as-received and GBE Alloy 617, respectively, tested at $700{ }^{\circ} \mathrm{C}$ in helium. As compared to the aged 617 Alloy, the grain size of the as-received and GBE is much smaller. The cracks appear to be intergrannular, and many crack branches are observed in the GBE sample. 


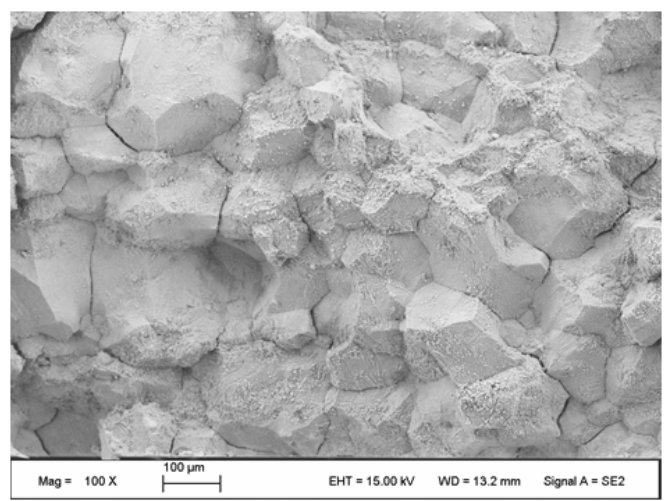

Figure 53 SEM image of the fracture surface of as-received Alloy 617 tested at $700{ }^{\circ} \mathrm{C}$ in helium (Test 8). Small grain size, and intergrannular cracking, and many small crack branches are observed.

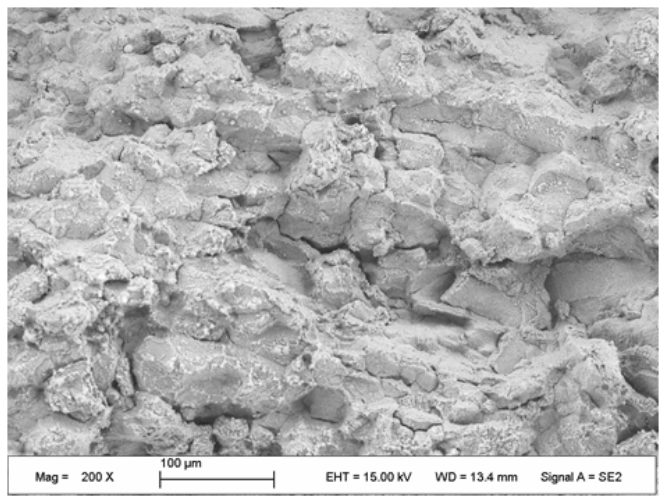

Figure 54 SEM image of the fracture surface of GBE Alloy 617 tested at $700{ }^{\circ} \mathrm{C}$ in helium (Test 6). Small grain size, and intergrannular cracking, and many crack branches are observed.

Figure 55 and Figure 56 show the oxidation of as-received and GBE Alloy 617, respectively. A thin chromium oxide layer is observed in both samples. A slight presence of an aluminum-rich phase is observed in both the GBE and as-received samples. 

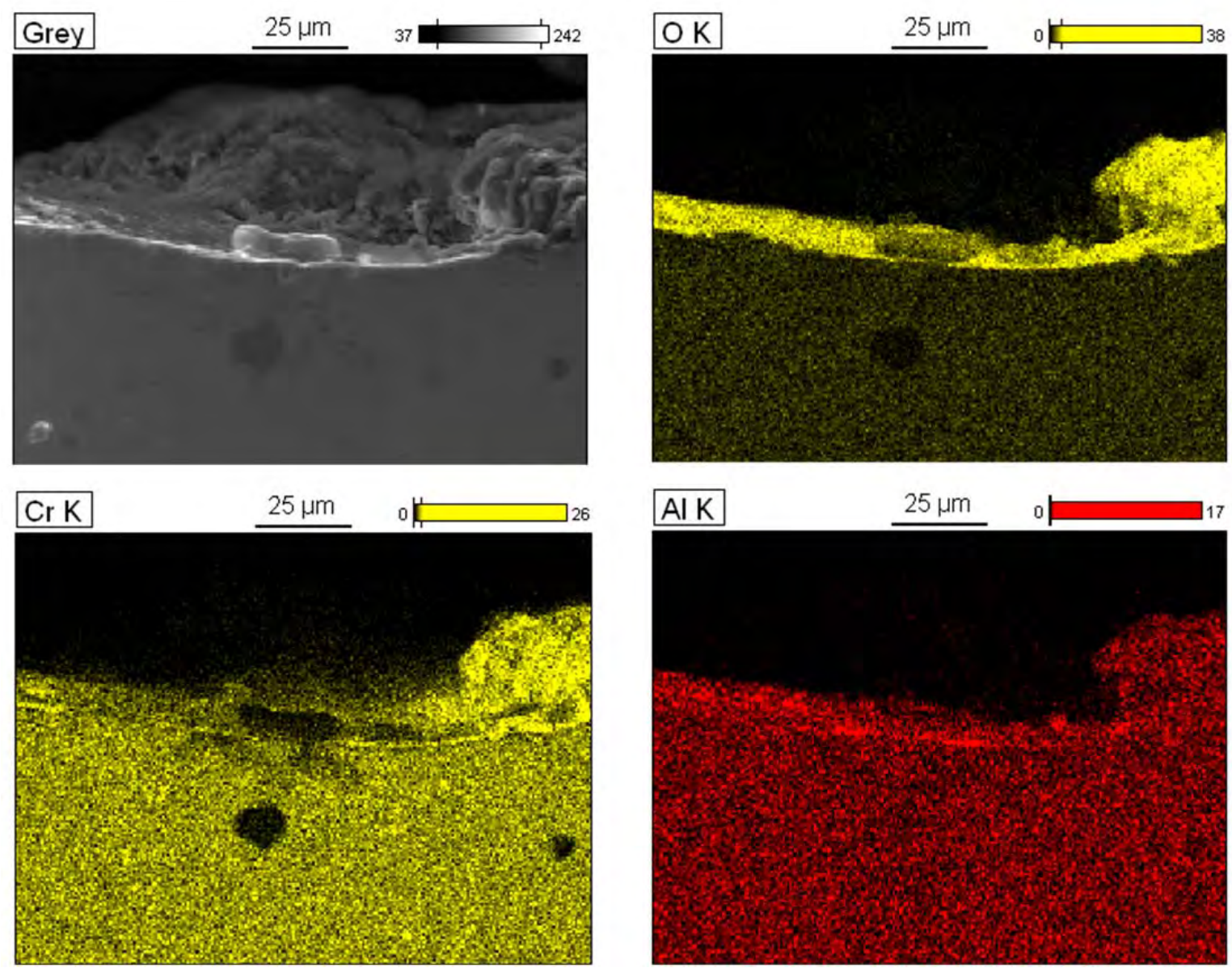

Figure 55 EDS mapping of as-received Alloy 617 tested at $700{ }^{\circ} \mathrm{C}$ in helium (Test 8). 

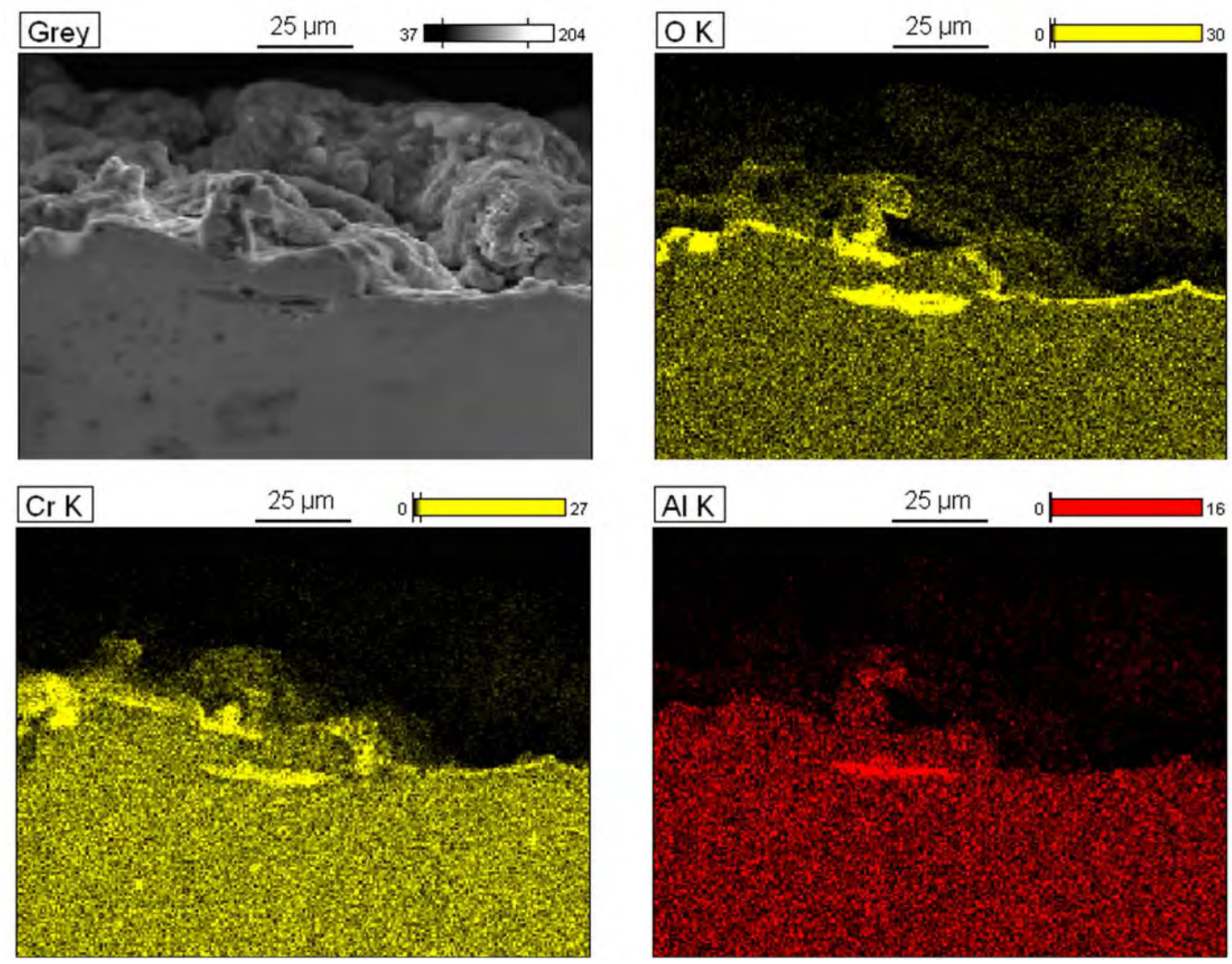

Figure 56 EDS Mapping of GBE processed Alloy 617 tested at 700oC in helium (Test 6). Very think chromium oxide layer. Some aluminum rich phase can be seen.

Figure 57, Figure 58, and Figure 59 present EBSD maps of the as-received and GBE Alloy 617 CCG samples. 

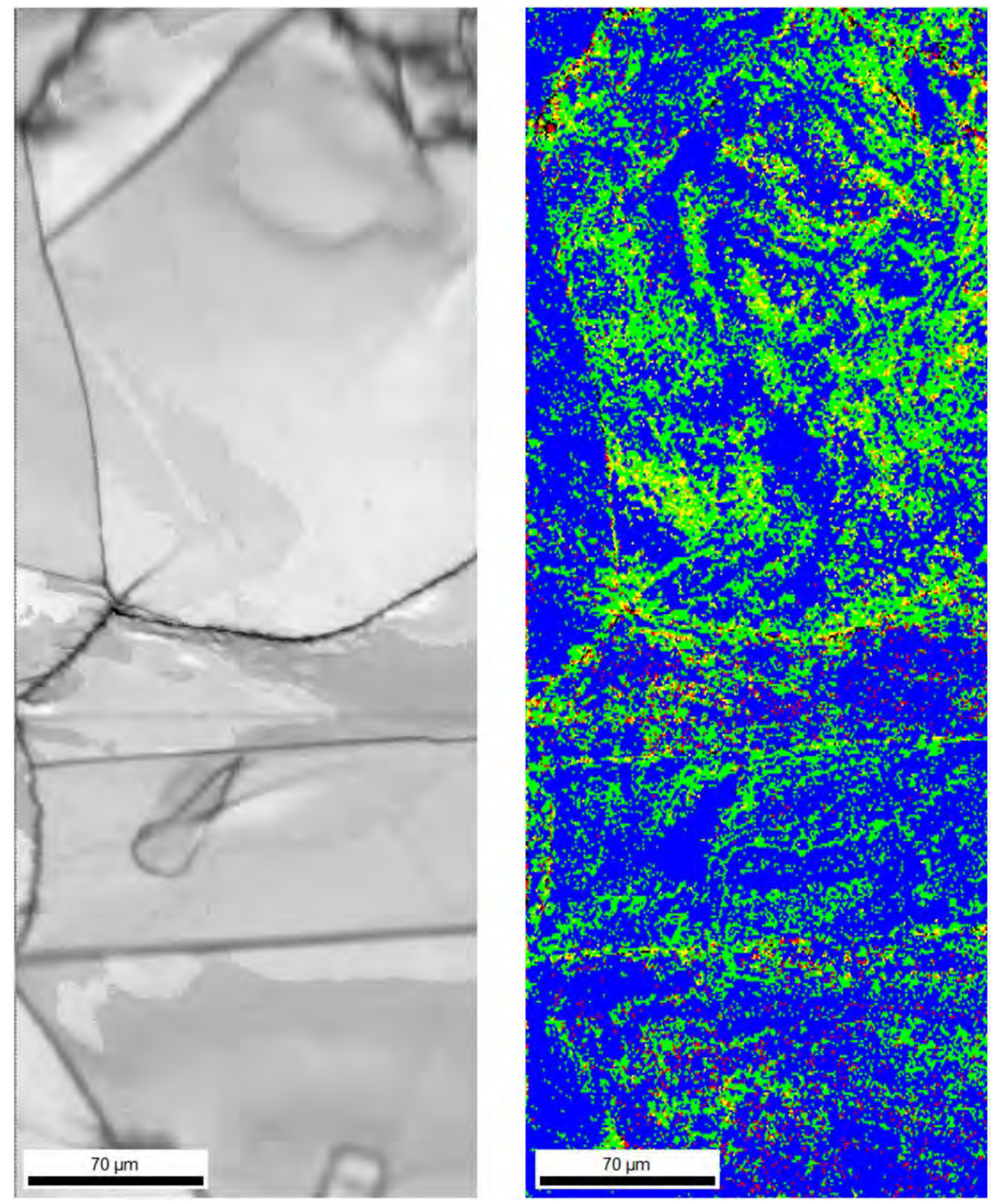

Figure 57 EBSD mapping of a crack initiation in as-received Alloy 617 tested at $700{ }^{\circ} \mathrm{C}$ in helium (Test 8). 

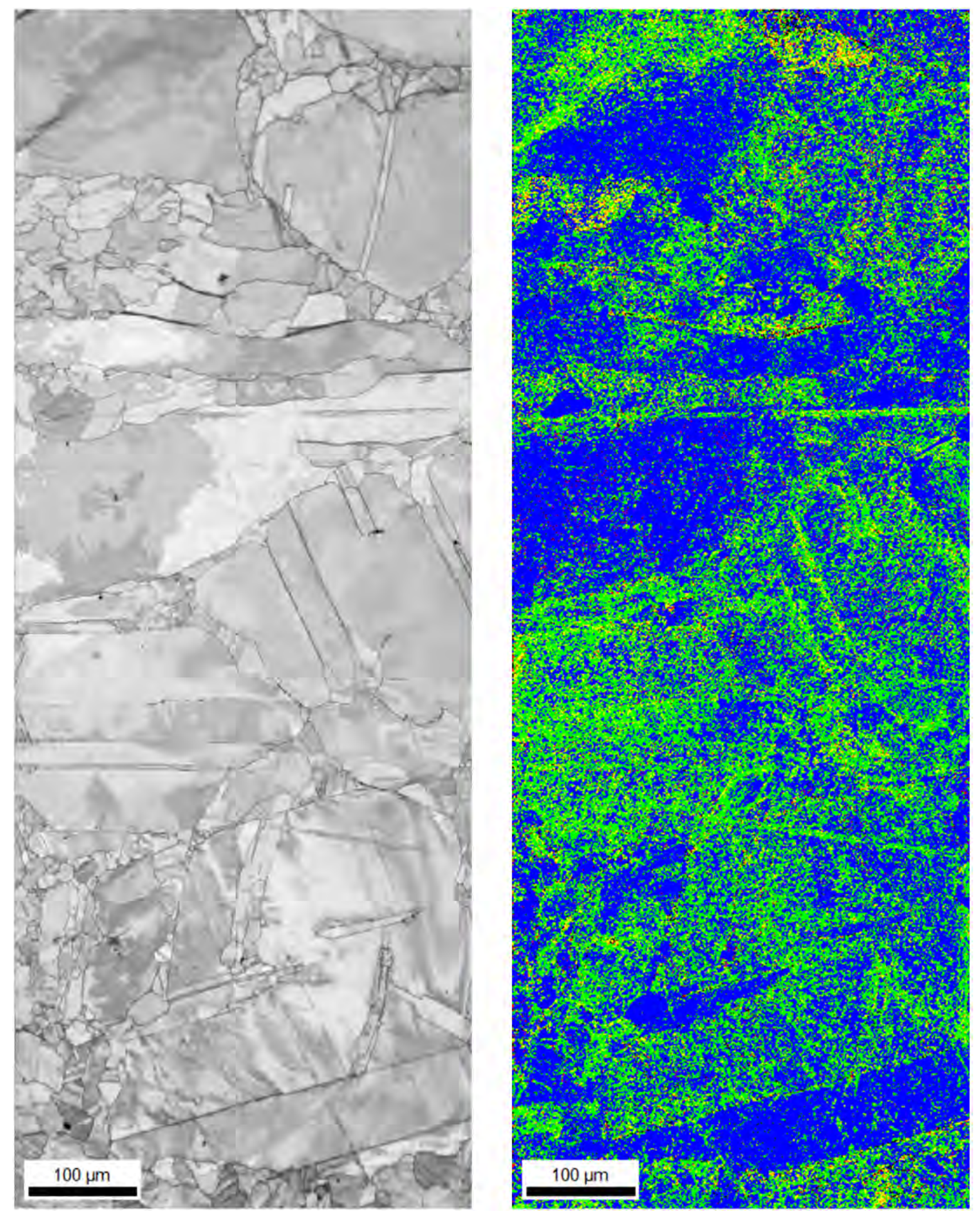

Figure 58 EBSD mapping of GBE Alloy 617 tested at $700{ }^{\circ} \mathrm{C}$ in helium (Test 6). Grains appear to be aligned parallel to the stress direction. 

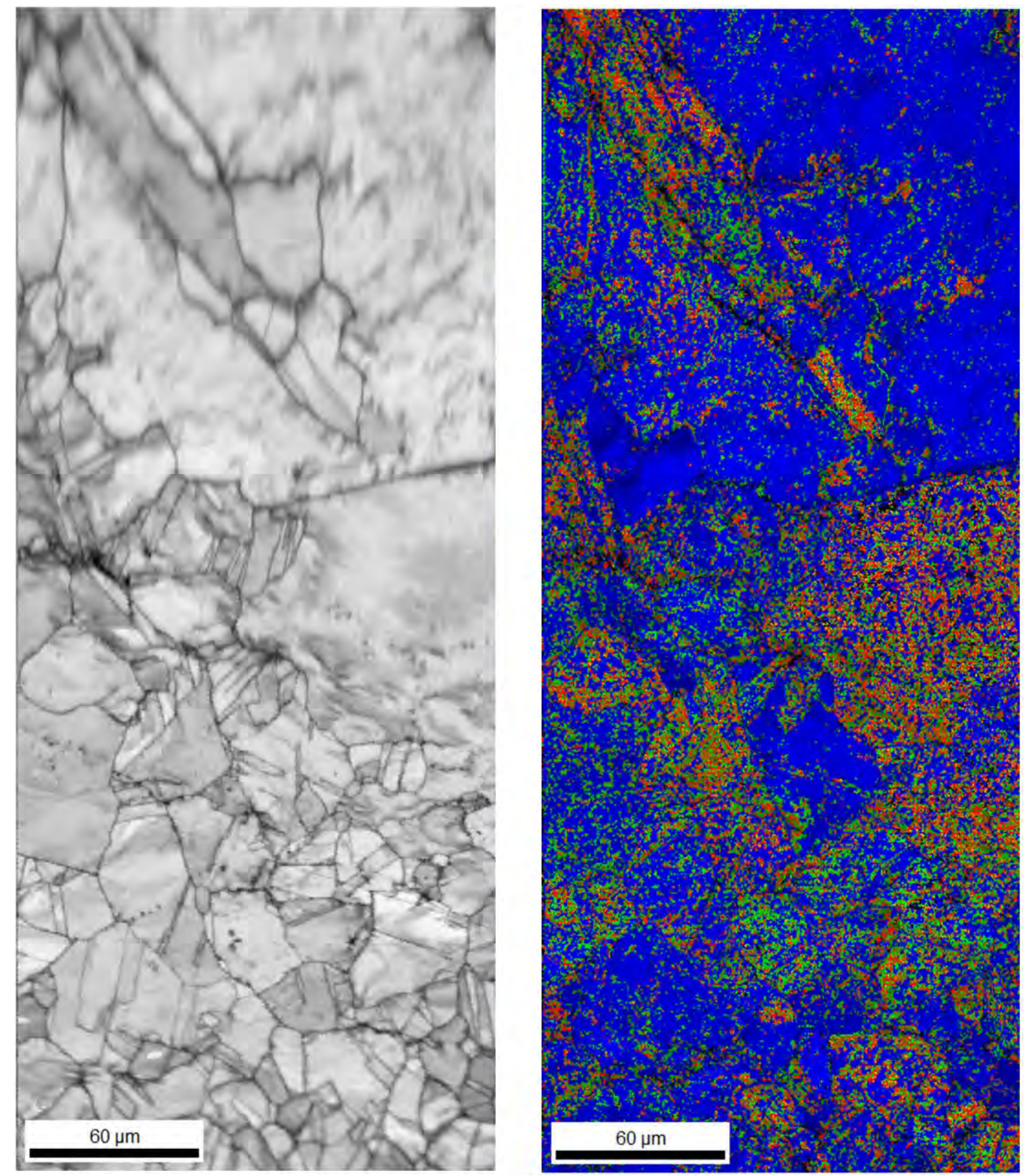

Figure 59 EBSD mapping of a crack cavitation in GBE Alloy 617 tested at $700{ }^{\circ} \mathrm{C}$ in helium. Crack initiation appears to have occurred at a triple point with highest strain.

In the as-received Alloy 617 samples, the grains are significantly smaller than those of the aged samples, and the grains of the GBE Alloy 617 samples are smaller than those of the as-received samples. A thin chromium oxide layer is observed in both the as-received and GBE samples, as is a small amount of an aluminum-rich phase. As was observed in Section 3.3 above, the long axis of the grains is observed to be parallel to the stress direction during testing. Grain size 
appears to have a significant effect on the creep crack growth rates in these candidate alloys. Both the GBE and the as-received Alloy 617 samples have much high crack growth rates compared to the aged Alloy 617 samples tested in the same helium environment and at the same temperature, with the GBE samples having the least resistance to crack growth among the samples tested at $700{ }^{\circ} \mathrm{C}$. It is therefore concluded that the samples with smaller grains have decreased resistance to creep and therefore exhibit a reduction in crack growth resistance. Future studies would be required to understand any dependence of crack-growth resistance within GBE samples on the direction of crack propagation.

\subsection{Summary of Accomplishments Achieved}

The work reported above overcame key technical challenges to create controlled air and helium environments for prolonged creep crack growth testing at elevated temperature. A fully integrated environmental control and crack growth monitoring system was designed that allowed translation of the dead load over the course of the test as the sample series deformed. The objectives and tasks outlined in Section 1 were achieved. A summary of conclusions drawn from the experiments and analyses conducted are given below.

*A creep crack growth (CCG) apparatus was designed, built, and employed to test candidate alloys at high temperatures and in controlled environments. The apparatus was validated and quality assurance measures were conducted on environmental conditions, load, and crack length for all tests reported.

*CCG testing of candidate alloys revealed the effects of temperature and environment on crackgrowth resistance within the parameter space explored. The 617 alloy had superior behavior to that of the $800 \mathrm{H}$ alloy. Grain boundary engineering of the 617 alloy produced inferior results compared to both aged and as-received 617 samples. Table 4 lists the tested samples and conditions in order from most resistant to least resistant to crack growth.

Table 4 CCG test conditions listed in order from most crack-resistant to least crack-resistant

$\left.\begin{array}{|c|c|c|c|c|}\hline \text { Test \# } & \text { Alloy } & \text { Pretreatment } & \text { Temperature }\left({ }^{\circ} \mathbf{C}\right) & \text { Environment } \\ \hline 2 & 617 & \text { ST + Aged } & 700 & \text { Air } \\ \hline 10 & 617 & \text { ST + Aged } & 700 & \text { He } \\ \hline 8 & 617 & \text { None (As-received) } & 700 & \text { He } \\ \hline 6 & 617 & \text { GBE } & 700 & \text { He } \\ \hline 7 & 800 \mathrm{H} & \text { ST + Aged } & 700 & \text { Air } \\ \hline 9 & 800 \mathrm{H} & \text { ST + Aged } & 700 & \text { He } \\ \hline 11 & 617 & \text { ST + Aged } & 850 & \text { He } \\ \hline 4 & 617 & \text { ST + Aged } & 850 & \text { Air } \\ 7\end{array}\right\} *$


*Creep cracks formed in both materials (Alloy 617 and Alloy $800 \mathrm{H}$ ) tested at $700{ }^{\circ} \mathrm{C}$ and $850{ }^{\circ} \mathrm{C}$ in air and in helium were determined to be intergrannular.

*Alloy 617 appears to have similar oxidation behavior in both environments, with a very thin oxidation layer forming on the surfaces of the alloy. When Alloy 617 is tested at $850{ }^{\circ} \mathrm{C}$, the degree of oxidation on the surface is more severe, and again the oxidation in the air and helium environments is similar. In both environments, there is significant formation of aluminum oxide phases along the inner oxidation layer and along a number of grain boundaries. However, the CCG behavior does vary significantly between the environments studied, with substantial reduction in creek crack growth resistance for samples tested $850{ }^{\circ} \mathrm{C}$ compared to the samples tested at $700{ }^{\circ} \mathrm{C}$. Further reduction in creek crack growth resistance is observed in the $\mathrm{He}$ environment compared to Air at $700{ }^{\circ} \mathrm{C}$. Furthermore, grain size appears to have a significant effect on the creep crack growth rates in Alloy 617.

*Alloy $800 \mathrm{H}$ shows some slight differences in oxidation in air compared with helium. When Alloy $800 \mathrm{H}$ was tested in air, the outer layer is iron oxide and the inner layer is chromium oxide. When Alloy $800 \mathrm{H}$ was tested in helium, the oxidation layer is mainly composed of chromium oxide.

*A thin chromium oxide layer is observed in both the as-received and GBE Alloy 617 samples, as is a small amount of an aluminum-rich phase.

*Significant strain is observed in the regions near the crack tips and microcracks. In general, the cracks appear to have initiated in the grain boundaries with a higher degree of misorientation and strain.

*In the as-received Alloy 617 samples, the grains are significantly smaller than those of the aged samples, and the grains of the GBE Alloy 617 samples are smaller than those of the as-received samples. These differences present a confounding factor for the direct comparison of CCG test results for the different $700{ }^{\circ} \mathrm{C}$ tests conducted on Alloy 617 samples. However, it is notable that the GBE samples had less creep crack growth resistance than any other conditions, despite the fact that GBE was shown to have a positive impact on other material properties such as yield strength, ultimate strength, and hardness.

\section{CONCLUSIONS}

Tensile properties, hardness, and resistance to creep crack growth have been explored for candidate alloys 617 and $800 \mathrm{H}$. Tensile properties and hardness were measured as a function of aging time, revealing changes in mechanical properties that occur due to extended exposure to elevated temperatures. Alloy 617 exhibited superior tensile properties and hardness compared to Alloy $800 \mathrm{H}$, with the grain boundary engineered (GBE) Alloy 617 samples having the highest hardness and tensile strength. CCG testing of both alloys revealed that, overall, Alloy 617 has superior resistance to creep crack growth compared to that of Alloy $800 \mathrm{H}$. CCG testing at $700{ }^{\circ} \mathrm{C}$ demonstrated that Alloy 617 has a higher resistance in creep crack growth in air compared to impure helium, while the CCG results for Alloy $800 \mathrm{H}$ suggest that air and helium environments produce similar behavior. CCG testing of grain boundary engineered (GBE) Alloy 617 samples 
revealed that this technique produces inferior resistance to creep crack growth compared to the other Alloy 617 samples tested under similar conditions. Grain size was found to correlate positively with resistance to creep crack growth, with the GBE samples having the smallest grain size of the Alloy 617 samples tested.

\section{RECOMMENDATIONS}

This project developed an apparatus for conducting CCG experiments on candidate alloys at elevated temperatures and in controlled environments. CCG results demonstrate that Alloy 617 is superior to $800 \mathrm{H}$; therefore, it is recommended to focus on Alloy 617 for future work related to structure alloys for VHTRs. Because grain size of Alloy 617 was found to correlate positively with creep crack growth resistance, future work should involve explorations into the nature of the relationship between grain size of Alloy 617 and resistance to slow crack growth at elevated temperatures. Lastly, although the creep crack growth resistance of the GBE-optimized Alloy 617 samples studied herein was inferior to the other 617 alloys tested under similar conditions, future work should involve investigations into the relationship between GBE processing conditions and cracking behavior at high temperatures in order to determine the degree to which the special grain boundaries provide resistance to crack initiation and propagation in Alloy 617.

\section{PUBLICATIONS, PRESENTATIONS, THESES}

\section{Published Work:}

D. Grierson, G. Cao, P. Brooks, P. Pezzi, A. Glaudell, D. Kuettel, G. Fisher, T. Allen, K. Sridharan, W.C. Crone, “An Apparatus for Creep Crack Growth Testing in Controlled Environments at High Temperatures” Proceedings of the 2013 SEM Annual Conference and Exposition on Experimental and Applied Mechanics, 350, p. 1-8, (2013).

\section{Planned Publications:}

D. Grierson, G. Cao, P. Brooks, P. Pezzi, A. Glaudell, D. Kuettel, G. Fisher, T. Allen, K. Sridharan, W.C. Crone, "Tensile Properties and Hardness of Alloy 617 and Alloy 800H as a function of aging time” (in preparation).

D. Grierson, G. Cao, P. Brooks, P. Pezzi, A. Glaudell, D. Kuettel, G. Fisher, T. Allen, K. Sridharan, W.C. Crone, "Experimental Method for Creep Crack Growth Testing in Controlled Environments at High Temperatures” (in preparation).

D. Grierson, G. Cao, P. Brooks, P. Pezzi, A. Glaudell, D. Kuettel, G. Fisher, T. Allen, K. Sridharan, W.C. Crone, "Creep Crack Growth Behavior of Alloy 617 and Alloy 800H in Air and Impure Helium Environments at High Temperatures” (in preparation).

\section{Presentations:}

Guoping Cao and Andrew Glaudell, “Assessment of Embrittlement of VHTR structural Alloys in Impure Helium Environments, NEUP \# 785”, INL visit to UW-Madison, October 5, 2011. 
Guoping Cao; Paul Pezzi; Graham Fischer; Kumar Sridharan; Todd Allen; Wendy Crone Creep Crack Initiation and Crack Growth of Alloy 617 in Impure VHTR Helium and Air at ElevatedTemperatures, Materials Science \& Technology 2011, October 16-20, 2011, Columbus , Ohio.

D. Grierson, G. Cao, P. Brooks, P. Pezzi, A. Glaudell, D. Kuettel, G. Fisher, T. Allen, K. Sridharan, W.C. Crone, “An Apparatus for Creep Crack Growth Testing in Controlled Environments at High Temperatures" Proceedings of the 2013 SEM Annual Conference and Exposition on Experimental and Applied Mechanics, June 3-5, 2013, Lombard, IL.

G. Cao, D. Grierson, A. Glaudell, D. Kuettel, T. Allen, K. Sridharan, W.C. Crone "Creep Crack Growth of Nickel Alloy 617 in VHTR Impure Helium and Air”, to be presented at SMINS-3 workshop, October 7-10, 2013, Idaho Falls, ID, USA.

\section{ACKNOWLEDGEMENTS}

The authors would like to thank Dr. Richard Wright of INL and Dr. Sam Sham of ORNL for helpful discussions regarding sample processing and testing. The authors would like to thank Peter Lin and Integran Technologies for helpful discussions related to GBE processing and evaluation of GBE samples. The authors wish to thank Jacob Jelinek and Paul Roman for massspectroscopy assistance, and Dr. Shiluo Yan for assistance with electrical measurements.

\section{PARTICIPANTS}

\subsection{Faculty/Staff}

Professor: Wendy C. Crone

Citizenship: US

Distinguished Research Professor: Kumar Sridharan

Citizenship: US

Professor: Todd Allen

Citizenship: US

Scientist: Guoping Cao

Citizenship: Chinese

Senior Instrumentation Specialist: Paul Brooks

Citizenship: US

Research Scientist: David Grierson

Citizenship: US 


\subsection{Students}

Student: Paul Pezzi

Citizenship: US

Major: Engineering Mechanics, Astronautics Option (BS) - Degree completed 5/11

Student: Graham Fischer

Citizenship: US

Major: Mechanical Engineering (BS)

Student: Erik Jochman

Citizenship: US

Major: Business (BS)

Student: Andrew Glaudell

Citizenship: US

Major: Engineering Physics (BS)

Student: Donald Kuettel

Citizenship: US

Major: Engineering Mechanics (BS)

\section{REFERENCES}

1 ASTM International, Standard test method for measurement of creep crack growth times in metals, ASTM E 1457-07.

2 ASTM International, Standard Test Methods for Tension Testing of Metallic Materials, ASTM E8

3 D. Grierson, G. Cao, P. Brooks, P. Pezzi, A. Glaudell, D. Kuettel, G. Fisher, T. Allen, K. Sridharan, W.C. Crone, “An Apparatus for Creep Crack Growth Testing in Controlled Environments at High Temperatures” Proceedings of the 2013 SEM Annual Conference and Exposition on Experimental and Applied Mechanics, 350, p. 1-8, (2013).

\section{COST DATA}

Table 5 and Table 6 show the budget data and actual cost data throughout the period of the project.

Table 5 Budget and expenditures for the entire project period.

\begin{tabular}{|c|c|c|}
\hline $\begin{array}{c}\text { Original } \\
\text { Budget }\end{array}$ & $\begin{array}{c}\text { Cumulative } \\
\text { Total } \\
\text { Expenditures }\end{array}$ & $\begin{array}{c}\% \\
\text { spent } \\
\text { to } \\
\text { date }\end{array}$ \\
\hline 489,707 & $489,707.00$ & $100 \%$ \\
\hline
\end{tabular}


Table 6 Quarterly reporting of actual spending and invoiced amounts.

\begin{tabular}{|c|c|c|c|c|c|c|}
\hline Year & $\begin{array}{l}\text { Planned } \\
\text { Amount \$ }\end{array}$ & $\begin{array}{c}\text { Cumulative } \\
\text { Amount }\end{array}$ & $\begin{array}{c}\text { Actual } \\
\text { Spending }\end{array}$ & $\begin{array}{c}\text { Cumulative } \\
\text { YTD }\end{array}$ & $\begin{array}{l}\text { Remaining } \\
\text { Funds }\end{array}$ & $\begin{array}{c}\text { Percent } \\
\text { Spent }\end{array}$ \\
\hline Year 1 Q1 & $\$ 54,541.00$ & $\$ 54,541.00$ & $\$ 34,764.00$ & $\$ 34,764.00$ & $\$ 454,943.00$ & $7.10 \%$ \\
\hline Year $1 \mathrm{Q} 2$ & $\$ 54,541.00$ & $\$ 109,082.00$ & $\$ 32,726.00$ & $\$ 67,490.00$ & $\$ 422,217.00$ & $13.78 \%$ \\
\hline Year 1 Q3 & $\$ 54,541.00$ & $\$ 163,623.00$ & $\$ 20,255.00$ & $\$ 87,745.00$ & $\$ 401,962.00$ & $17.92 \%$ \\
\hline Year $1 \mathrm{Q} 4$ & $\$ 54,541.00$ & $\$ 218,164.00$ & $\$ 27,756.45$ & $\$ 115,501.45$ & $\$ 374,205.55$ & $23.59 \%$ \\
\hline Year 2 Q1 & $\$ 33,447.75$ & $\$ 251,611.75$ & $\$ 20,428.00$ & $\$ 135,929.45$ & $\$ 353,777.55$ & $27.76 \%$ \\
\hline Year 2 Q2 & $\$ 33,447.75$ & $\$ 285,059.50$ & $\$ 17,947.87$ & $\$ 153,877.32$ & $\$ 335,829.68$ & $31.42 \%$ \\
\hline Year 2 Q3 & $\$ 33,447.75$ & $\$ 318,507.25$ & $\$ 27,469.16$ & $\$ 181,346.48$ & $\$ 308,360.52$ & $37.03 \%$ \\
\hline Year $2 \mathrm{Q} 4$ & $\$ 33,447.75$ & $\$ 351,955.00$ & $\$ 47,532.90$ & $\$ 228,879.38$ & $\$ 260,827.62$ & $46.74 \%$ \\
\hline Year 3 Q1 & $\$ 20,000.00$ & $\$ 371,955.00$ & $\$ 15,502.58$ & $\$ 244,381.96$ & $\$ 245,325.04$ & $49.90 \%$ \\
\hline Year 3 Q2 & $\$ 34,438.00$ & $\$ 406,393.00$ & $\$ 71,722.00$ & $\$ 316,103.96$ & $\$ 173,603.04$ & $64.55 \%$ \\
\hline Year 3 Q3 & $\$ 34,438.00$ & $\$ 440,831.00$ & $\$ 68,787.06$ & $\$ 384,891.02$ & $\$ 104,815.98$ & $78.60 \%$ \\
\hline Year $3 \mathrm{Q} 4$ & $\$ 34,438.00$ & $\$ 475,269.00$ & $\$ 55,002.78$ & $\$ 439,893.80$ & $\$ 49,813.20$ & $89.83 \%$ \\
\hline Year 4 Q1 & $\$ 25,760.80$ & $\$ 501,029.80$ & $\$ 25,760.80$ & $\$ 465,654.60$ & $\$ 24,052.40$ & $95.09 \%$ \\
\hline Year 4 Q2 & $\$ 24,052.61$ & $\$ 525,082.41$ & $\$ 24,052.61$ & $\$ 489,707.21$ & $(\$ 0.21)$ & $100.00 \%$ \\
\hline
\end{tabular}

